أثر التطورات المعاصرة في بيئة المراجعة علي سلوك المراجعين عند تقدير أتعاب

المراجعة في جمهورية مصر العربية

The Impact of Contemporary Developments in Auditing, Environment on Aduditors

Behavior in Determining Audit Fees in ARE.

\author{
دكتــــــور \\ عـارف عبد الله عبد الكربهم \\ قسم المحاسبة والمراجعة \\ كلية التجارة - جامعة طن كـ كل


. 


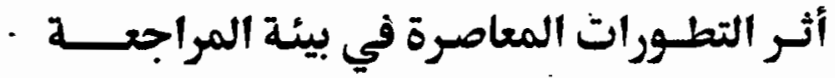 \\ علي سلوك المراجعين عند تقدير أتعاب

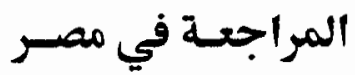

\section{Introduction 1-1}

شـهـت بينة مهنة المراجعة خلال عقدي الثمانينات والتسعينات من القرن الماضني

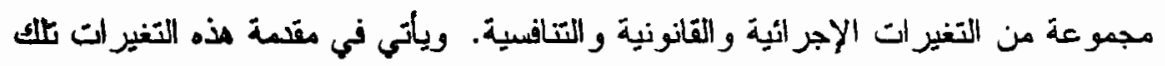

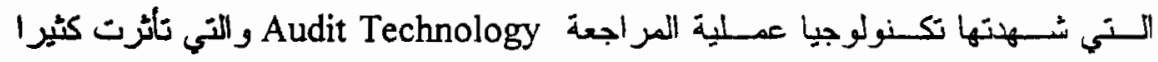

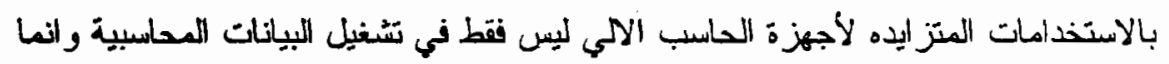

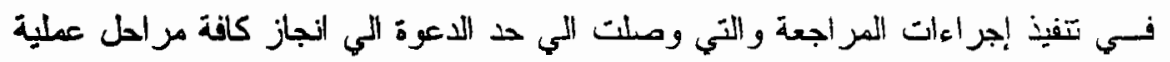

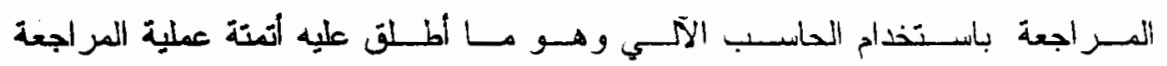
. Audit automation

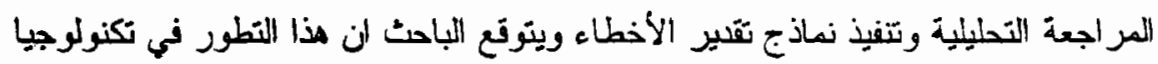

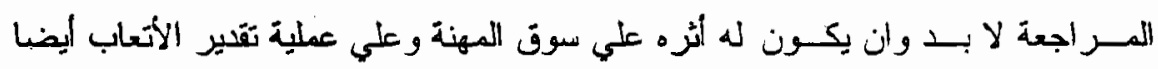

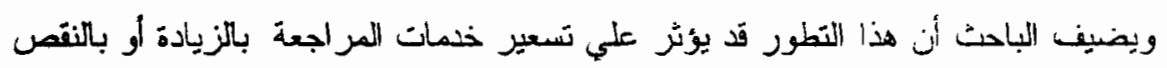

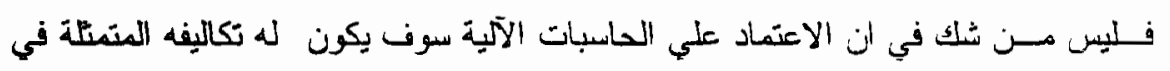

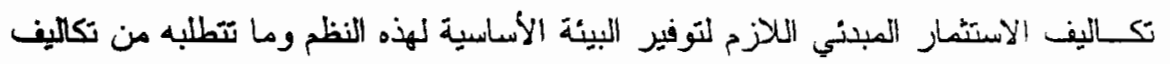

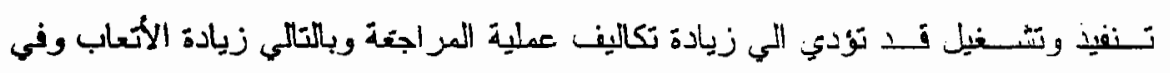

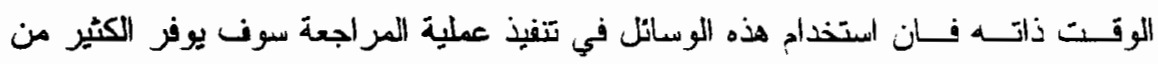

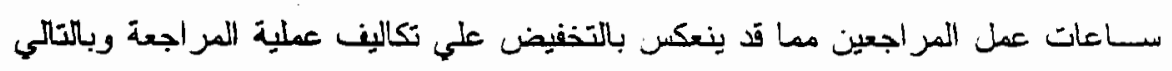

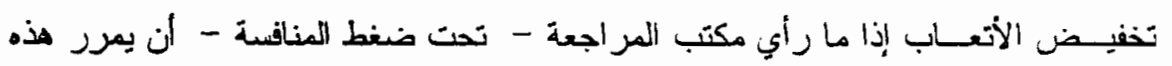

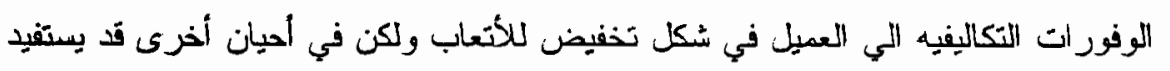

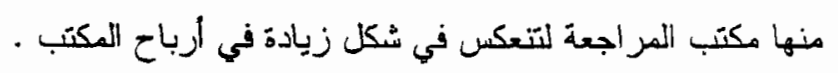

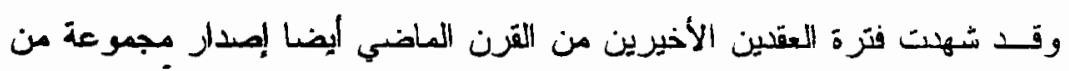

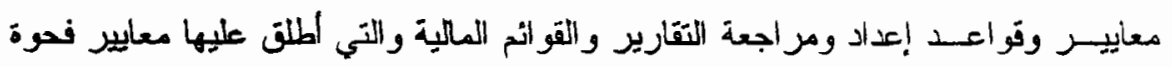
الستوقعات

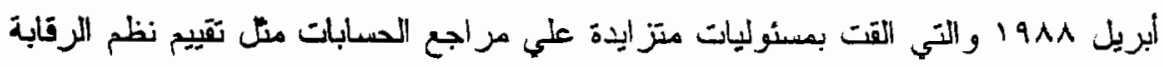




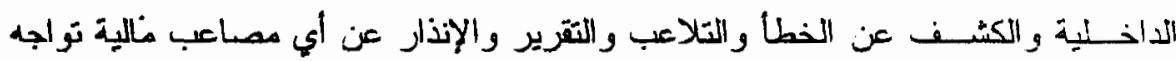

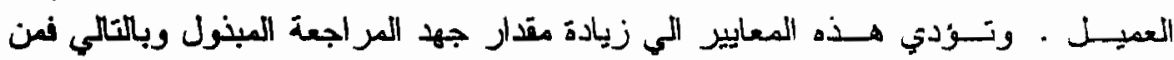

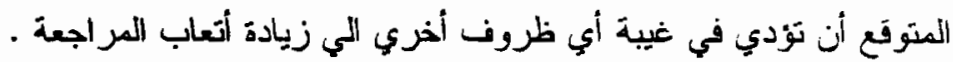

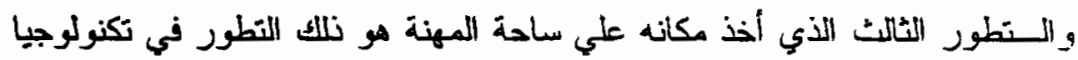

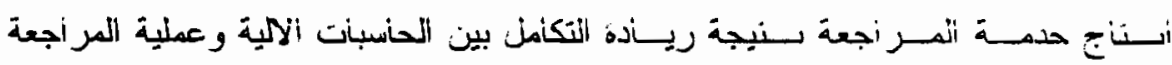

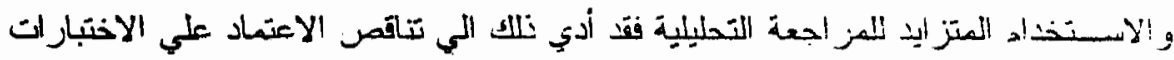

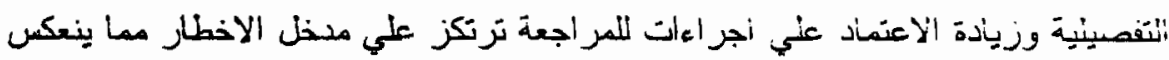

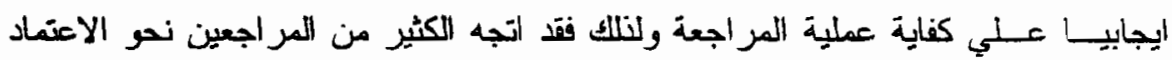

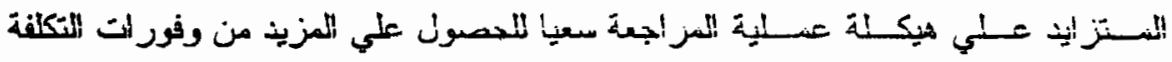

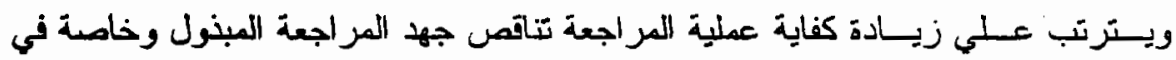

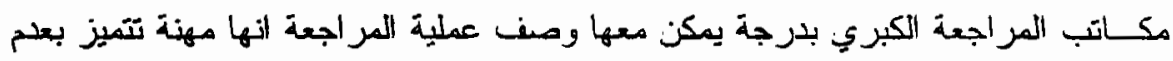

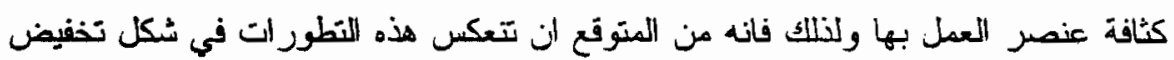

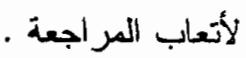

أمسـا عـن سوق مهنة المراجعة وشكل المنافسة في هذه العوق والذي يؤئز وينأثر

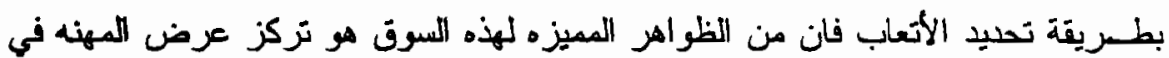

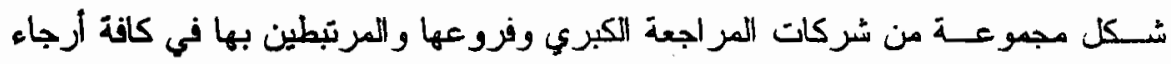

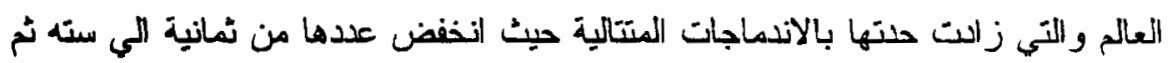

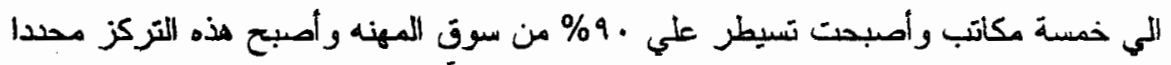

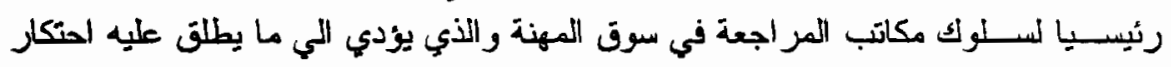

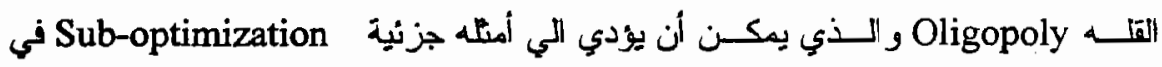

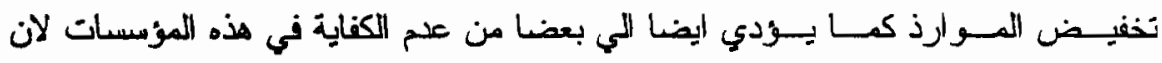

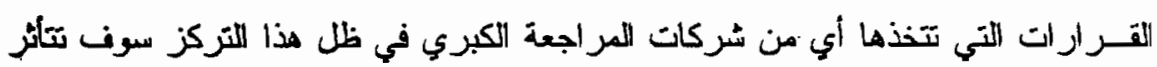

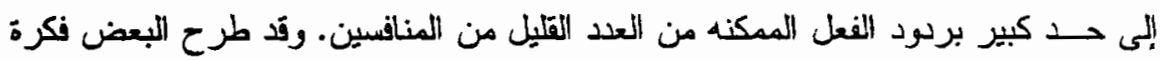

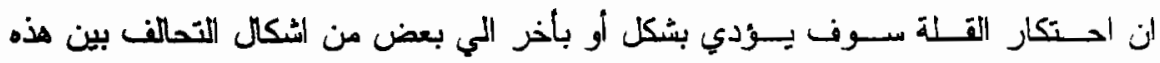

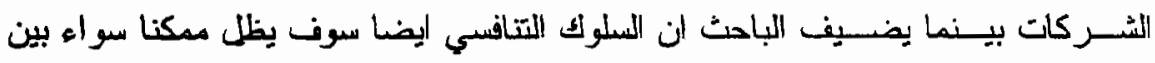

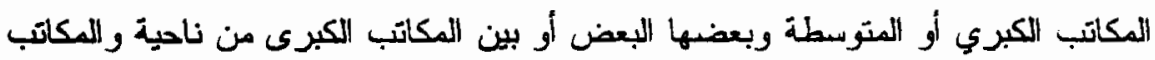
المتوسطه التي تحاول الزحف نحو القمة من ناحية أخري.

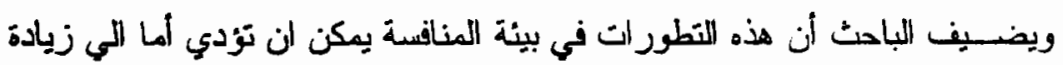

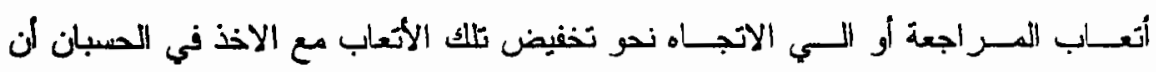


مؤسسـات المراجعة الكبري تتجه كل منها ايضا ندو التخصص في صناعة أو صناعات

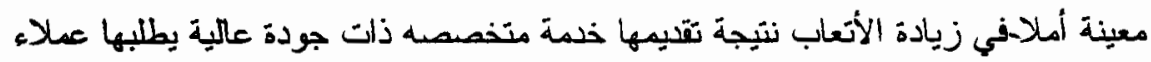

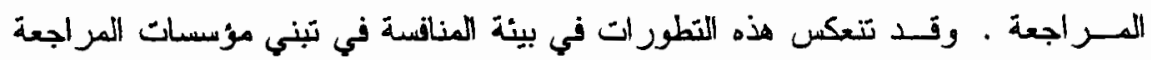

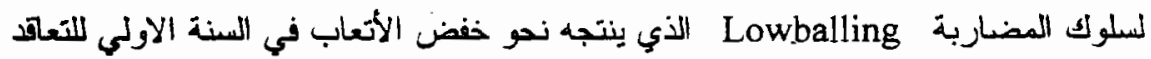

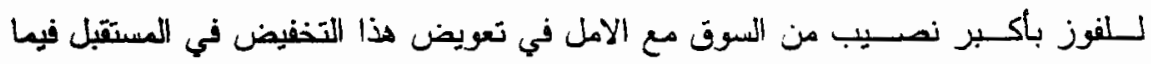
يحمسل عليه المر اجع من عميله فيما بعد من فو ائد أثارت ولاز الت تثير الكثير من الجلل.

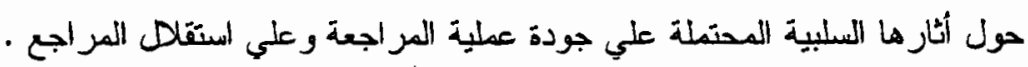

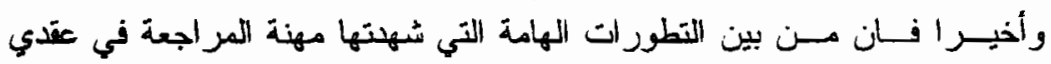

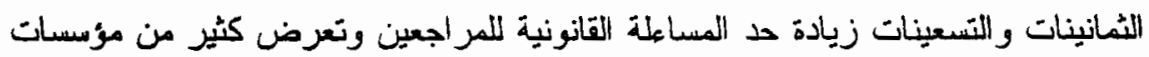

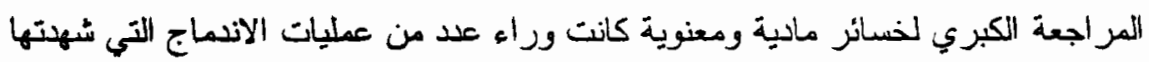

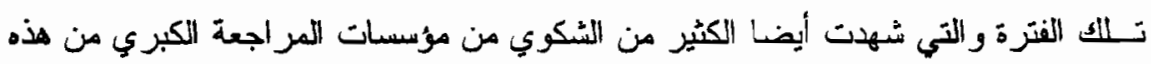

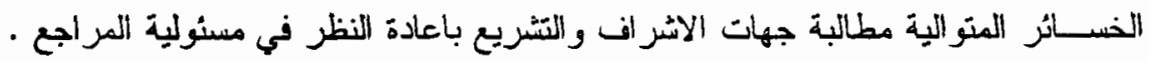

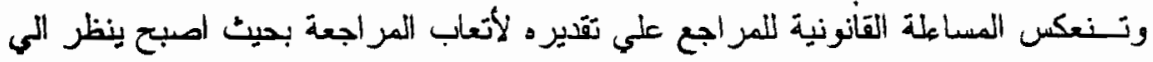

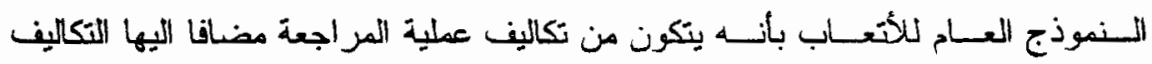

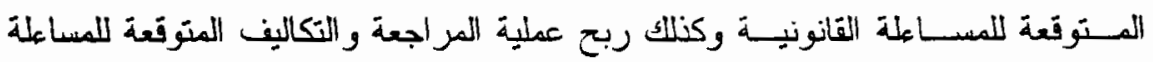

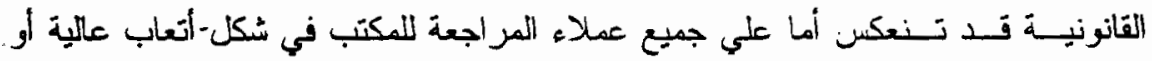

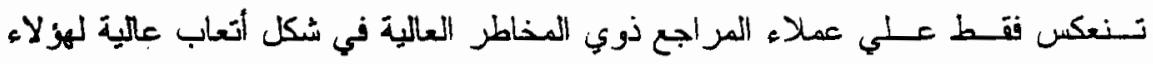

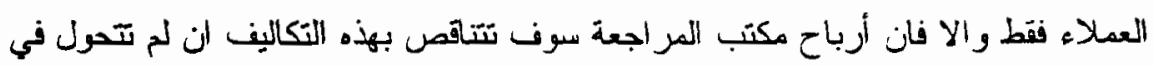

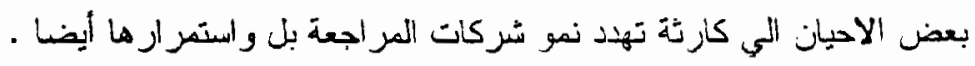

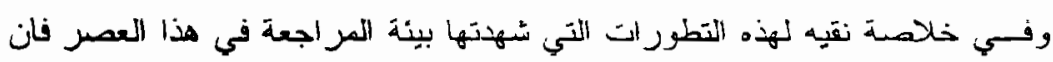

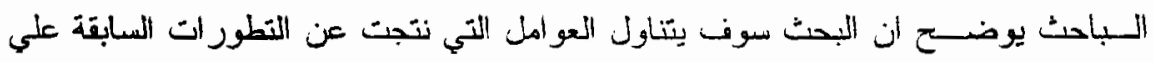

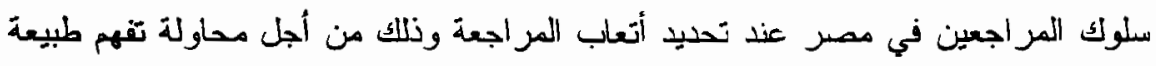

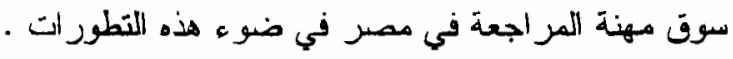
Purpose

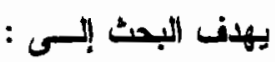

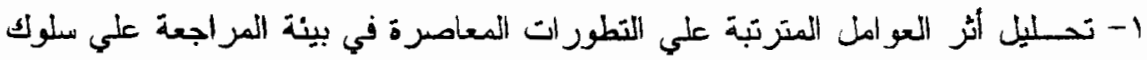

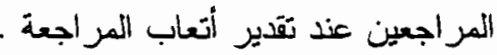


r- تفهـم طبيعة سوق المراجعة في مصر باستطلاع ر أبي المراجعين في مصر عن كيفية

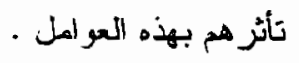

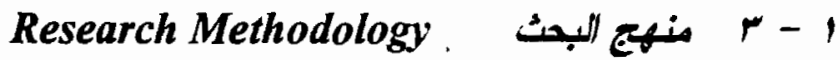

اعتد الباحث في إنجاز هذا البحث أولا علي المنهج الإيجابي Positive Approach الذي

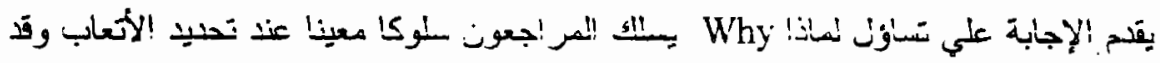

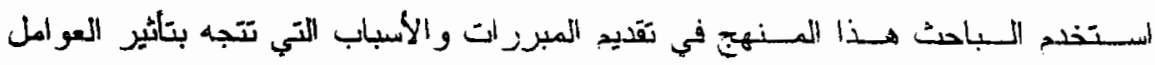

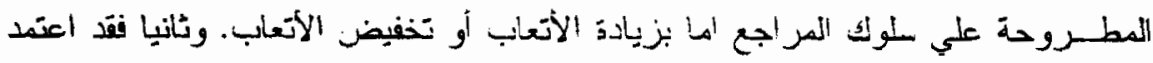

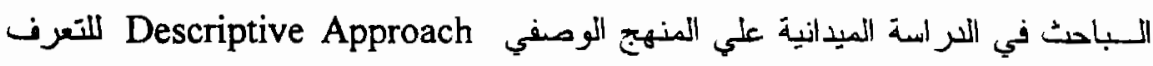

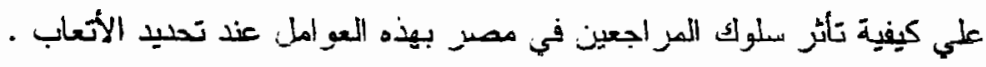

Contents

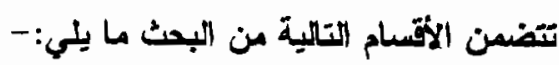

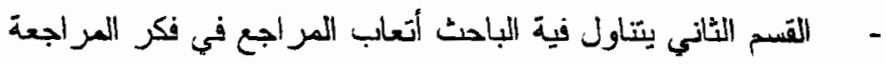

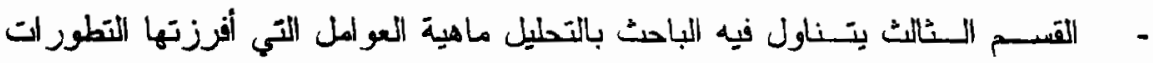

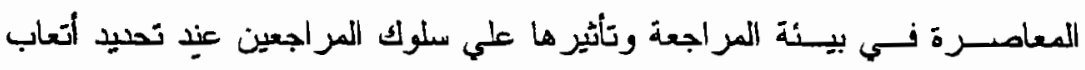

$$
\text { المر اجعة . المعامجن. }
$$

القسم الزر ابع الكراسة الميدانية التي تمت علي عينه من المر اجعين في مصر

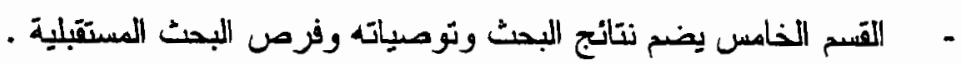

$$
\text { r - أتعاب المراجع في فكر المراجعة }
$$

The Literature

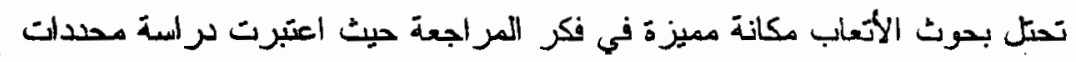

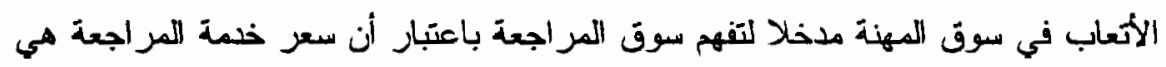

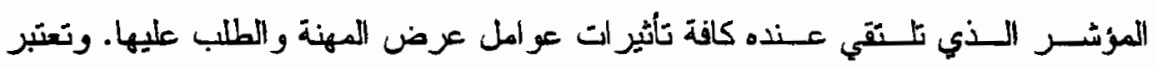

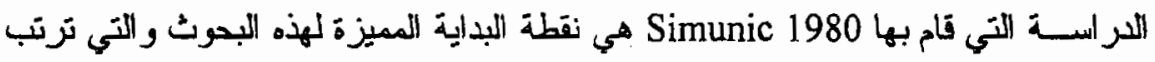

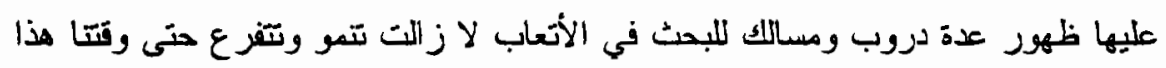

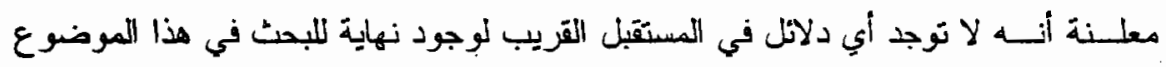

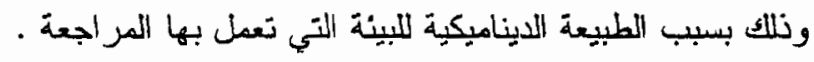

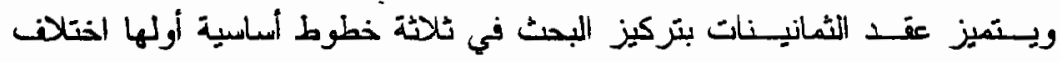

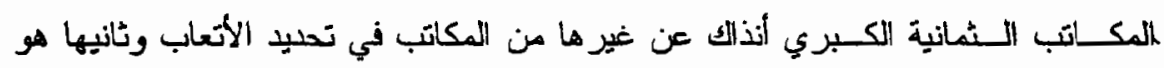




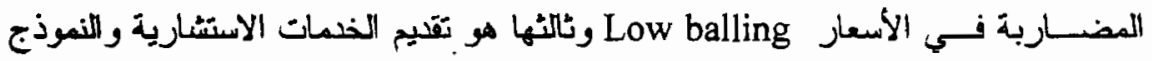

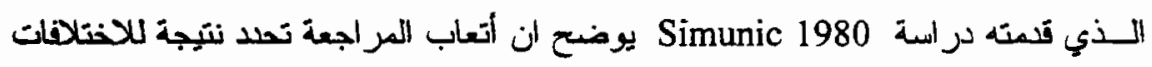

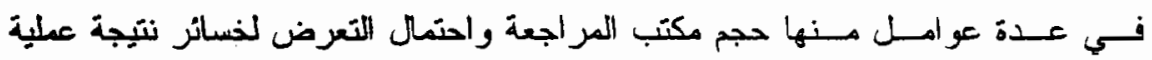

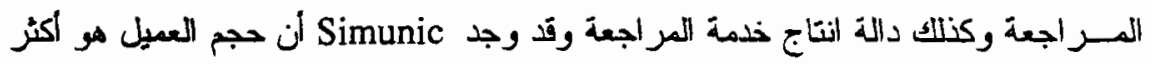

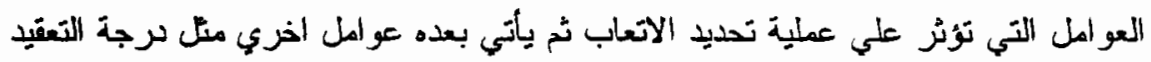

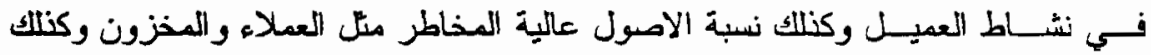

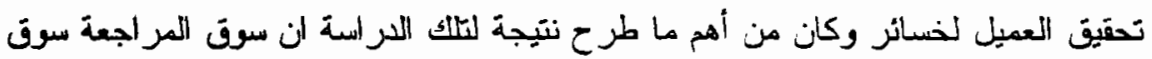

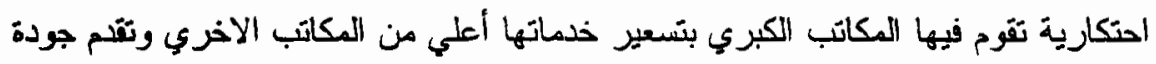

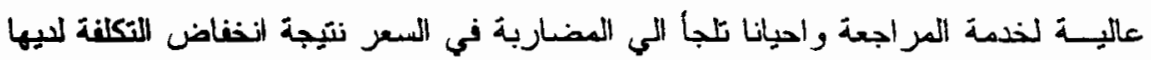

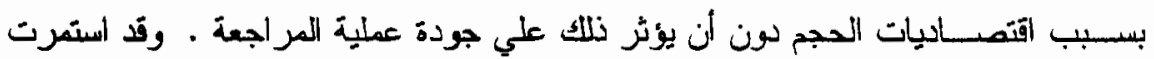

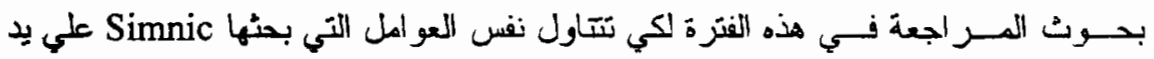
الكـيّرين مثل (1981) De Angelo التي وجدت ان سلوك المضاربة في السعر سلوك

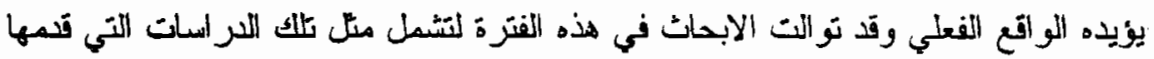
Simon 1985 ، Palmrose 1986، Siminic 1984

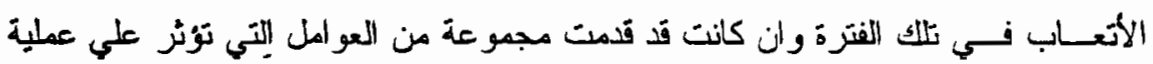
تحديد أتعاب المر اجعة إلا انها تتارلت عملية تحديد الأتعاب لكل مؤثر اتها ومحداتها والتئي

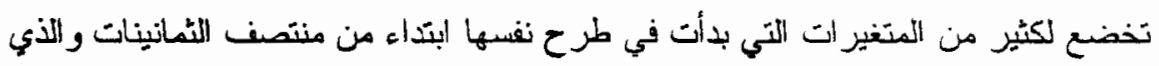
يزى الباحث معه ان نلاك هو المبب الرئيسي في تتاقص بعض النتانج من حالة لأخرى.

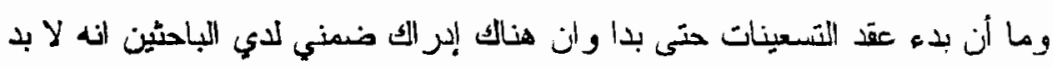

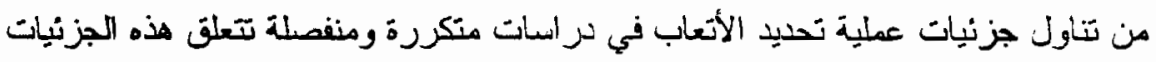

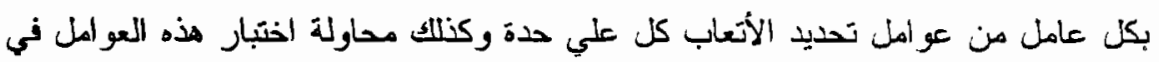

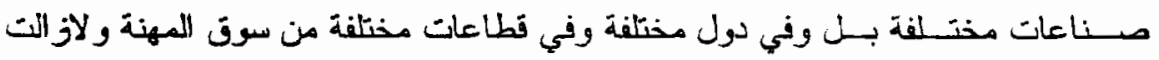
حـركة الـبحث في المر اجعة تواصل سبرها في هذه الاتجاهات حتى يمكن في يوم ما ان

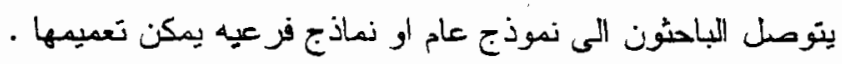

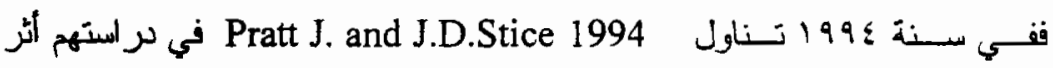

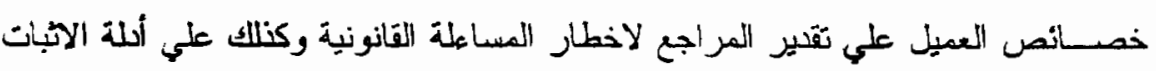

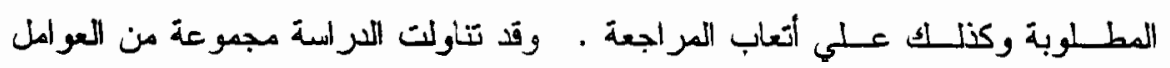

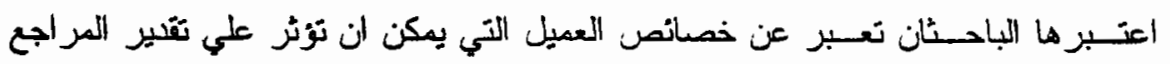

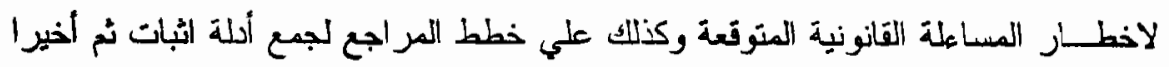


أنسرها علي أتعاب المر 'جعة . . وهذه العوامل التتي تبنتها تلك الدراسة هي الاحوال المالية

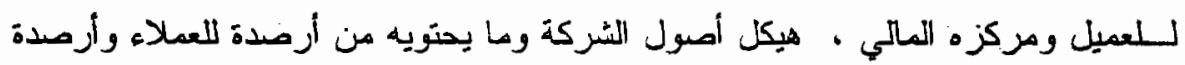

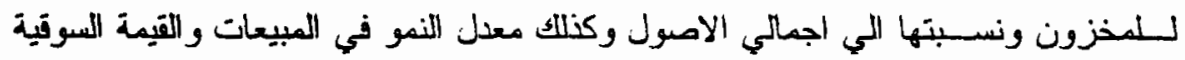

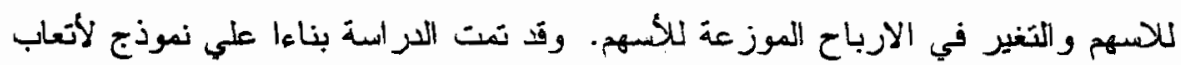

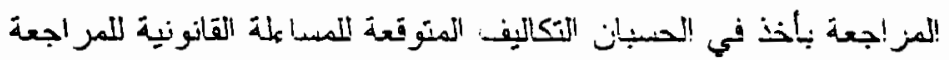

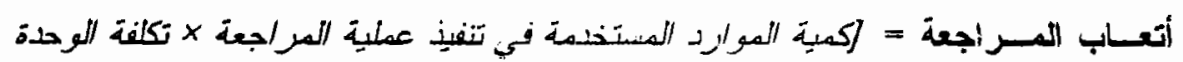

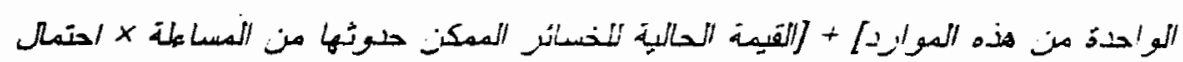

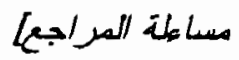

وكان من نتائج الدراسة ان تقدير المراجعيز، لاخطار المساعلة القانونية ينعكس في الميا

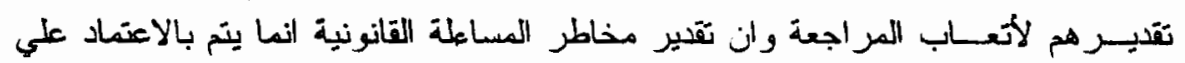

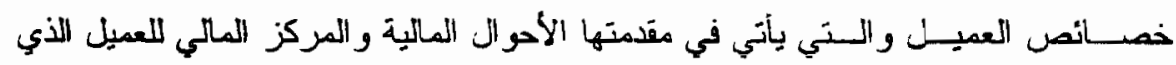

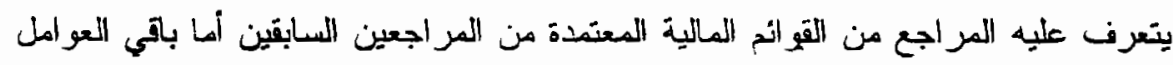

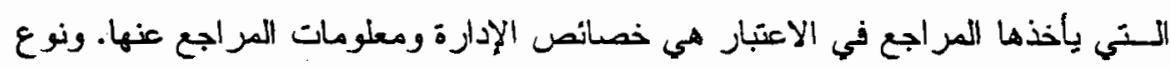

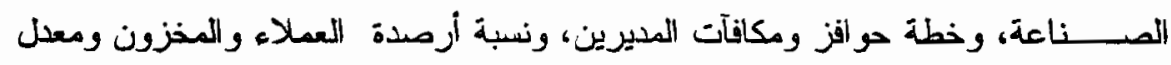

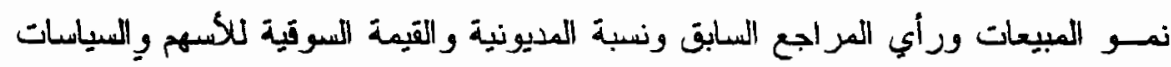

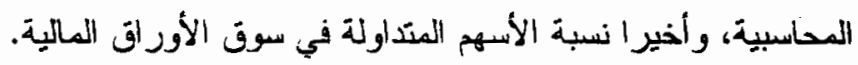

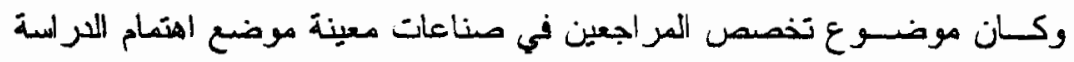

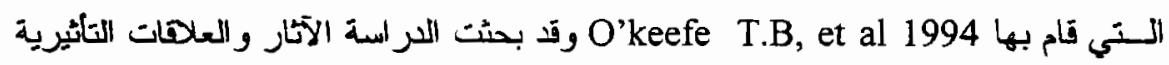
المتبادلة بين كل من تخصص المر اجع في صناعة معينة والتمشي مع معايير إعداد التقرير

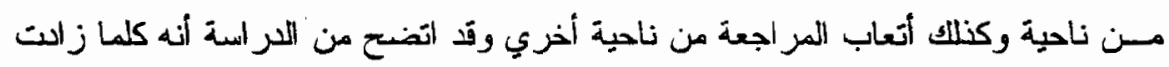

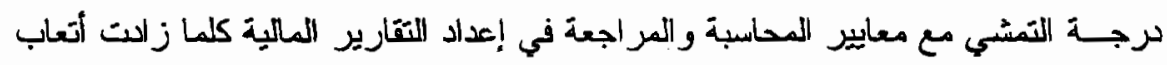

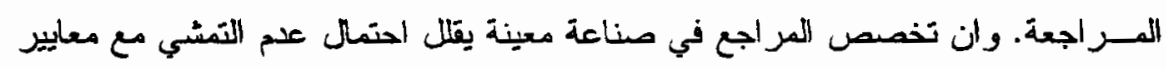

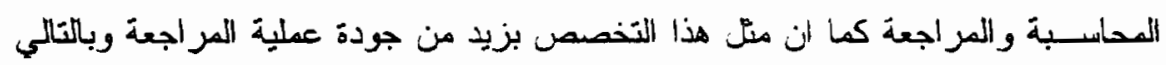
يكون دافعا لزيادة الأتعاب.

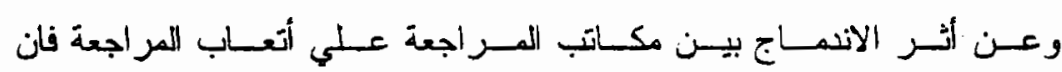
Lyer V. M. and G. S, Lyer 1996

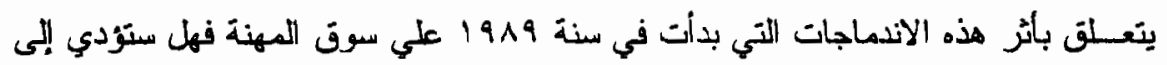

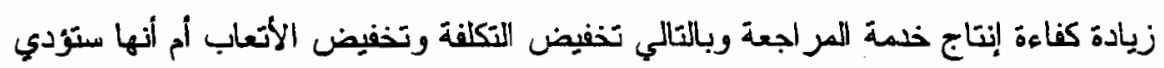

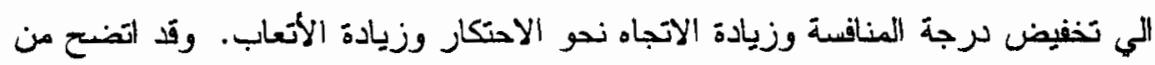


المراســة ان هذه الاندماجات قد ألت الي زبيادة درجة تركز المهنة ومع نللك فلم تؤدي الي

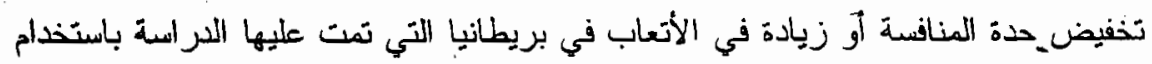
بيانات فعلية عن الأتعاب في بريطانيا .

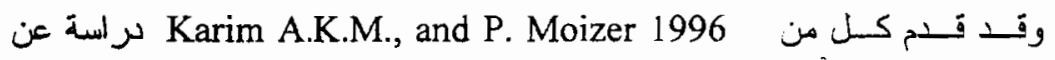
مدسدات أتعاب المر اجعة في بنجلاديش وقد غطت عينة اللدراسة مجموعة من الشركات

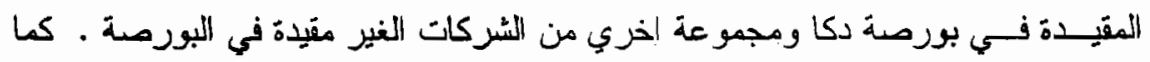

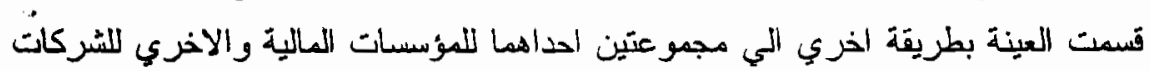
غير المالية وقد أظهرت الدر اسة النتاتج التالية:-

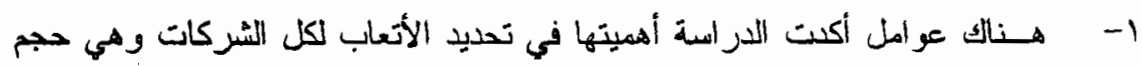

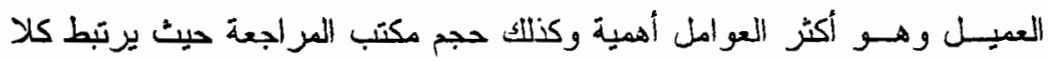

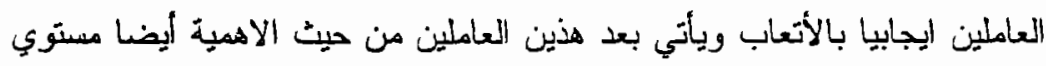

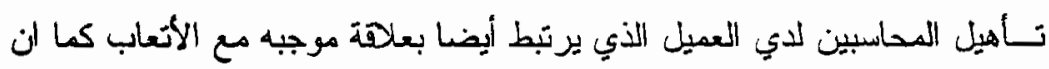

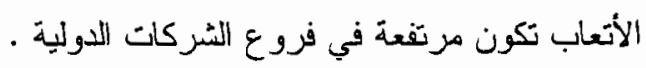

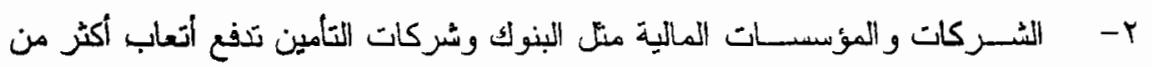

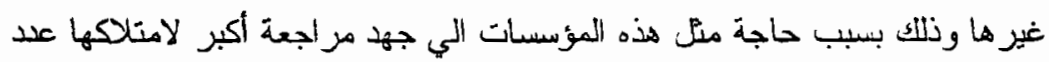

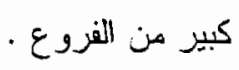

r- لــم تظهر الاراسة معنوية عنصر ربحية العميل وخاصة في الشركات والمؤسسات

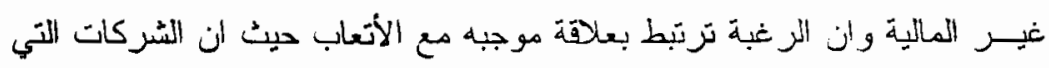

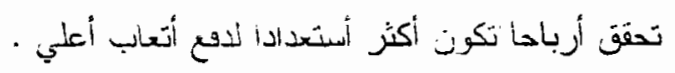

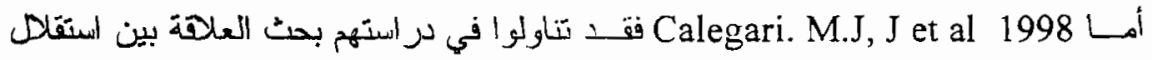

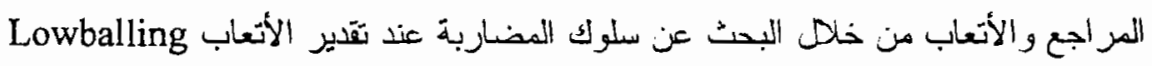

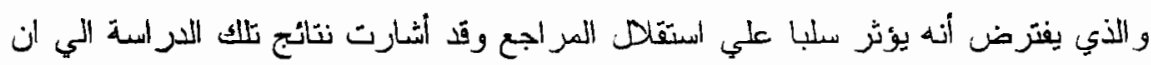

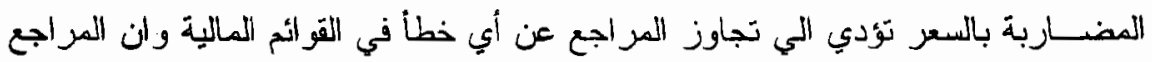

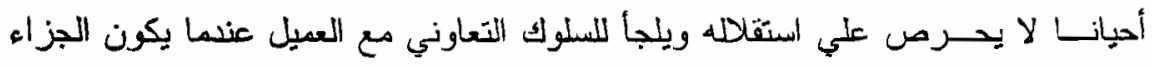

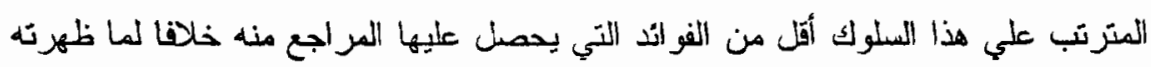
De Angelo 1981

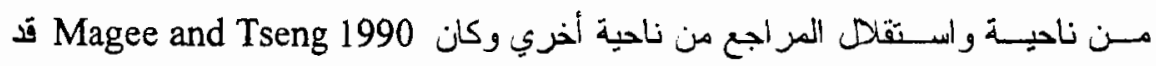

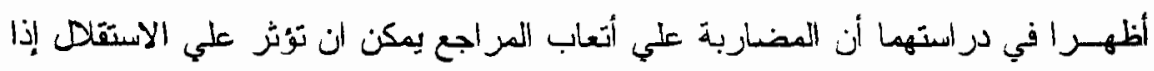


كسان هـناك حالة من عدم الاتفاق تسود بين المرشحين للقيام بالمر اجعة حول مدى سلامة

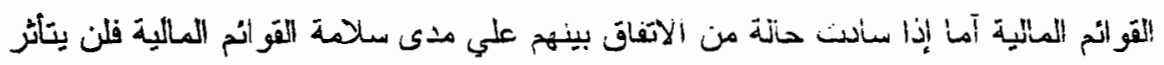

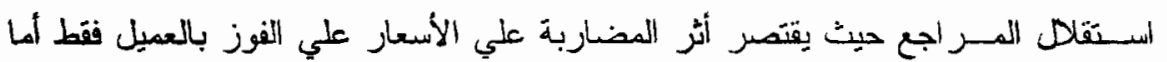
Dopuch. N. and R. King 1996

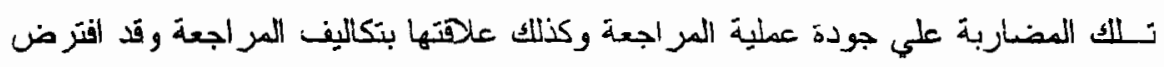

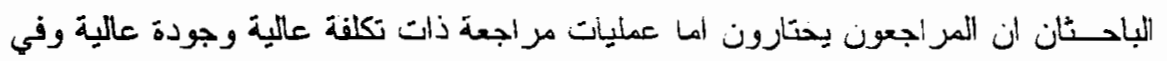

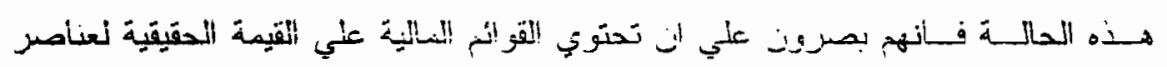

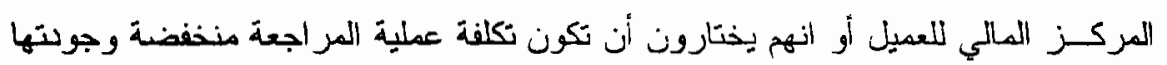

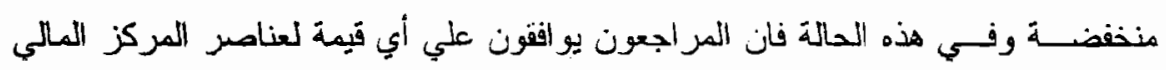

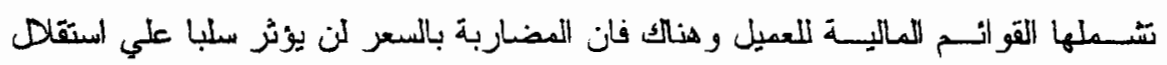

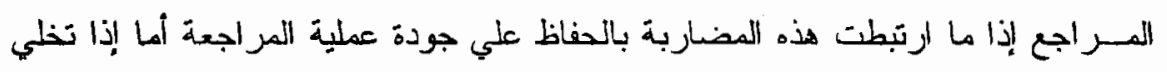

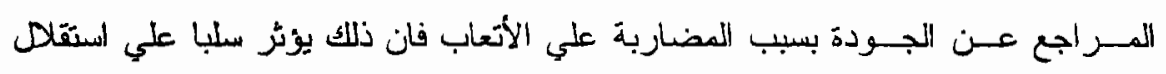

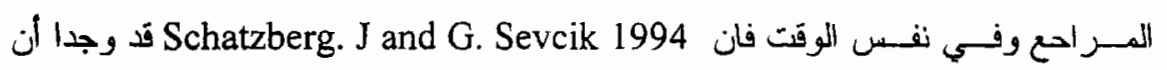

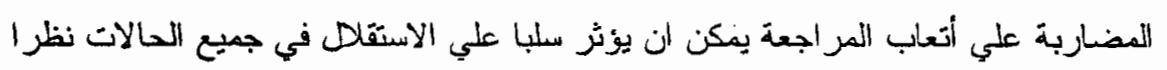

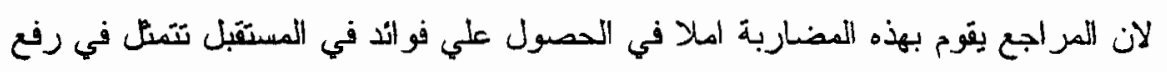

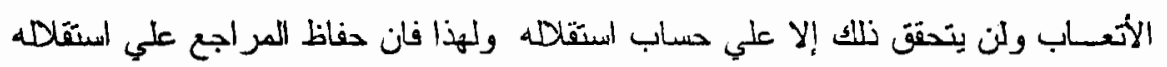

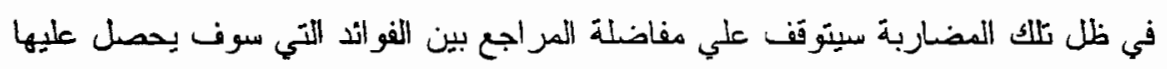

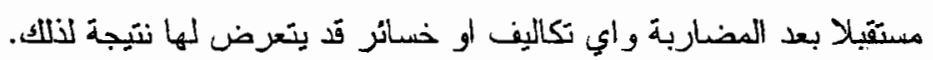

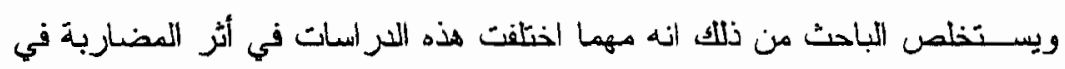

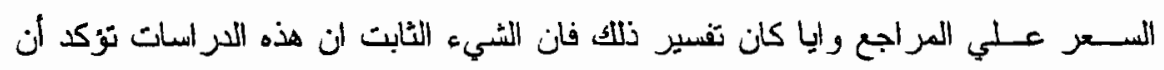
هناك مضاربة علي الأسعار في سوق المهنة.

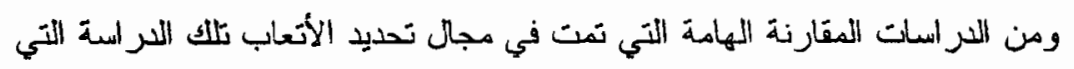

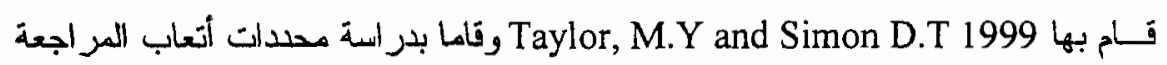
في ·r دولة مع التركيز علي عوامل المساعلة والإفصاح وحدود الإشراف علي الشركات

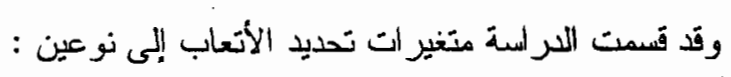

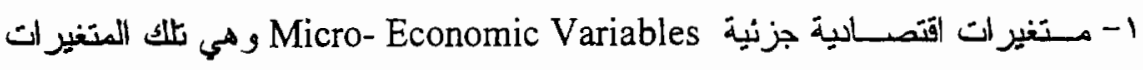

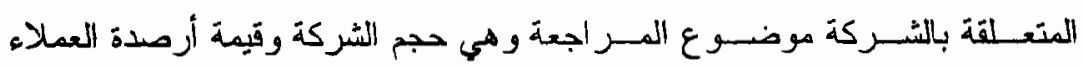

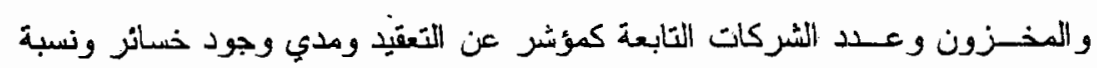

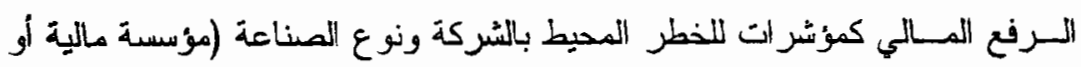


شــركات مــنافع أو شــركات تعدين) وأخيرا حجم مكتب المراجع وما اذا كان من

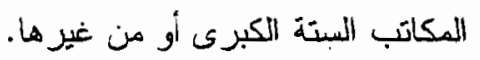

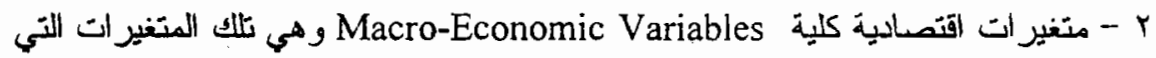
تعسبر عن الثر العوامل السياسية والاتتصادية في البيئة التي تعمل بها المُركة والتي

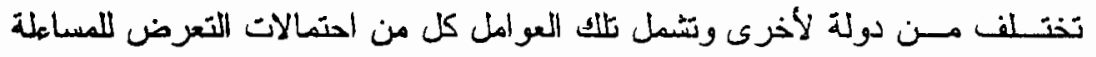

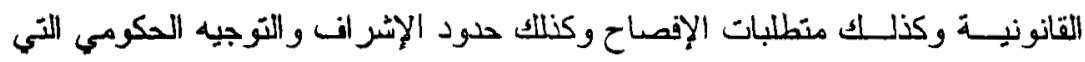
تحيط بمهنة المراجعة وكذلك عملية إعداد ونشر القو ائم المالية للشركات.

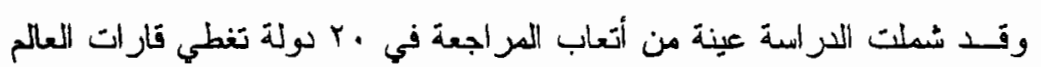

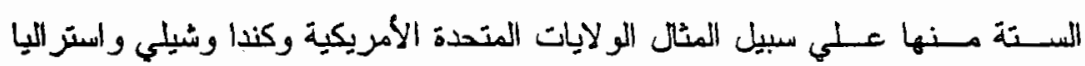

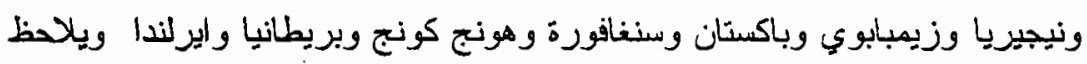

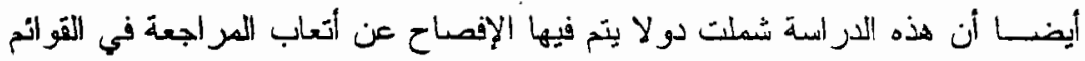

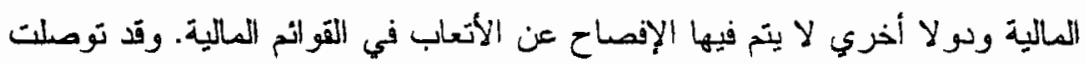

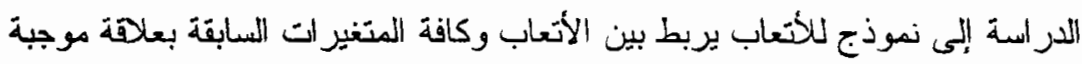

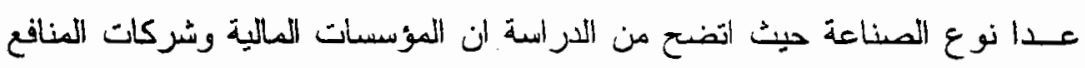

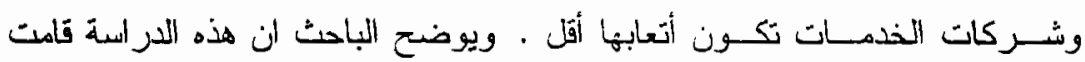

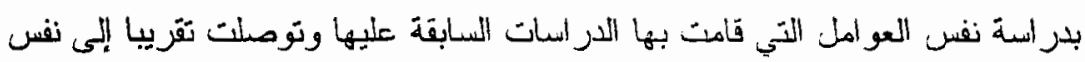

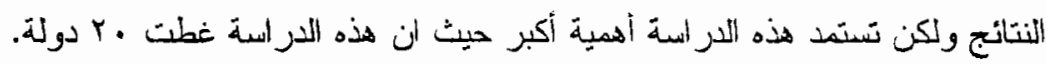

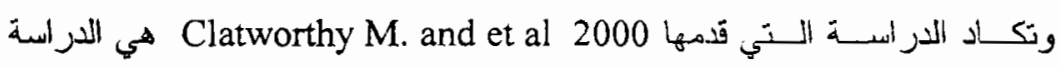
الوحيـدة انستي تناولت عملية تحديد الأتعاب في نطاع معين هو قطاع الخدمات الصحية National Health Service (NHS)

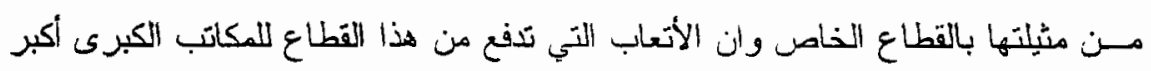

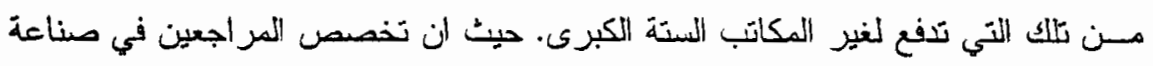

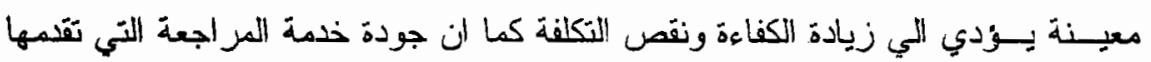

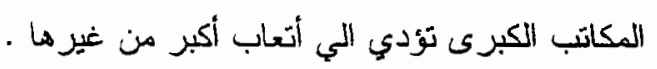

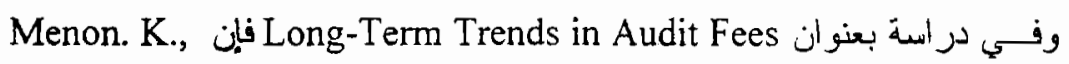

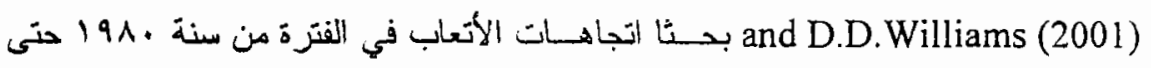
سنة ، 199 وقد أوضح الباحثان ان هناك زيادة ملموسة في أتعاب المراجعة في الثانينات

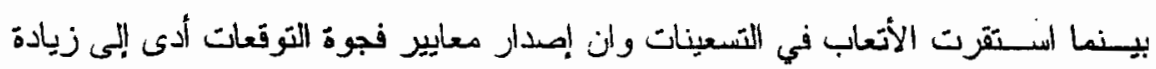

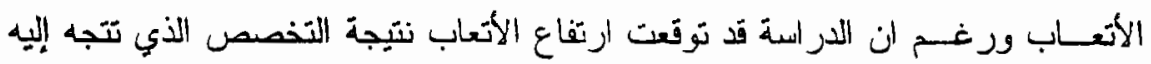


المكساتب الكبرى الا أن النتائج الميذانية لج تؤكد هدوث ذللك وان التخمص لم يؤدي الي التي

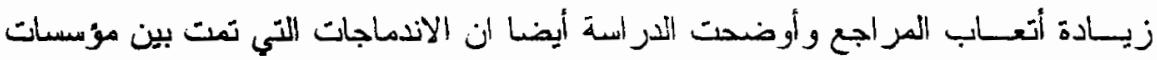

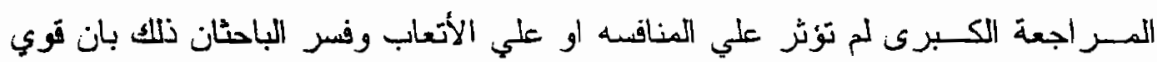

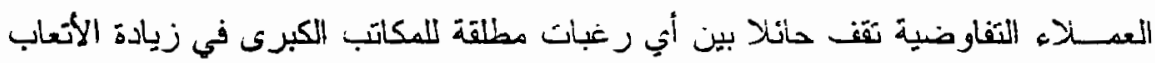

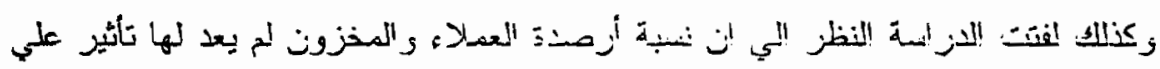

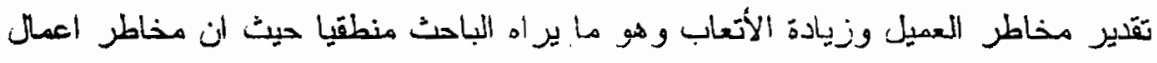

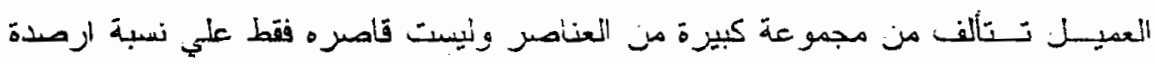

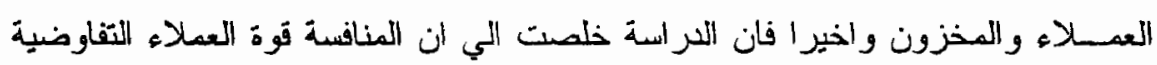

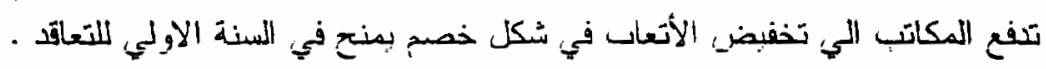

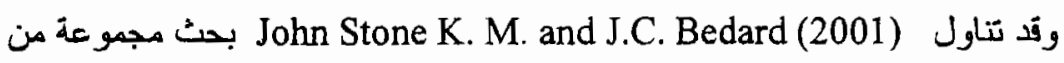

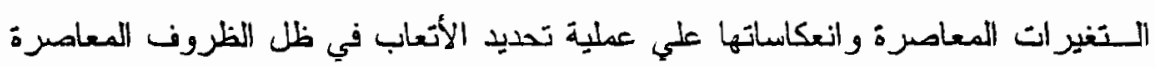

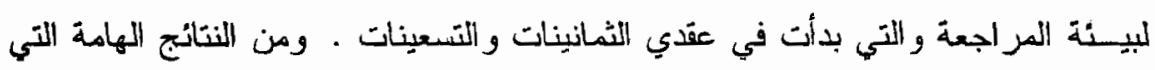

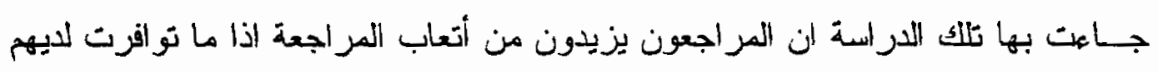

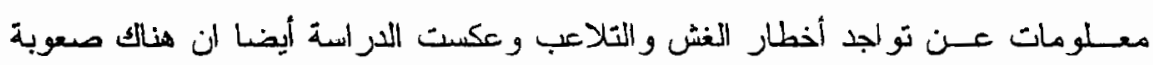

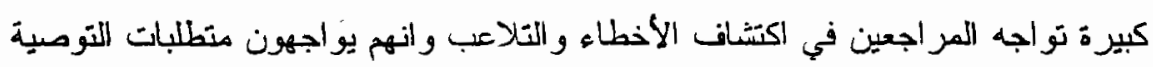

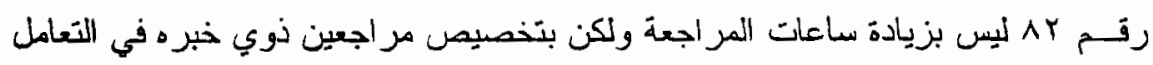

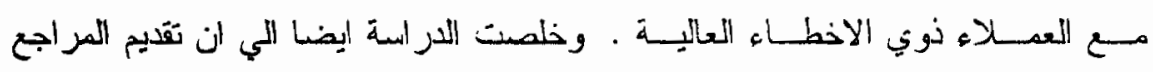

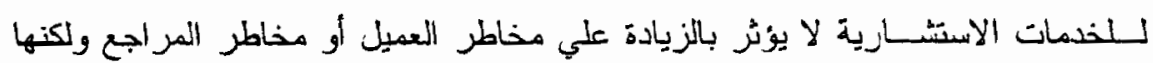

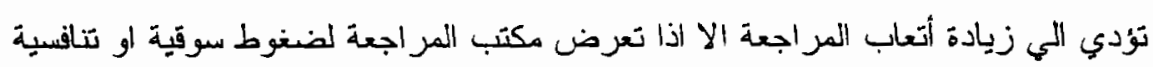

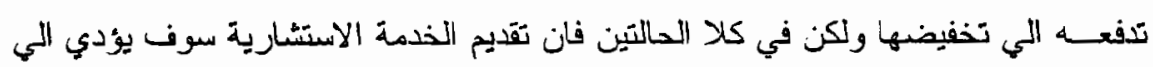

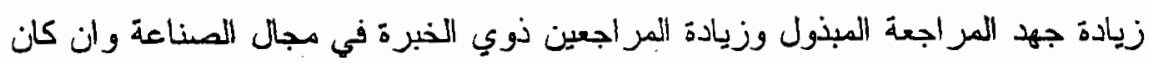

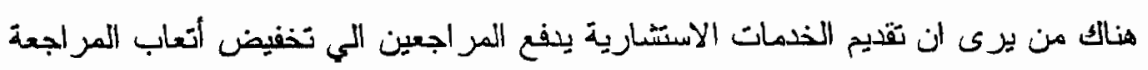

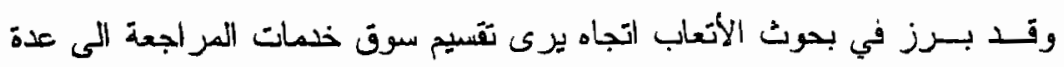

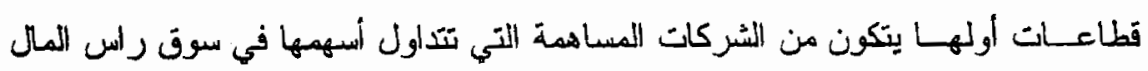

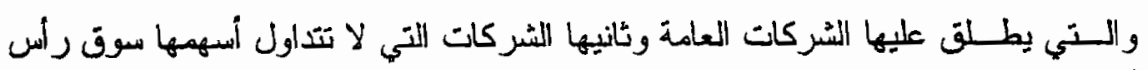

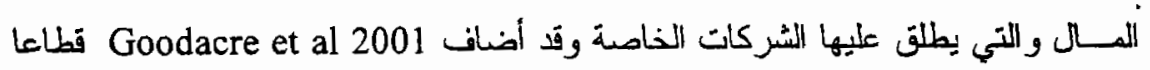

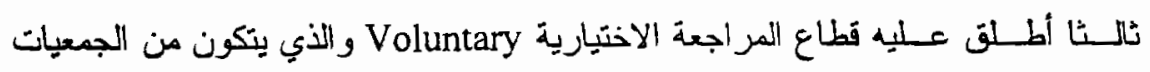

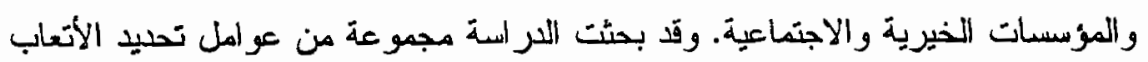
في هذا القطاع وهي: 
- حجم العميل معبر ا عنه بحجم الأصول حيث يؤنز حجم الأصول في جهد المراجعة

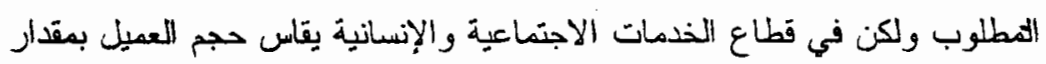

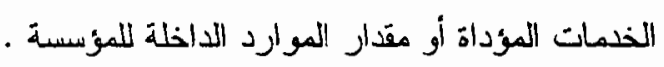
r- برجة التعقيد في نشاط العميل والذي بعبر عنه بعدد المواقع التي تخمها المؤسسة

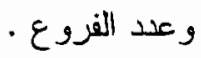

r- ت تكساليف انتاج خلمة المر اجعة وعدد العاملين و المسافة بين موقع مكتب المر اجعبة

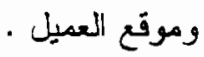

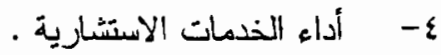

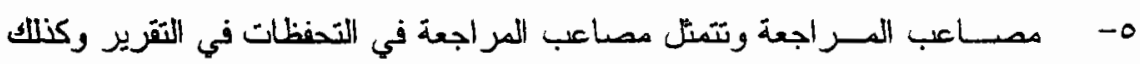

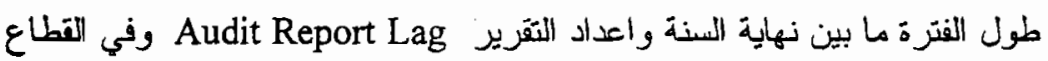

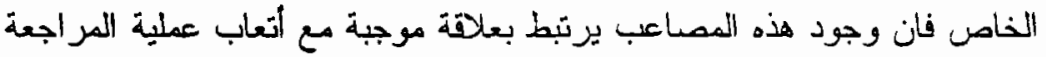

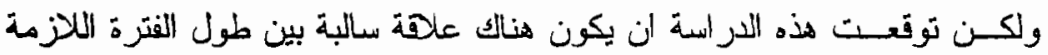

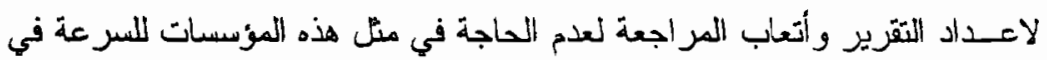

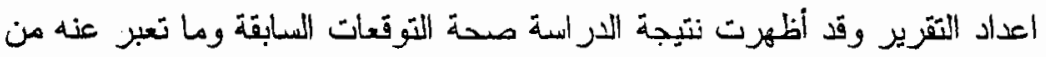

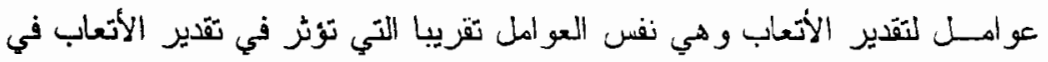

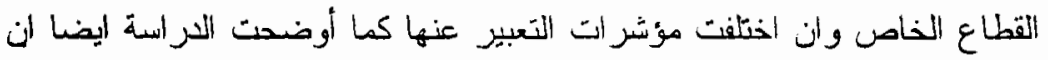
مكاتب المر أجعة الكبرى الخمسة تحصل من هذا القطاع علي أتعاب أعلى من تلأك

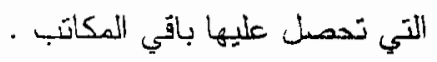

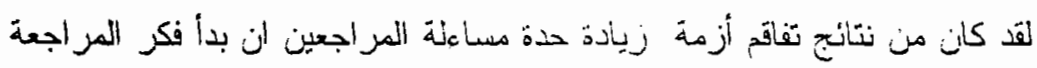

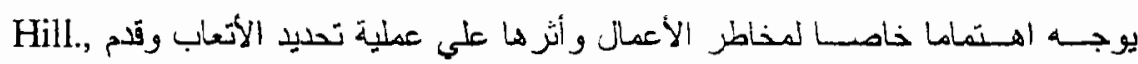
J.W.et al (1994)

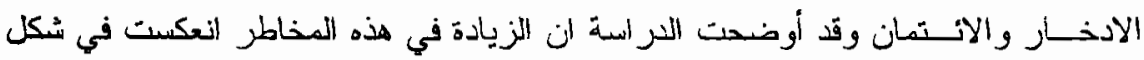

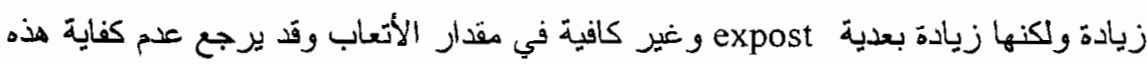

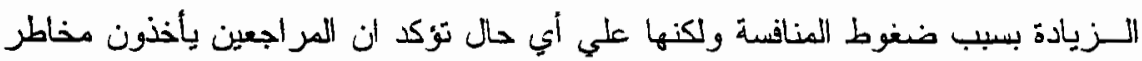

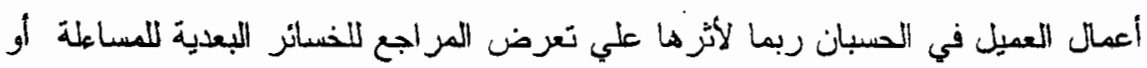

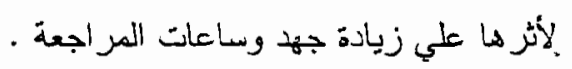

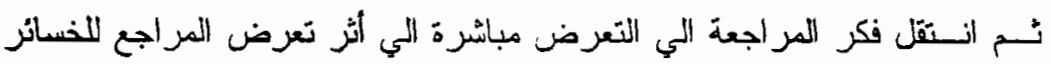

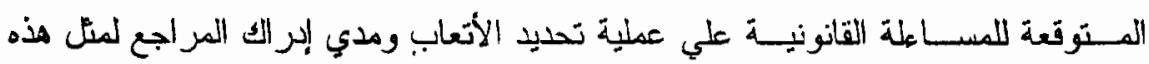

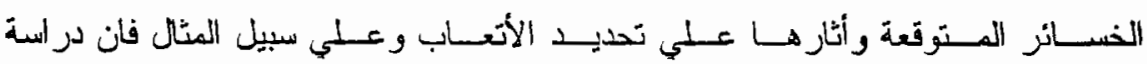


Bell et al 2001

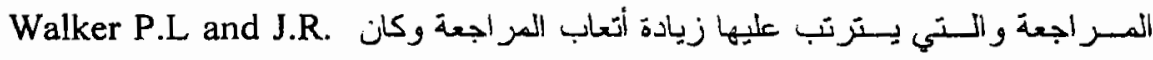
Casterella 2000

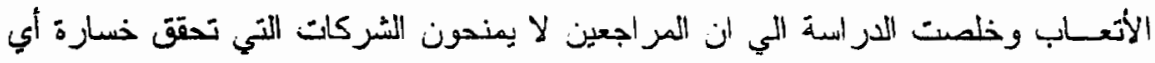

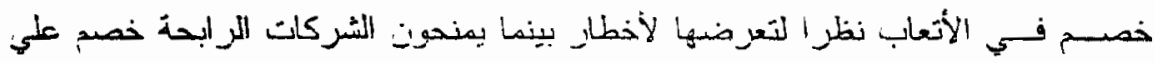

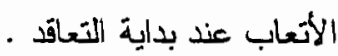

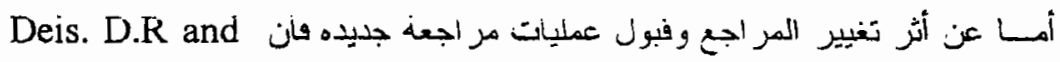
G.Giroux 2000

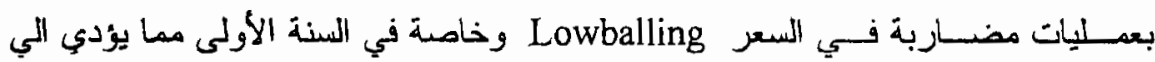
تخفيـض اتعاب المراجع في الوقت الذي يحافظ فيه المر اجعون علي جودة مر اجعة عالية

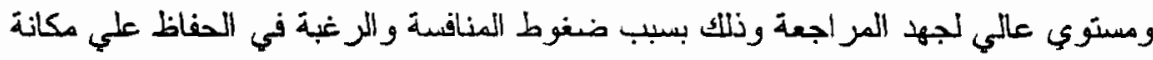

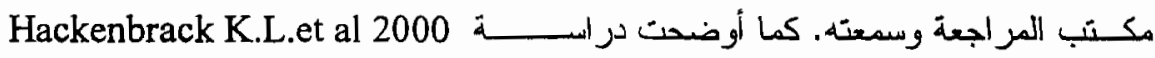
أن القيــود التي تضعها الجهات الإشرافية والتي تحتم عدم استخدام أتعاب المراجعة كاحد

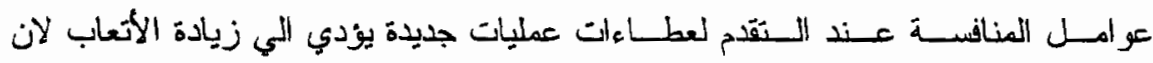
المــراجعون بتتافسون بجودة عملية المراجع ولذلك فان الاختيار سيتم علي أساس العطاء

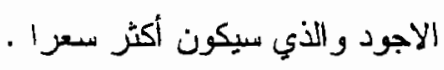

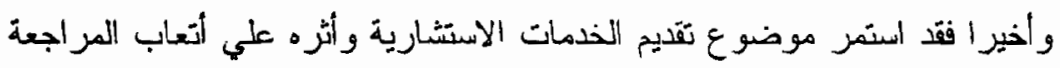

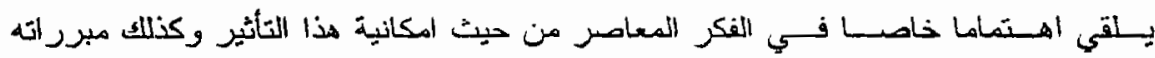

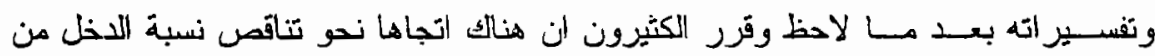

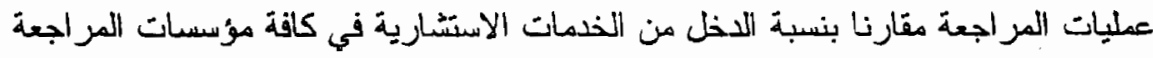

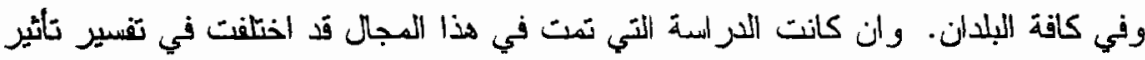

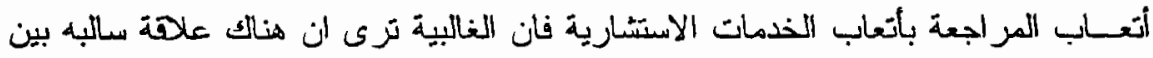

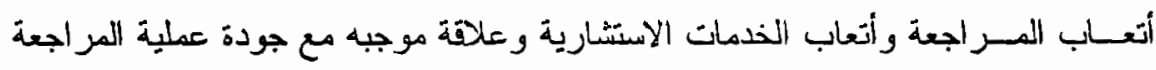

. Lennox, C.S. 1999

وتَـد كان تحديد أتعاب المر اجع ومحدداته محلا لاهتمام بعض الدراسات واليحوث العربية

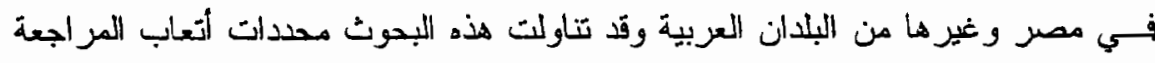

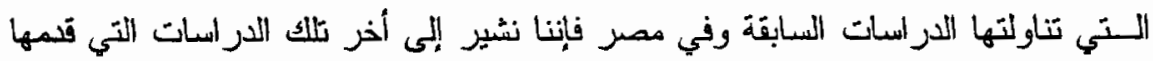

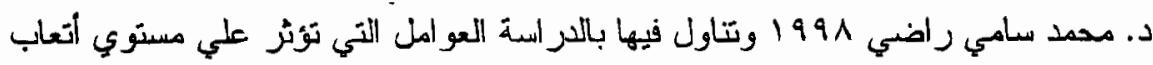

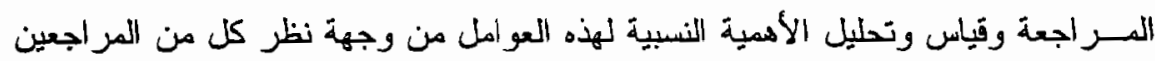




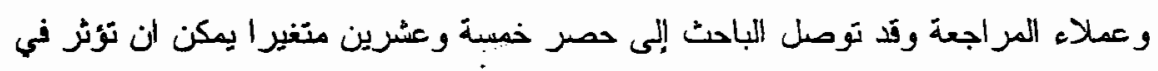

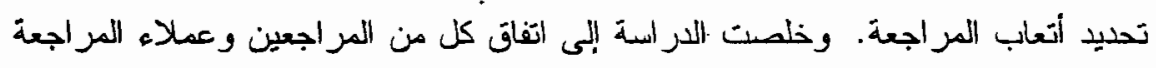

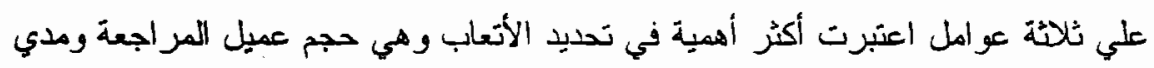

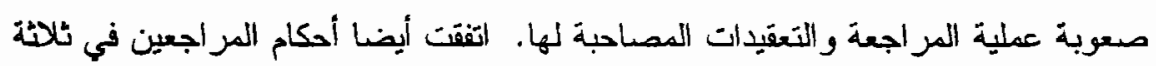
عشـر متغيرا أخري واختلفت أحكامهم في باقي المتغيرات. وتمثل المتغيرات التي بحثنها

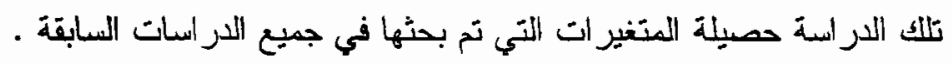

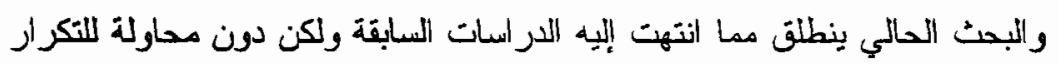

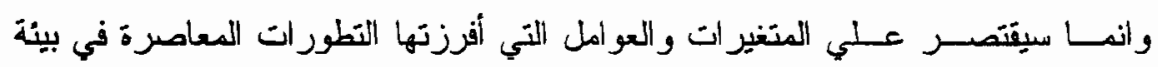

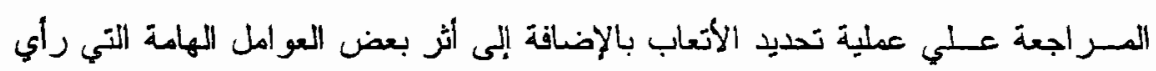

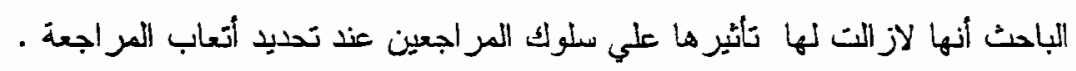
r - العوامل المؤثرة في سلود المراجعين عند تقدير

\section{الأتعاب في بيئة المراجعة المعاصرة}

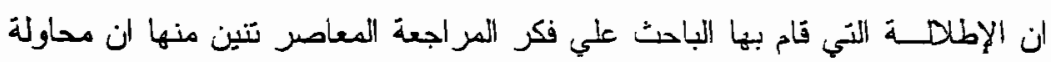

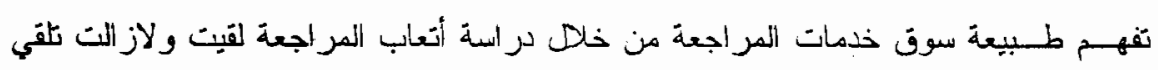

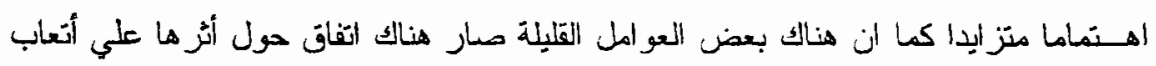

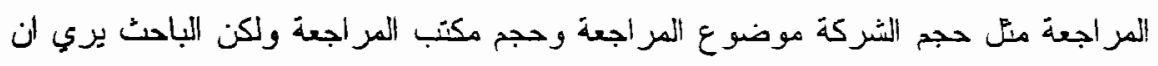

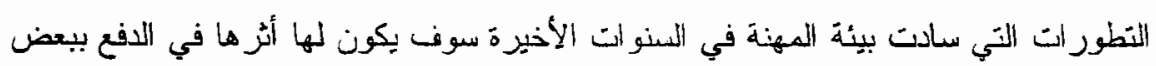

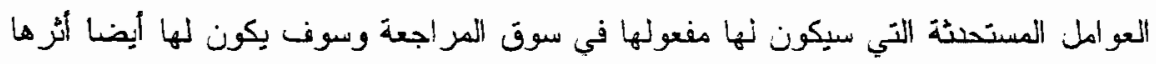

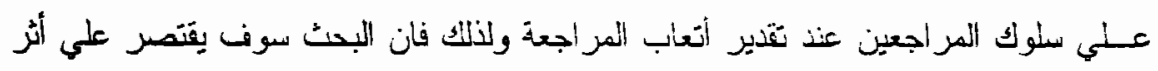

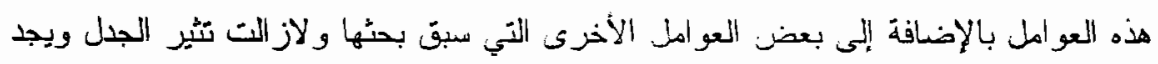

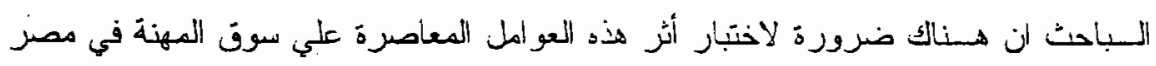

\section{Audit Structure} وهذه العوامل هي :

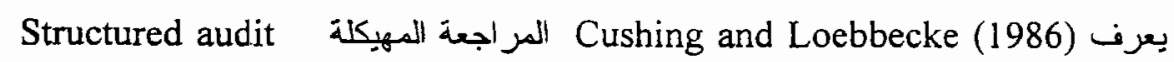

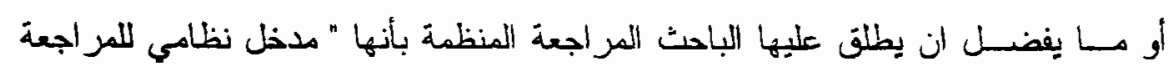

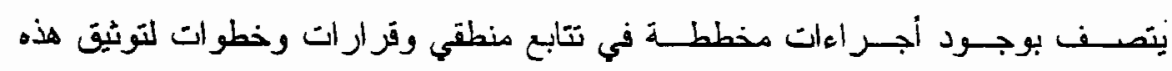

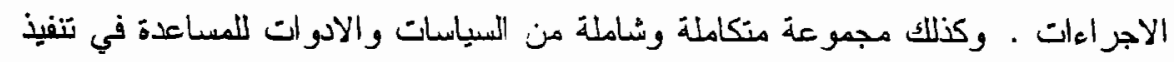

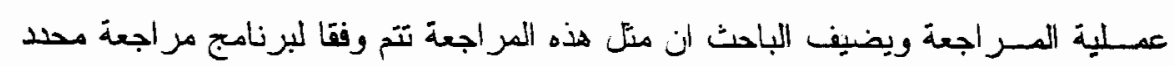


و مطبوع مقدما اما المر اجعة غيز المنظمة (غير الهيكلية) Unstructured audit فتصفف غالبا بعدم وجود برنامج مر اجعة ثـامل هرنسوم ومكتوب ومحلد مقذها ويمارس المراجعون القائمون علي تتفيذ عملية المر اجعة قدر كبيز من الاختيار من الاجراءات انثاء تنفيذ عملية المر اجعة - لهذا فان Wiliams \& Drsmith يريان ان المر اجعة غير المنظمة

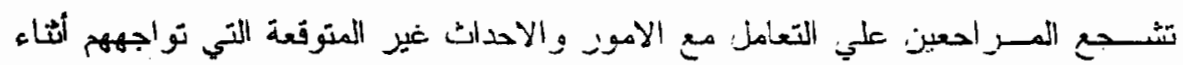
التـنفيذ كمــا أنهـــا نتطلب ممارسة المر اجعين لقدر كبير من التقدير الشخصي عند اتخاذ قــز أر أت نــفيذ عملية ألمر اجعة وفي الوفت داتيه فان هدخل هيكلة عملية المر اجعة يؤدي

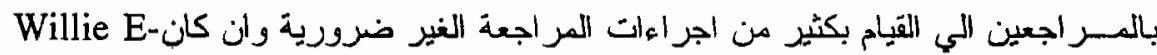
Gist (1994) يرى أنه من الممكن ان تؤدي المراجعة المهيكلة أيضا الي قيام المر اجعين بــبعض الاجهـراعات غيــر الضرورية وذللك اذا لم يكن اللمراجعين القائمين بتتفيذ عملية المــراجعة الحستو والحــرية في الخروج علي تلك الاجراءات المعدة من قبل في برنامج المراجعة المكتوب وفي هذه الحالة يقوم المر اجعين بأداء بعض الاجر اءات لمجرد الالتز ام بالتعـليمات المكتوبة في البرنامج · وقد لاحظ الباحث ان فكر المراجعة شهد جدلا و اسعا حــول المفاضــلة بين هيكلة وعدم هيكلة عملية المر اجعة حبث اكد بعض الباحثين ملّل Cushing and loebbecke 1986 فاءـلية Effectiveness وكفايـة Efficiency عملية المراجعة ونلك بتخفيض الوقت الـلكزم لتـنفيذ عملية المر اجعة وذلك علي فرضية ان هيكل التكلفة لعملية المراجعة انما بيتوقف علي درجة الهيكلة التي تتفذ بها عملية المراجعة وأكد Cushing and loebbecke (1986) ان مسن أهم مز ايبا هيكلة عملية المراجعة هو مساهنها في الرقابة علي نكاليف عملية المر اجعة - ومن ناحية اخري فقد عارض بعض اللباحثين عملية الهيكلة و علي سبيل

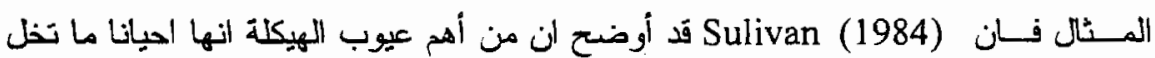
باعتبار ات كفاية عملية المر اجعة لاهدالها كيفية الحصول علي أللة اثبات وصفية . ويضـين البياحث ان الجلل الدائر في فكر المراجعة حول المفاضلة بين هيكلة وعدم هيكـلة عملية المر اجعة لم ولن بنتهي لان هذه المفاضلة تختلف من مهمة لاخرى من مهام المــراجعة حيث هنالك بعض المهام الروتينية لتنفيذ عملية المراجعة يمكن هيكلتها بقو اعد مكــتوبة ومدــدة مــن قبل لتتفيذها و هنالك بعض المهام الاخرى غير الروتينية لا يمكن

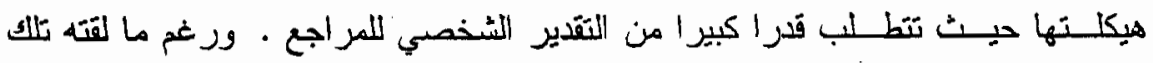

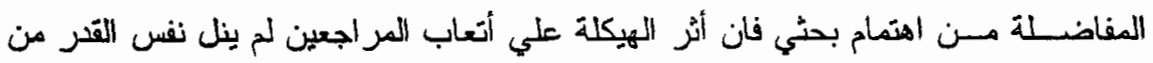

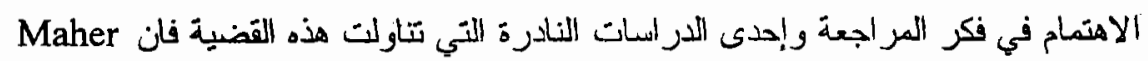


et al (1992) قـــــــرروا أنه في أوقات ارتفاع حدة المنافسه في سوق المراجعة ما بين

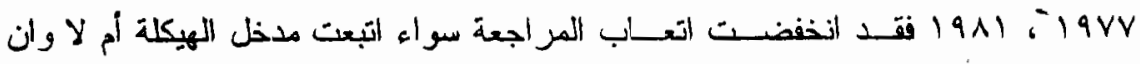
الاتخفـاض كان بالنسبة للمر اجعة غير المهيكلة اكبر من حالة المراجعة المهيكلة وان كان

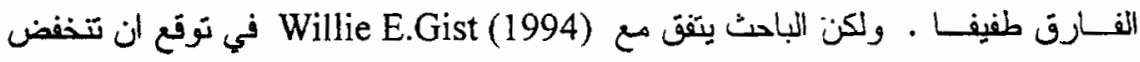

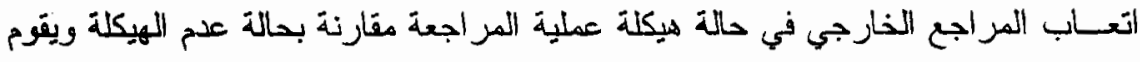

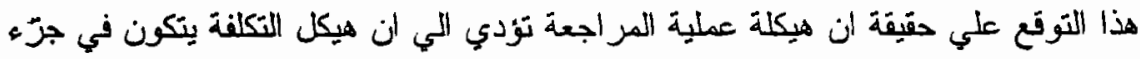

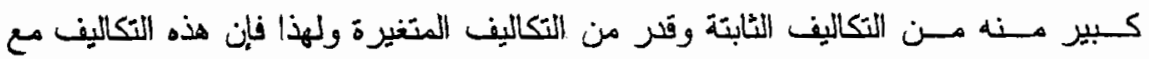

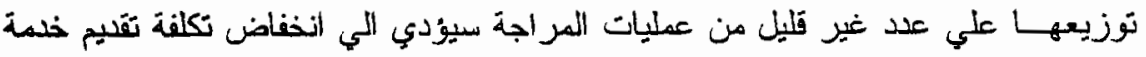

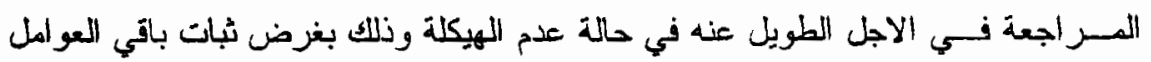

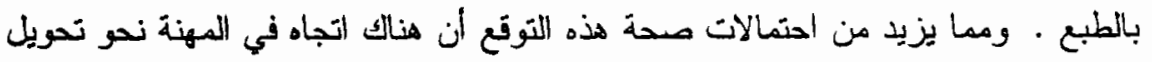
قــر كبير من المهام غير الروتينية في المر اجعة الي مهام روتينية مهيكلة بفضل استخدام

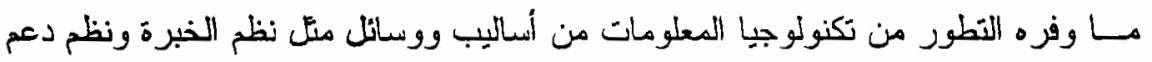

$$
\text { ومساعدة القزار ات . }
$$

\section{Audit Automation}

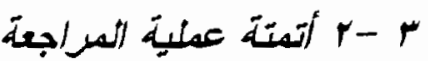

$$
\begin{aligned}
& \text { r - r - الهفهوم والمبالات }
\end{aligned}
$$

تعـرن أتمــتة عمـلية المراجة بانها " عملية استخدام أبي نظلام من نظم تكنولوجيا

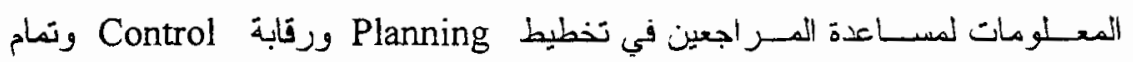
و إبدارة Completion

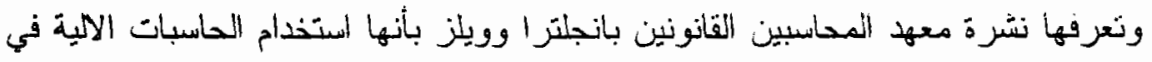

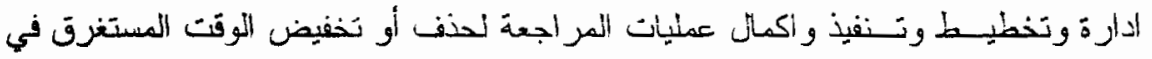

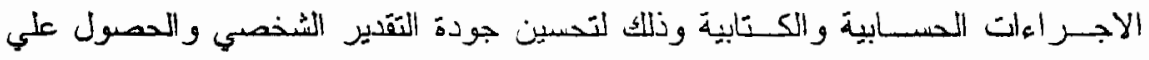

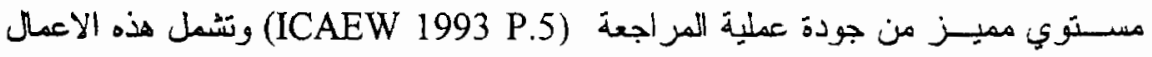
إعداد أور اق المر اجعة أو اعداد مكتبة تحتوي مجمو عمة من الاورات النموذجية المعدة مسبقا

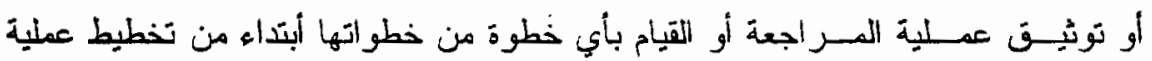

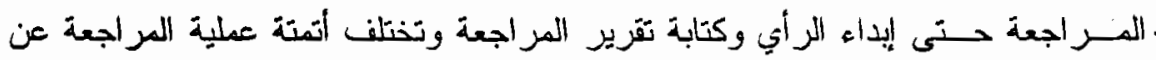
الســتذدام نكــنولمجيا المعلومات في مراجعة نظم العميل التي تقوم علي استخدام التشغيل

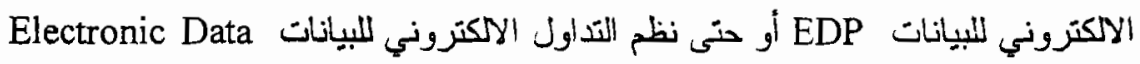
Interchange (EDI) 
فان أتمتة عملية المر اجعة لا تقف عند حد مراجعة أنظمة الماسب فا الأتمنة تعني استخدام

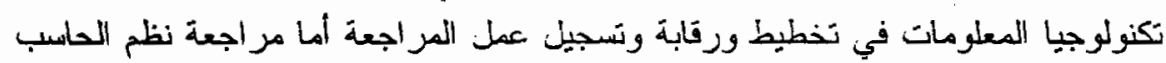

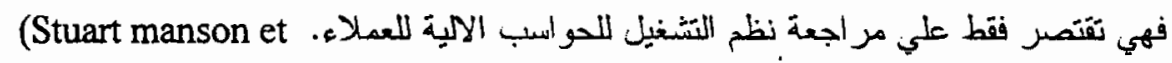
al 1997 P 254).

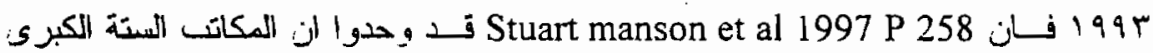
ونسبة كبيرة من المكاتب المتوسطة ونسبة أقل من المكاتب الصغرى تعتمد علي تكنولوجيا

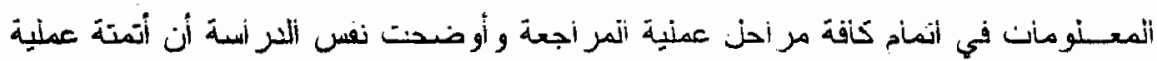

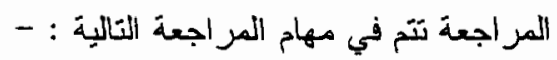

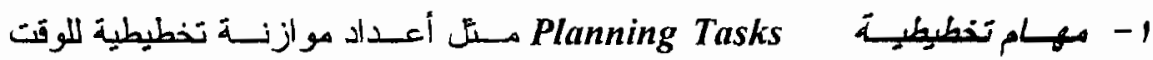
وتذصيص فرينق المر اجعة علي المهام راعداد وادارة الخطط وحساب وتنفيذ عمليات

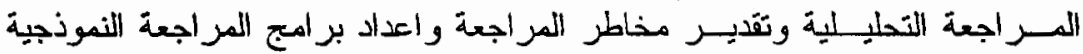

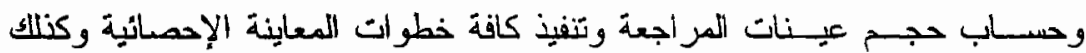

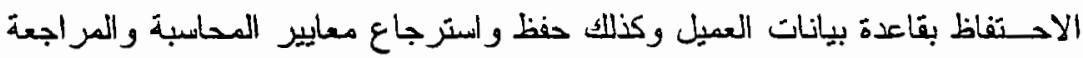

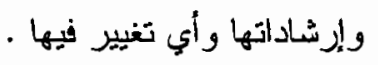

\section{Recording Tasks م - مام التسجيل}

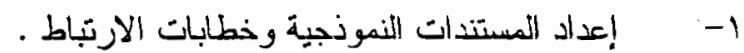

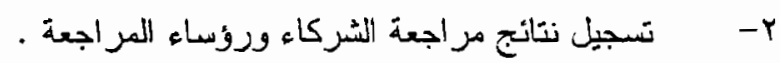

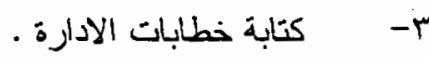

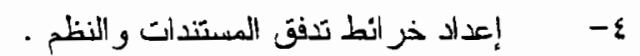

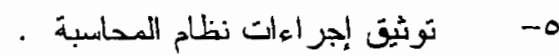

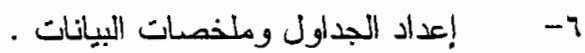

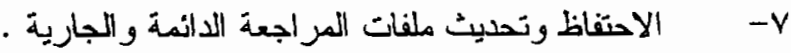

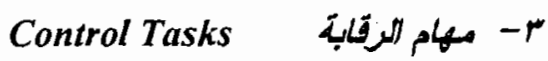

1- تسجيل الوقت الفعلي ومقارنة الوقت الفعلي بالوقت المخطط لكل مهمة من

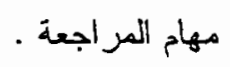

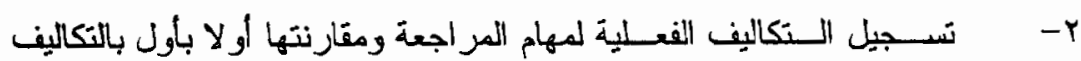

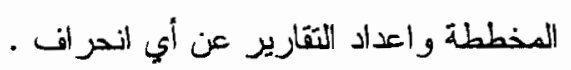

r- التقرير عن أي انحراف في الزمن المقدر لكل عملية ولكل مهمة من مهام

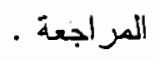


ع- تسجيل الملاحظات الرقابية للشركاء ومديزو المراجعة لأغر اض المتابعة .

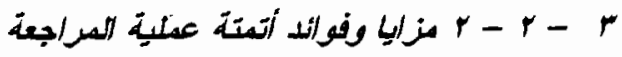

اولا : تحسين جهدة عملية العر/جعة

أن الاعــناد عـلي تكنولوجيا لمعلومات في تخطيط وتنفيذ ورقابة عملية المر اجعة بــؤدي الــي تحسـينين جـودة عملية المر اجعة بصفة عامة اما عن كيفية تحقيق هذا التحســين تحديــا فــان أتمتة عملية المر اجعة تودي الي تحسين طريقة تفكير أفراد المر اجعة وتحسين ممارسة التقدير الشخصي للمر اجعين وتشير نشرة معهد المحاسبين القــانونيين بانجلـتر ا وويلز رقم عـ بعنوان Audit Automation ان أتمتة عملية المـــر أجعة تــؤدي الــي تحسين جودة التقدير الشخمي للمراجع وذلاك بزيادة هيكلة عمليات أتخاذ القرار ات في المر اجعة وتوفر للمراجعين كم من المعرفة ينيح لهم تقميم اجابسـات صــحيحة وفـي الموقت الصحيح لكافة ما يصادفهم من مواقف وتظهر هذه المــز ايا بصــورة أثــد وضوحا في المراجعة التحليلية وكنلك في عمليات الفحص

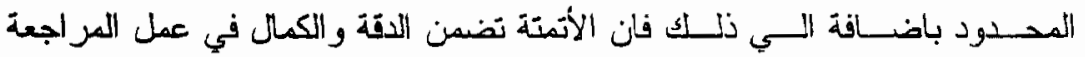
وباســنخدام تكــنولوجيا المعلومات فلنه يمكن للمراجع ان يحتفظ في ذاكرة الحاسب

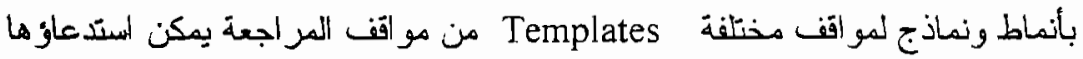
عـند الحاجسـة لتحسين التقدير الثخصي للمراجع وخاصهة في المهام غير الروبتينية بالاضــافة اللي نلاك فان أتمتة عملية المر اجعة تزيد من (ICAEW, 1993 No 4.) الر الك المعيل لجودة عملية المر اجعة فالحداثة التي تحملها تكنولوجيا المعلومات تعطي انطسباعا بـالجودة حيث يرتبط نكنو لو جيا المعظومات دائما بكل جديد ومتقدم ومحقق

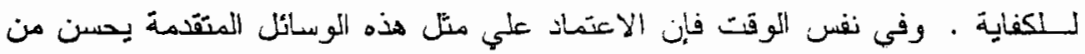

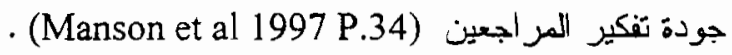
ثانيا : تحسبن الكفاية وتنفيض تكالبف عملية المر/جعة .

وفـي هذا المدد فن نشرة معهد المحاسبين القانونيين في انجلترا وويلز وعن أتمتنة عملية المر اجعة والمنشورد سنة بهو 199 قد قررت ان الهخف النهاتي الأي يسعي اليه

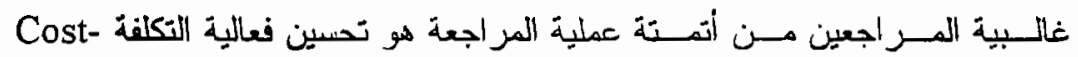
effectiveness بما يسمح بأداء أعمال مر اجعة اضافية بدون زيادة في التكلفة مها يودي الي تخفيض اليض أتعــاب المسر اجعة أو زيــادة ربحية عملية المراجعة ICAEW,1993 P.5 ولكن Stuart Manson et al 1997.262 
التكـ لفة ولكـن ذلك بأتي ثاليا لهدف زبادة جودة عملية المر اجعة ويضيقون أن هذا

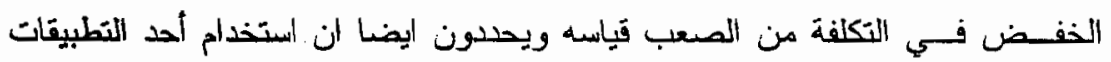

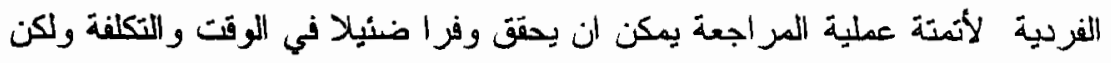

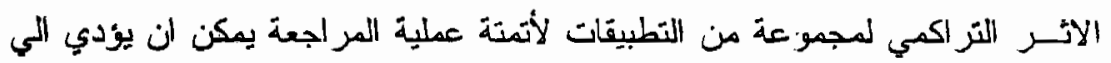

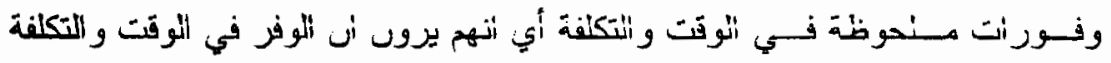

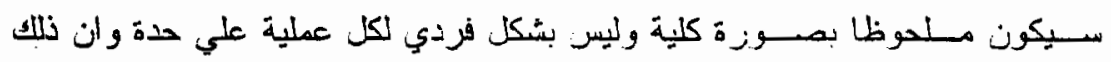

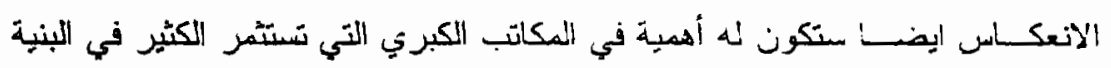

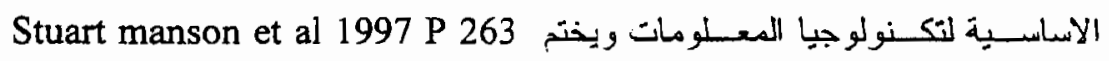

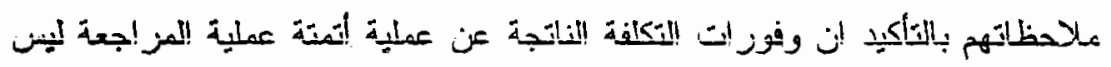

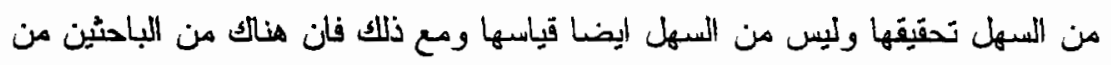

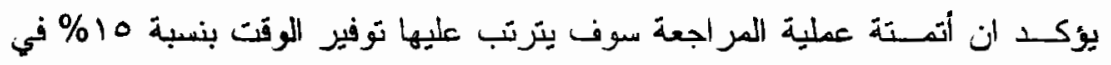

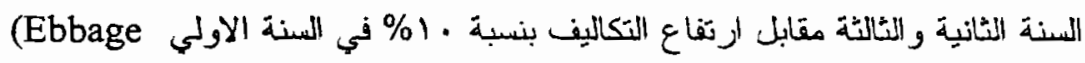

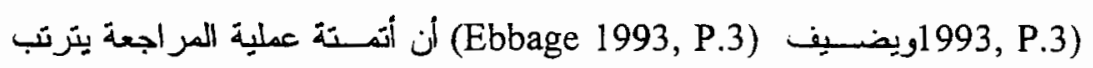
عـليها مجموعة من النكاليف ينبغي أخذها في الحسبان عند بحث أثرها علي الكفاية و هذه التكاليف هي :

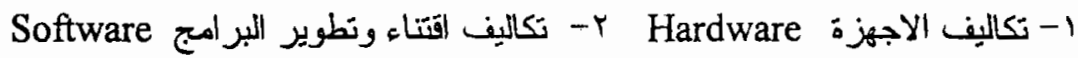

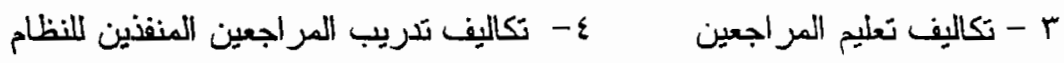

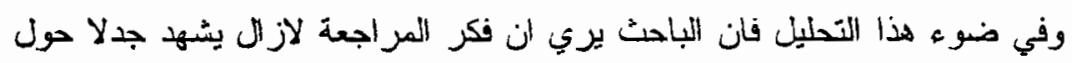

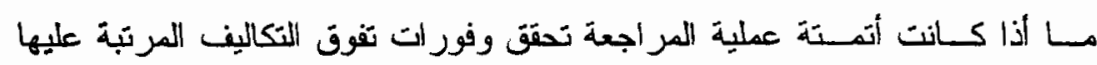

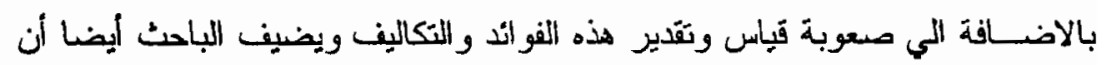

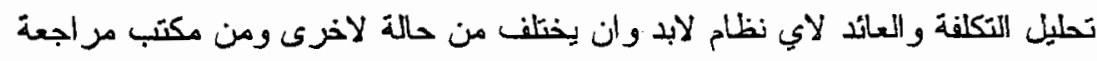
لاخر

\section{كأثاً : تحسين الموتف التتافسي لمكتب المراجعة .}

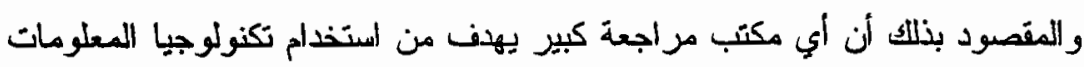

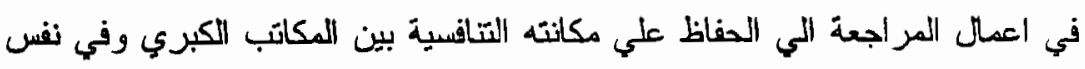

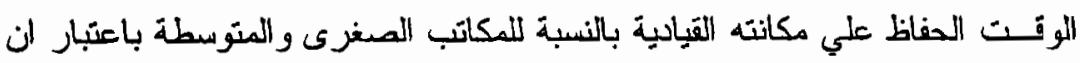

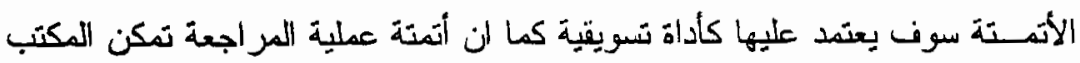

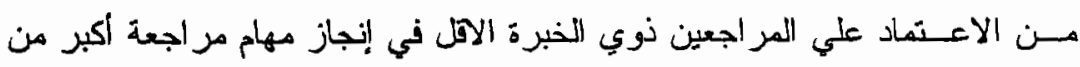

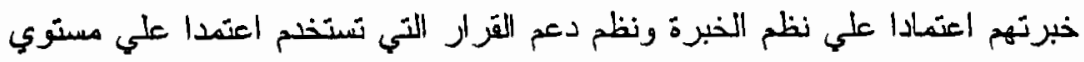


عـلال من تكنولوجيا المعلومات كما ان أتمتَة عملية المراجعة تساعد فريق المراجعة

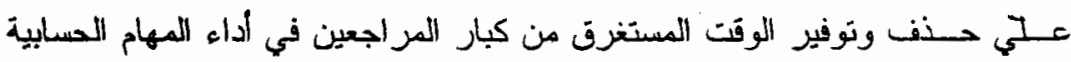

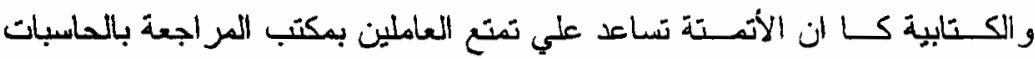

. Starbuk and Webster 1994

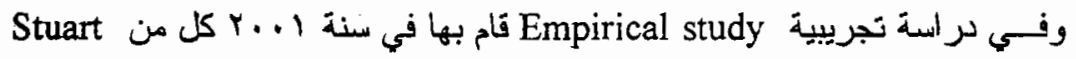
manson, S. mceartneg and M.Sherer

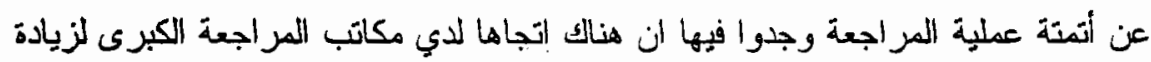

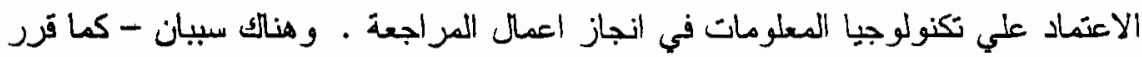

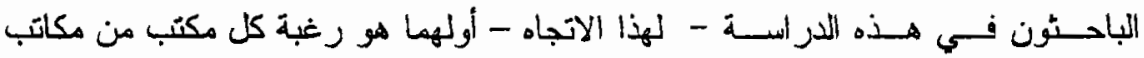

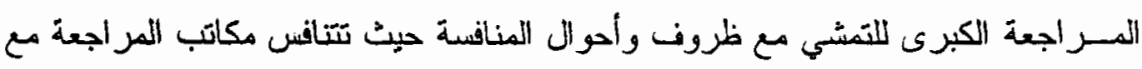

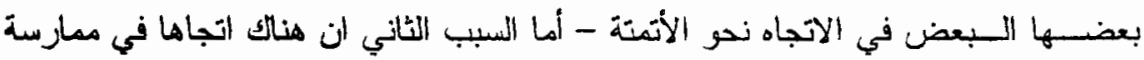
المـر اجعة للتحول من مدخل العطليات Transaction Approach وايضا مدخل النظم Risk Based Auditing الـي مدخـلـل مخاطـر الهــراجعة Systems Approach Approach

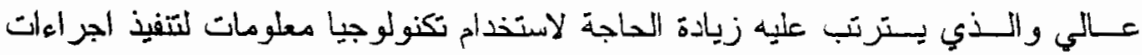

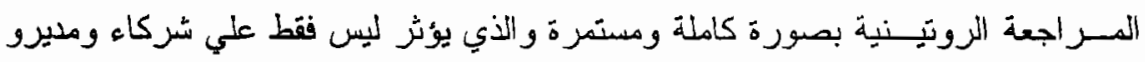

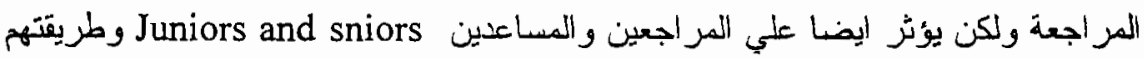

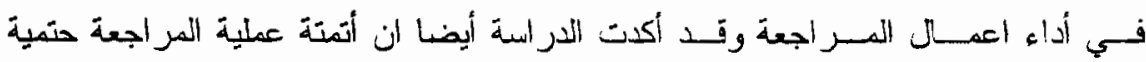

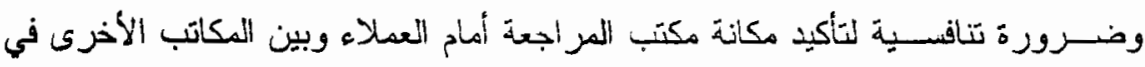

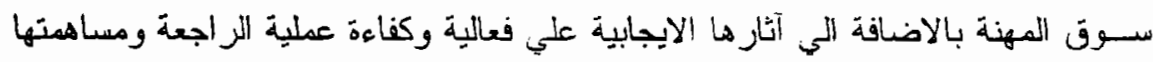

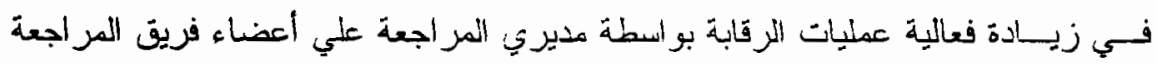

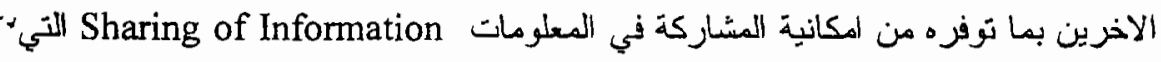
تتو افر بقدر كبير مما يمكن من فرصة الرقابة الجيدة . ومع ذلك فقد تخوف الباحثون في هذه الدراسة من بعض فير الآثار السلبية لأمثنة عملية

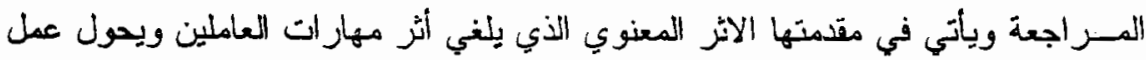

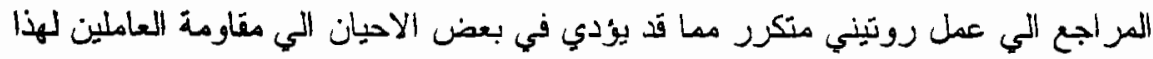

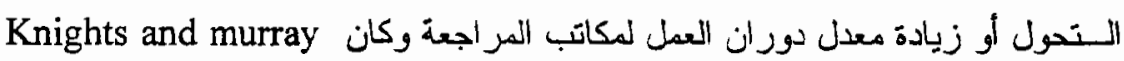

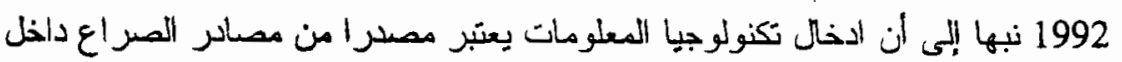

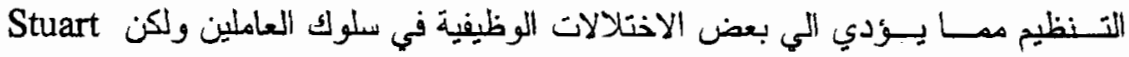


manson et-at 2001

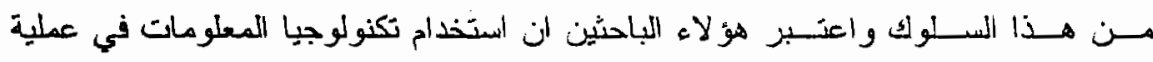

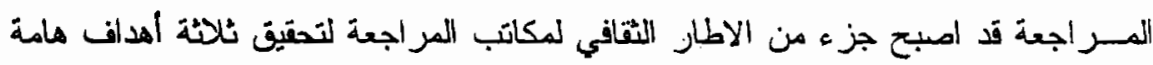

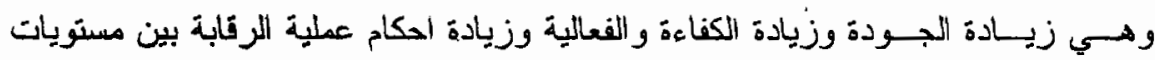

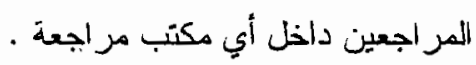

وفـي نهايسة هذا التحليل لعملية الاتمتة من حيث أثارمها الايجابية و السلبية كما قدمها

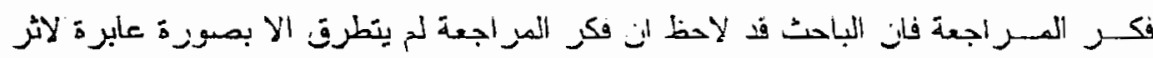

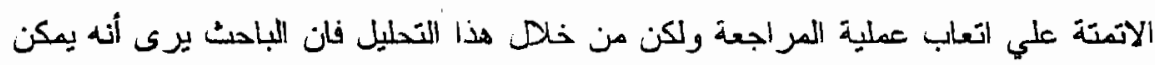

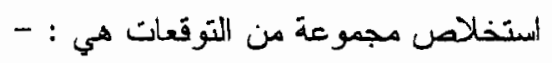

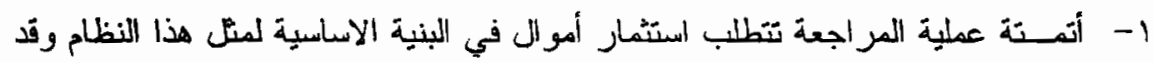

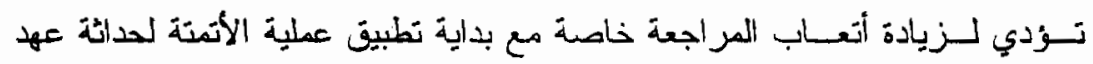

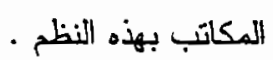
r- اذا كـانت الاتمــتة ستودي الي توفيز الوقت وتحقيق التكلفة فان هذا قد يكون حافزا

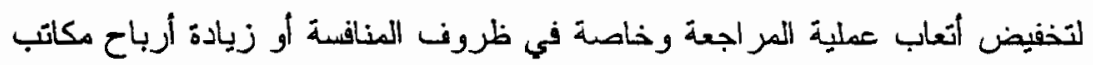

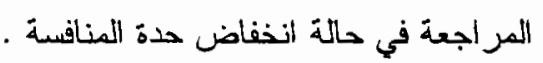

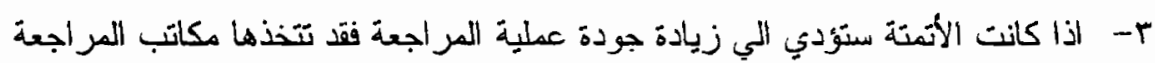

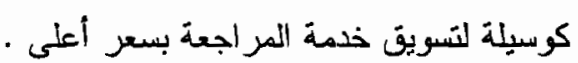

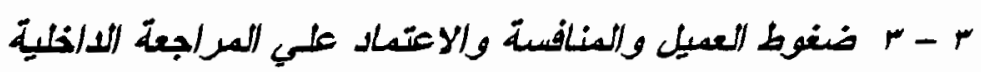

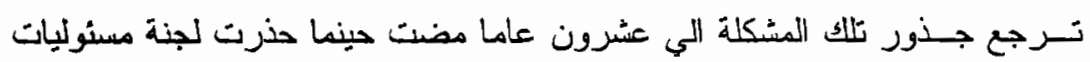

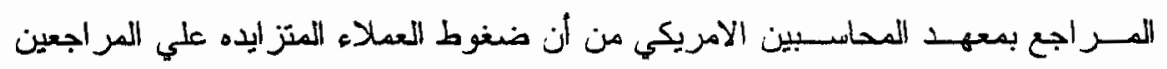

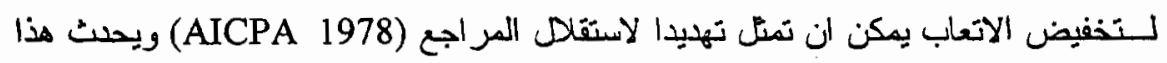

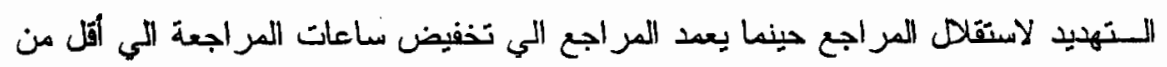

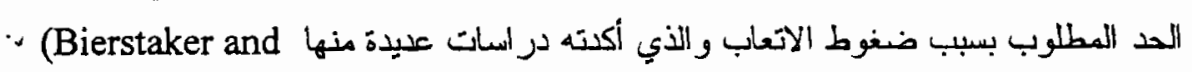
Wright 1999, Houston 1999)

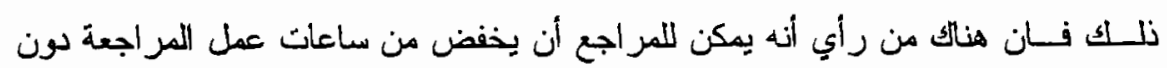

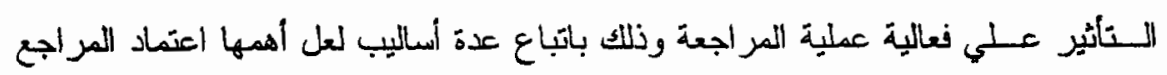

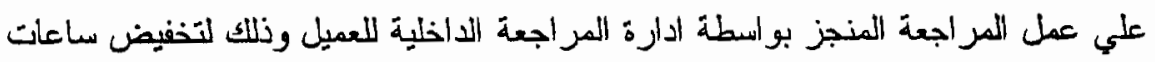

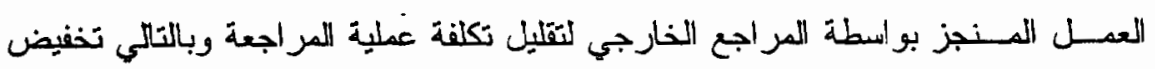


الاتعـاب 1999 Gramling, Audrey A. وذلــك أستجابة للضغوط التي يشهـها سوق

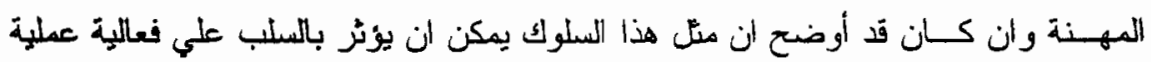

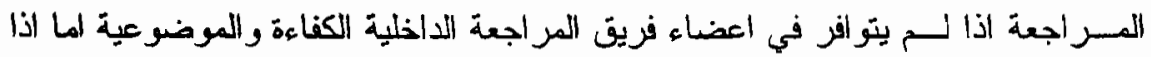

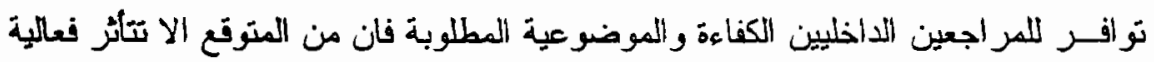

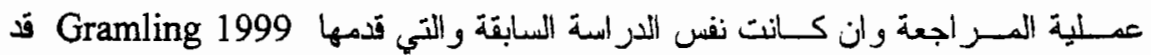

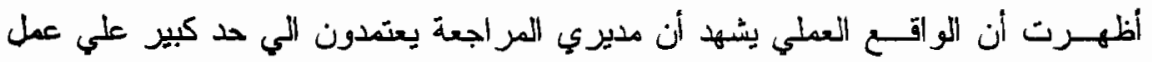

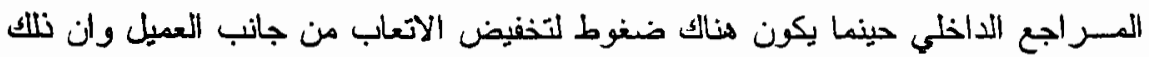

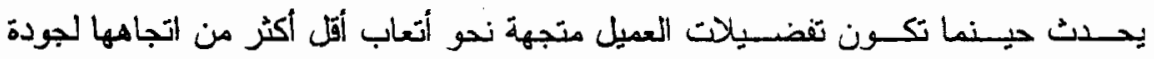

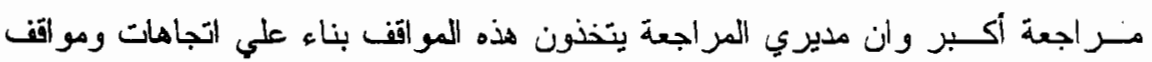
مركاء المراجعة Partners

ويستقق اعتماد المر اجعة علي عمل المر اجعة نتيجة لتخفيض الاتعاب نتيجة لضنغوط

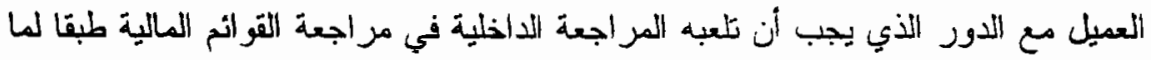

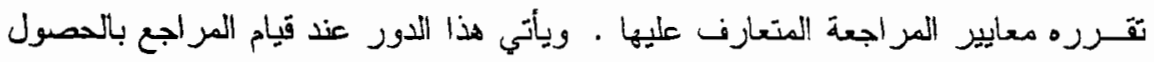

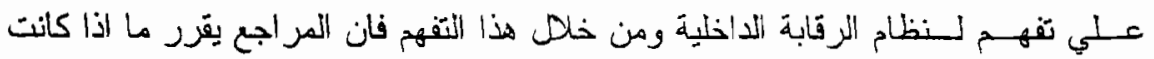

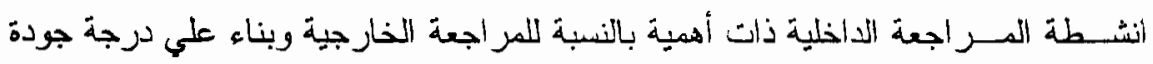

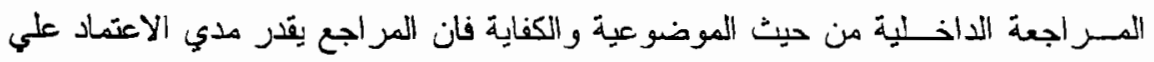

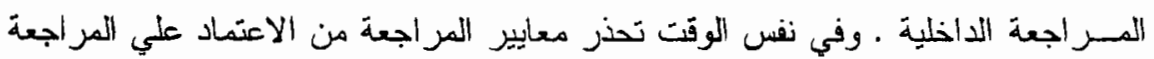

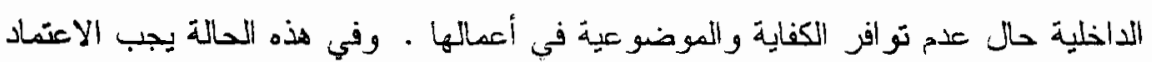

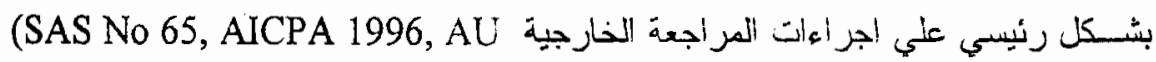

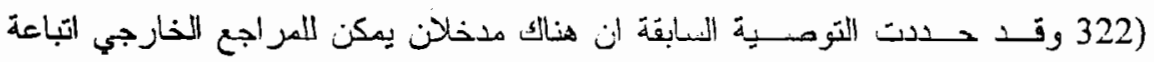

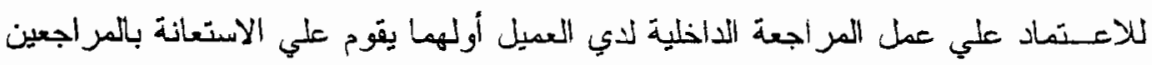

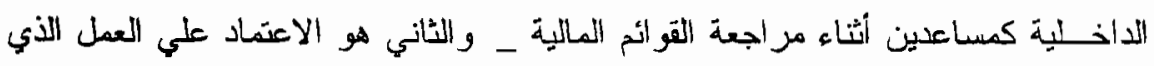

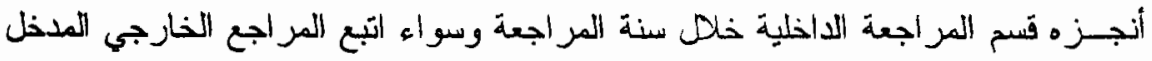

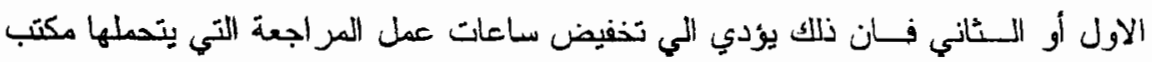

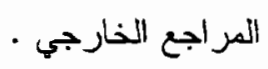
و هناك ثمة مدخل أخر لتفسير وتغهم سلوك المراجع الخارجي في اعتماده علي عمل

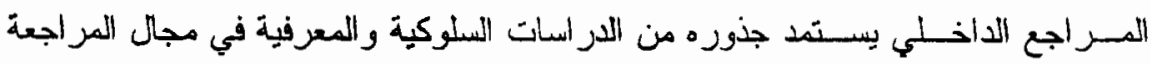
ويشـير الباحث بالتحديد التي وصف Gibbins and Newton (1994) البيئة التي يهل

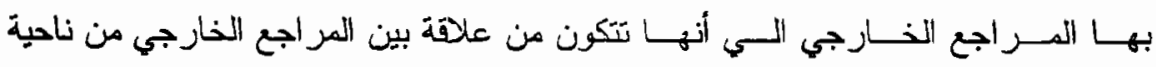


ومجموعة من الاخرين ذوبي القدرات الخلهدة Powefull others وهم الشريك المسنول

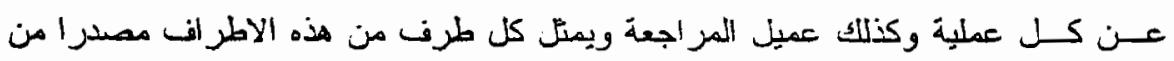

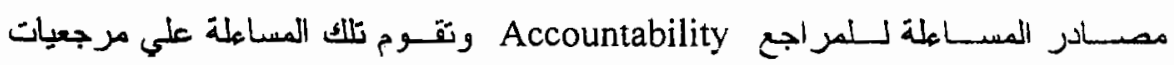

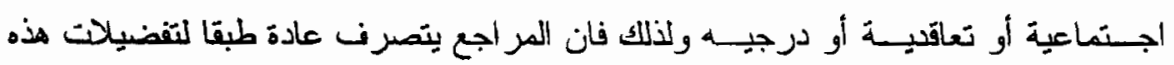

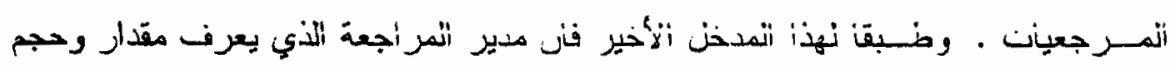

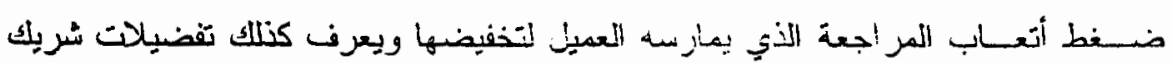

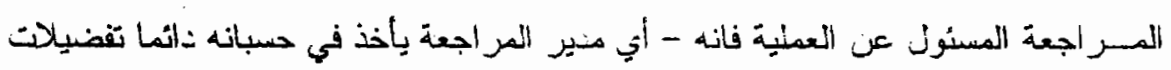

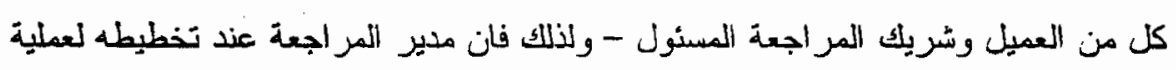

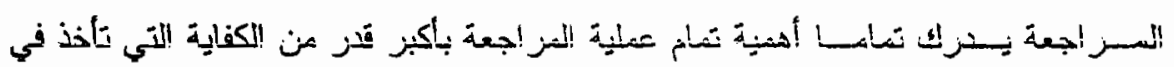

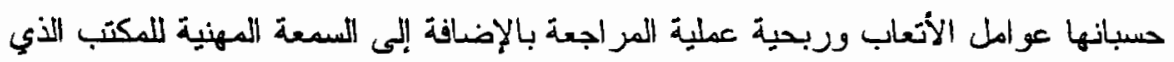

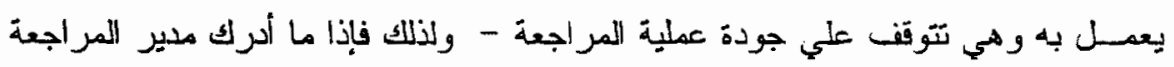

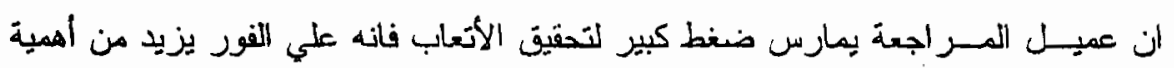

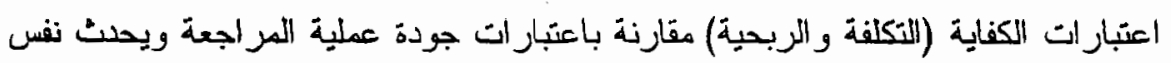

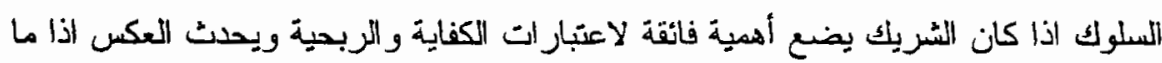

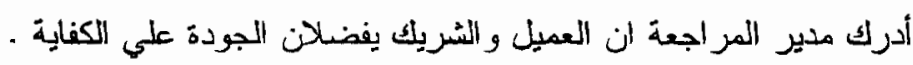

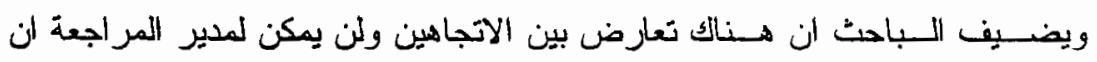

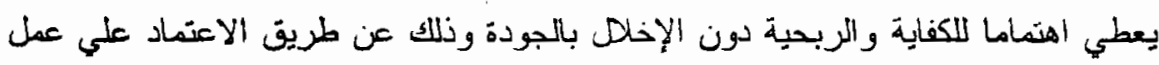

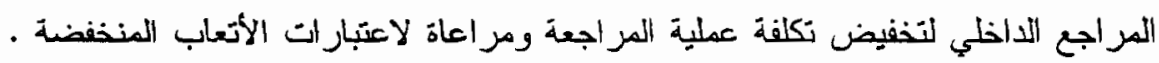

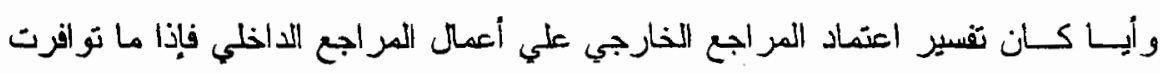

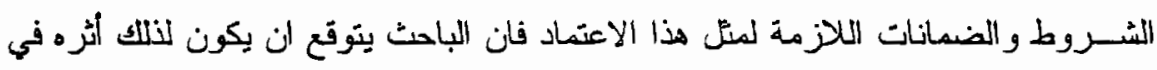

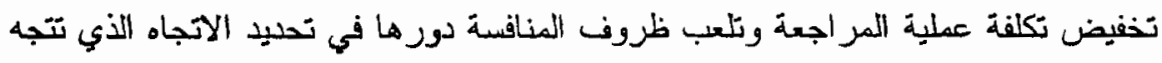

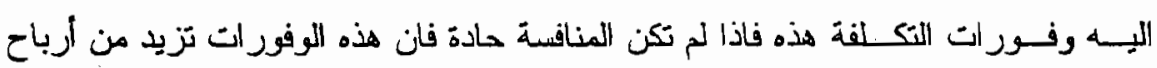

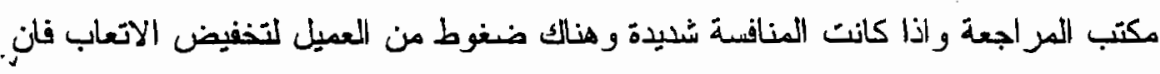
هذه الوفورات ستنعس في شكل تخفيض لاتعاب المر اجعة .

\section{Client Business Risk}

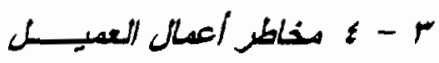

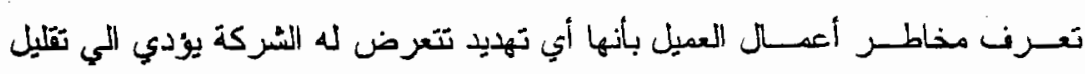

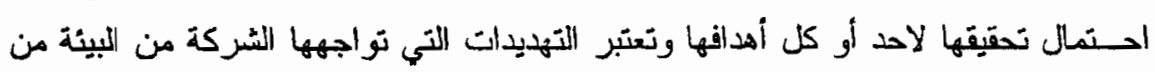

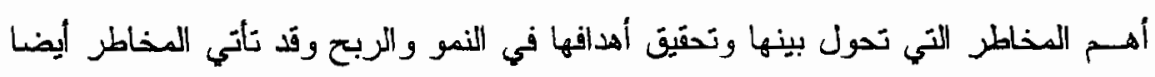


مسن داخل الشركة سواء. من العاملين أو من الادارة وأخيرا فلرن مجرد عدم أخذ رد الفعل

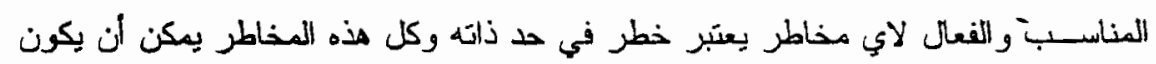

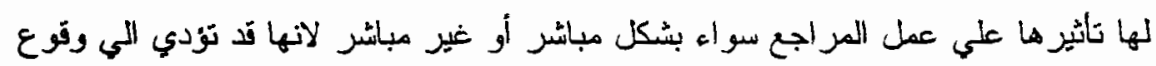

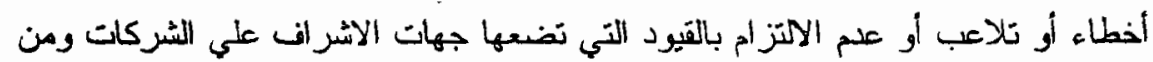

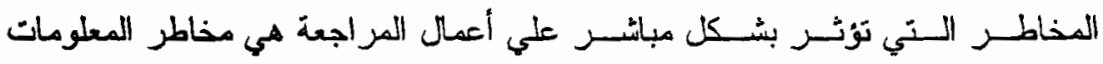

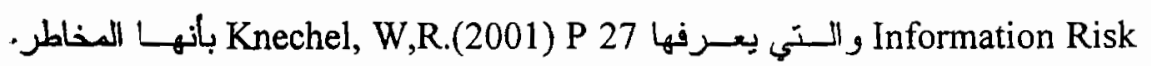

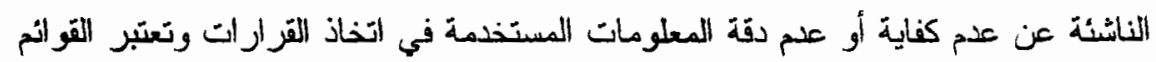

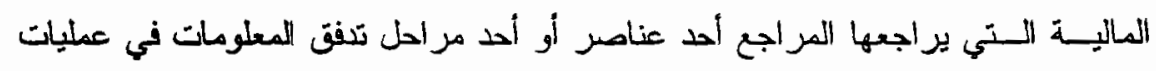

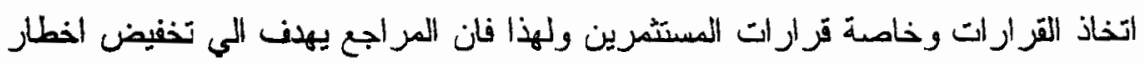

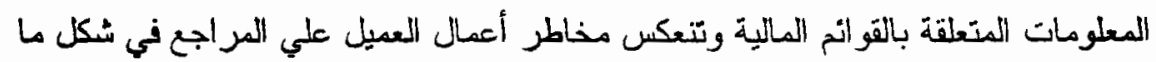

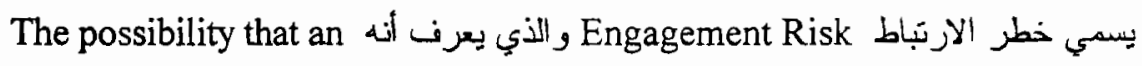
audit firm will suffer loss due to assoiation with a client.

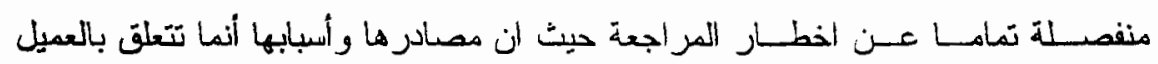
واحـتمال انعكاس هذه الاسباب علي المر اجع في شكل خسائر وانها قد تحدث رغم تطبيق

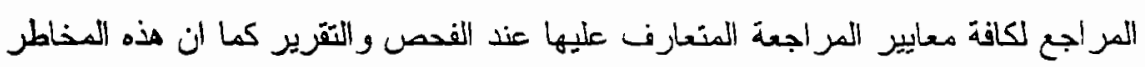

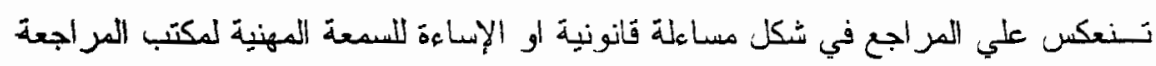

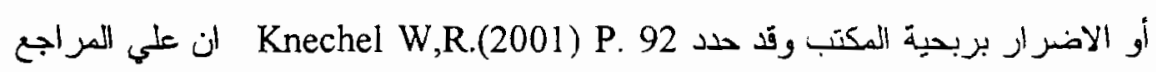

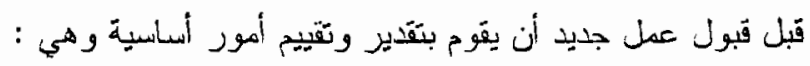

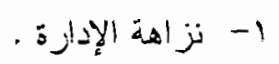
ب- سمعة الثركة وصورتها العامة .

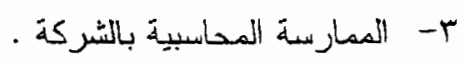

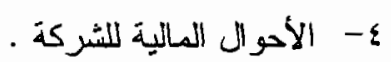

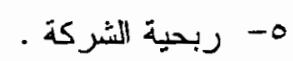

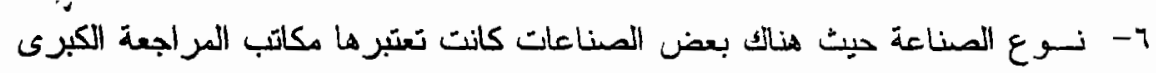

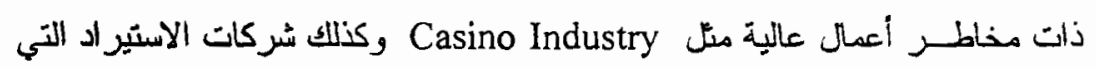

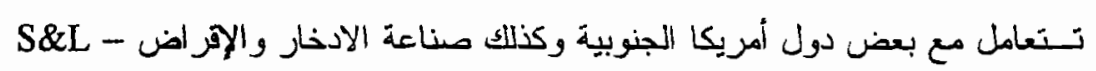

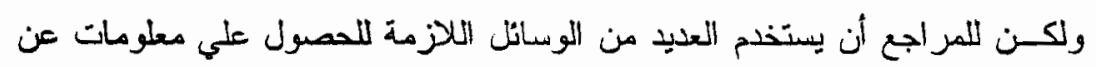

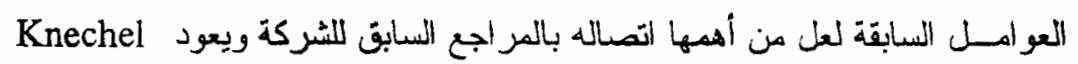
External threat 2001 p. 132 
وتهنيد داخلي Internal Threat و التهنيد الخنز جي الذي قد تو اجهه المثركة بتألف.

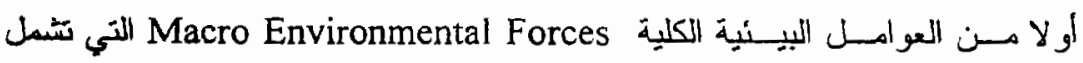

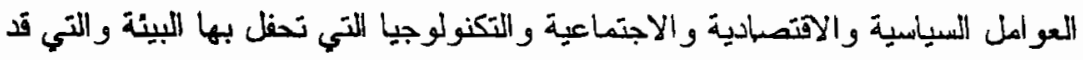

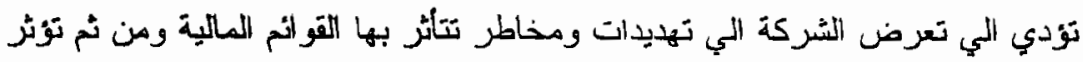

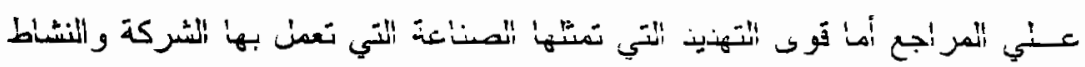

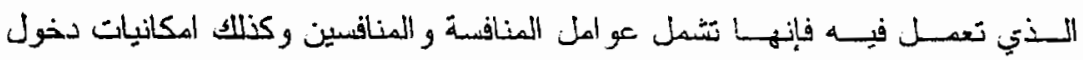

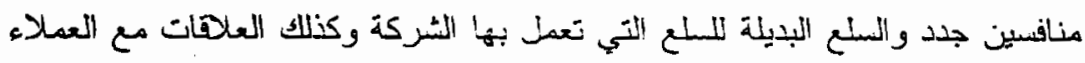

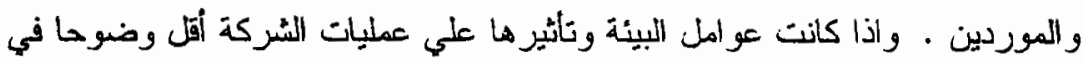

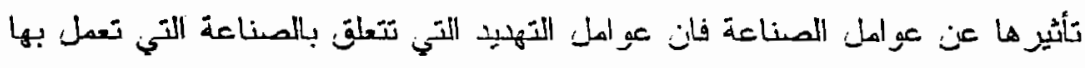

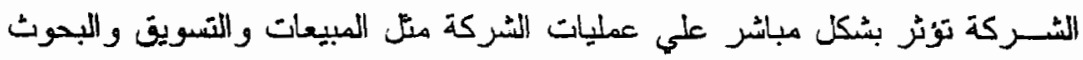

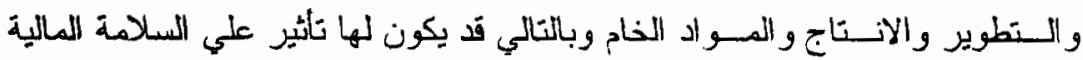

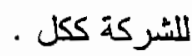

ومن جهة أخري فان أخطار التهديد الأخلي والتي بطلق عليها أيضا اخطار العمليات Process Risks

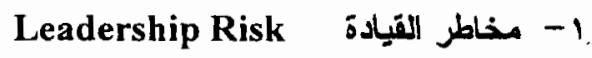

وهـي المخاطسر الناشــئة عـن علم جودة الادارة لوجود خلل في ممارسة الادارة

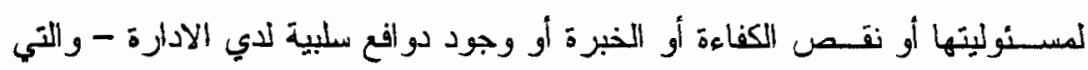

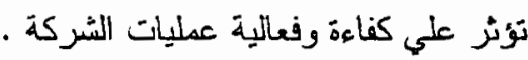

Integrity Risk r- بخاطر النزاهة و الشقاقية وهـي مخاطــر وجود سلوك غير اخلاقي يتعلق بنز اهة وشفافية الادارة او العاملين

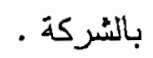

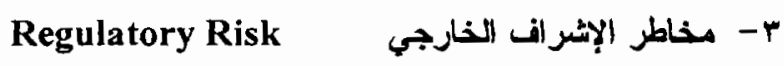

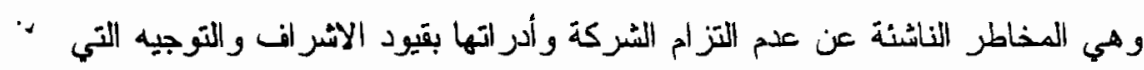

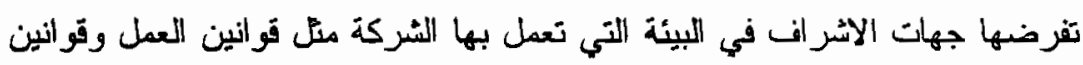

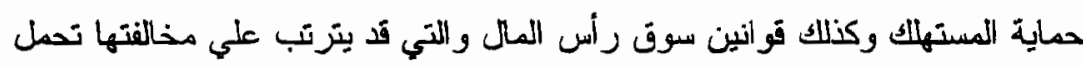

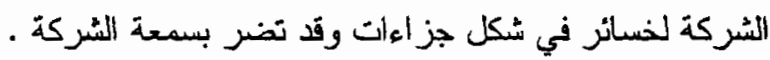


هـي المخاطــر الناشتئة عن ظهور وطرح أساليب تكنولوجية حيثة تؤدي الي تقادم

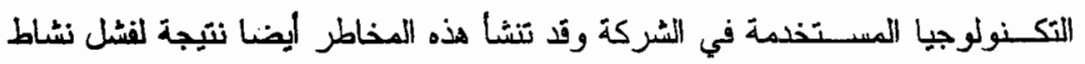

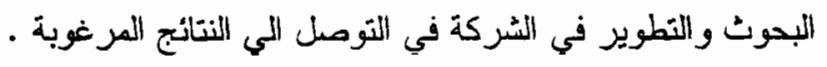

\section{Financial Planning} هـ - مخاطر التخطيط المالي

وهـي تعسبر عـن سوء عملية تخصيص موارد الثُركة لمقابلة احتياجاتها التشغيلية وتـنـكس تلاك المخاطر في شكل خطط وموازنات تخطيطية غير واقعية وغير نقيقة

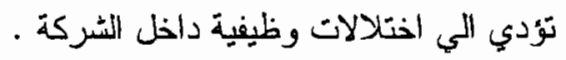

Human Resource Risk

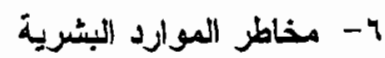
وهـي المخاطر الناشئة عن عدم توافر الكفاية والتأهيل والتسريب لدي الافراد والتي التي

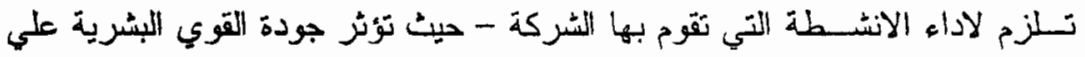
كفاية وفعالية عمليات التركة .

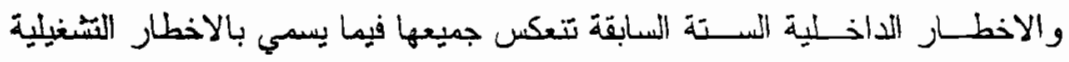

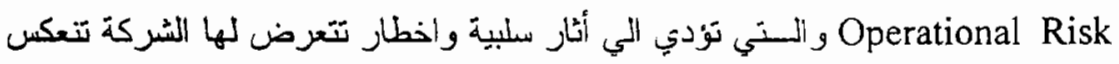

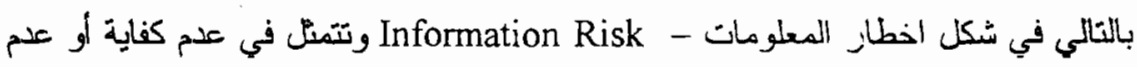

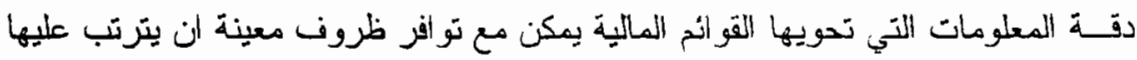

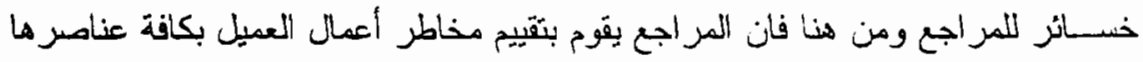

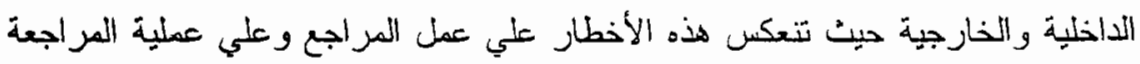

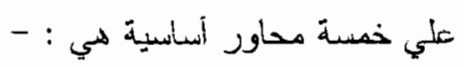

\section{Auditor Expectations

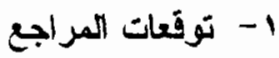

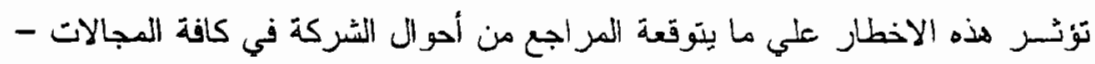

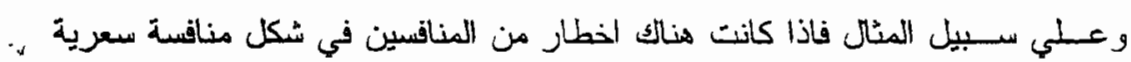

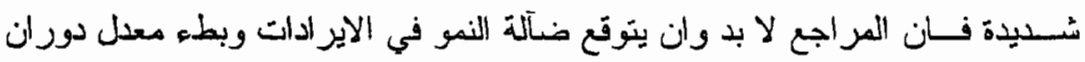

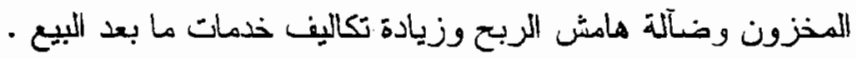




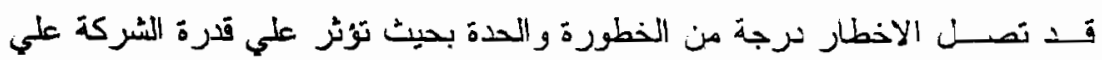

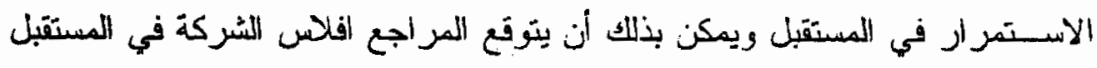
القريب و علي ذلك ان يتأكد من أن هناك إنصاح كان عن الاثار المبالية لهذه الاخطار

Audit Risk

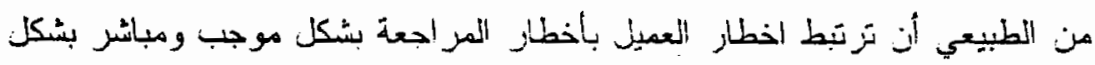

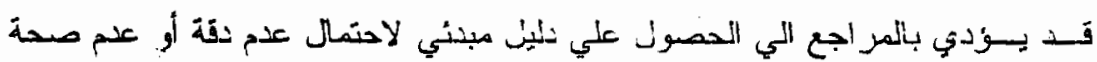

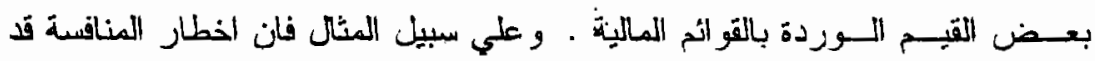

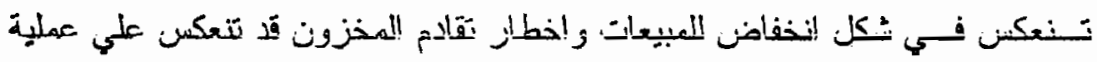

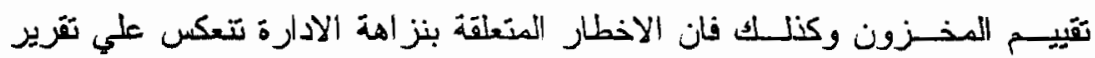

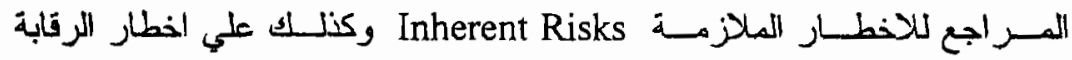
. Control Risks

\section{Control Environment}

\& - بيئة الرقابــة

وتــنعكس كـئير من مخاطر الاعمال السابقة علي بيئة الرقابة والتي قد تعجز معها

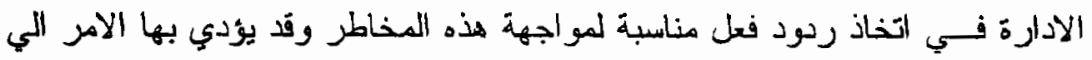

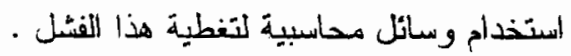

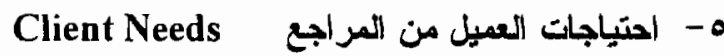

في حالة فشن الادارة و العميل في اتخاذ رد الفعل المناسب لمواجهة الاخطار الداخلية

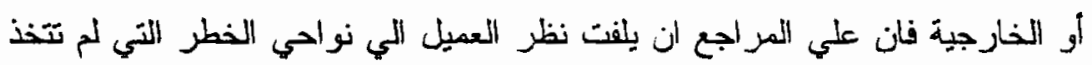

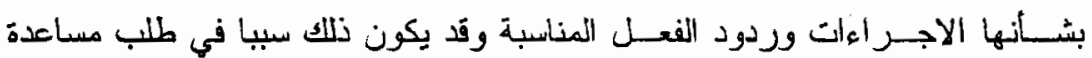

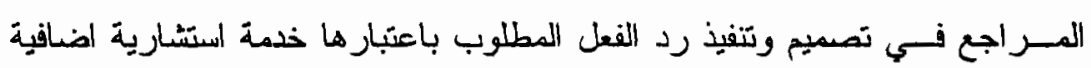

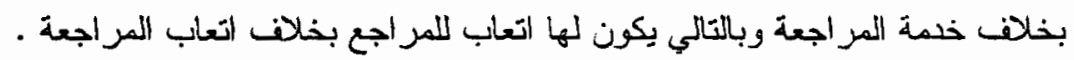

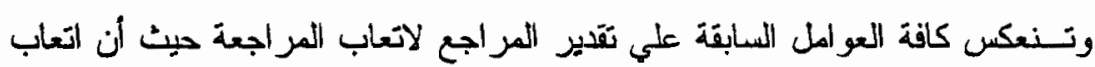

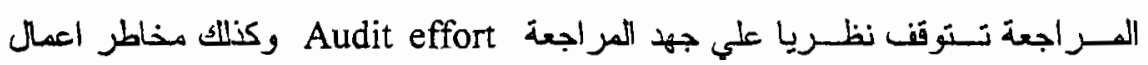
- المراجع Auditor Business Risk

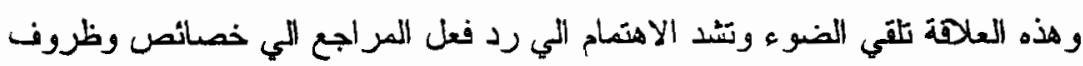

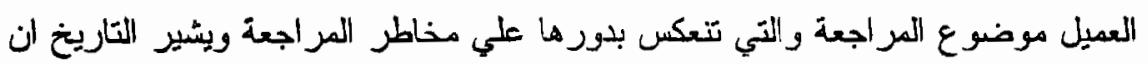

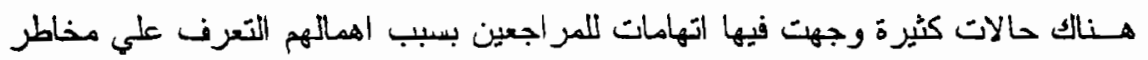


(GAO Feb.1989 , اعمـال المر إجعة من خلال التعرن علي مخاطر اعملل العملاء . GAO Jun.1989. Hill and Metzgen 1992)

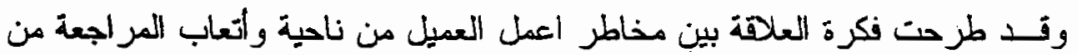

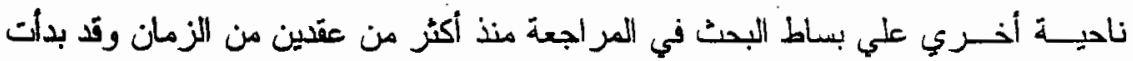

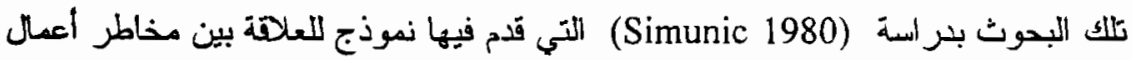

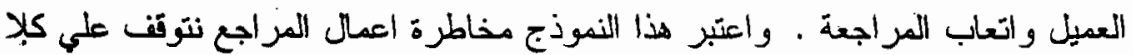

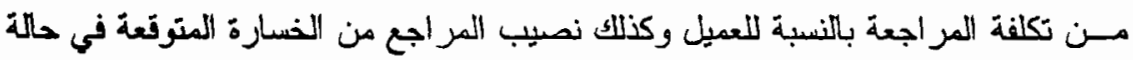

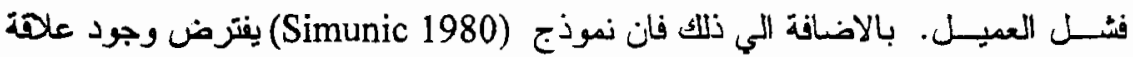

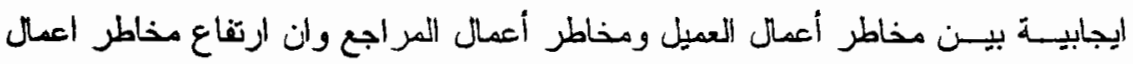

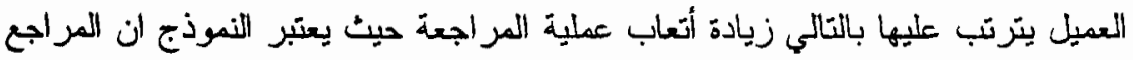

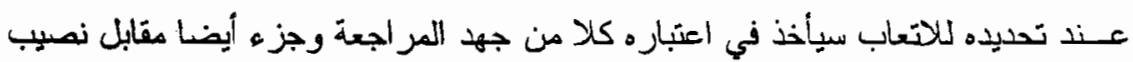

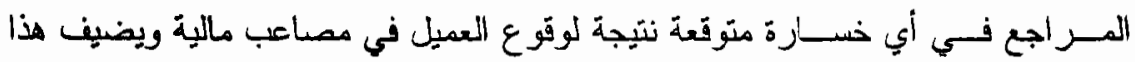

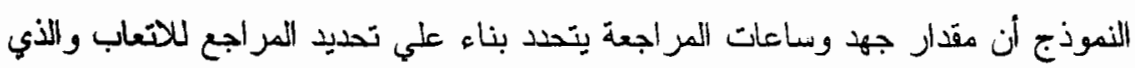

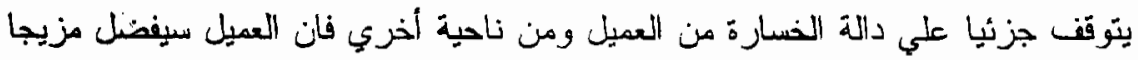

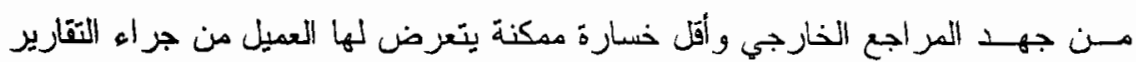
المالية .

وبيزى (H.J.W. et al (1994) انعكاسات هذا التصور لسلوك العميل والمراجع

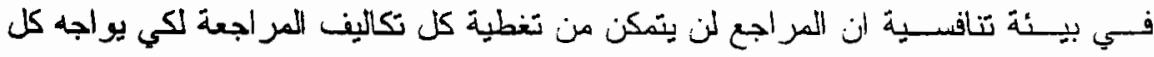

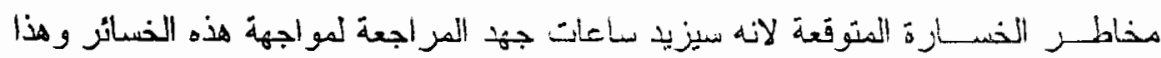

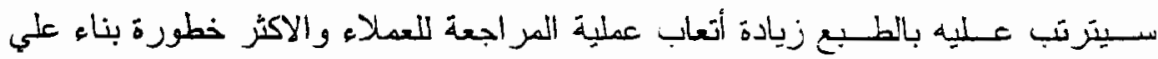

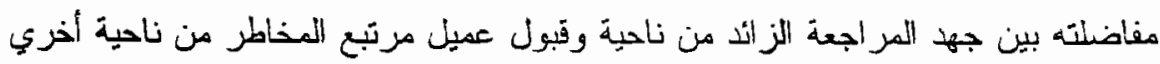

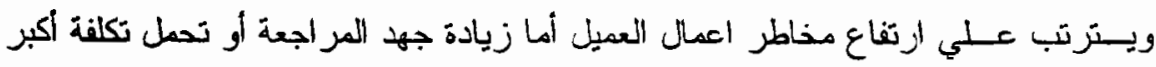

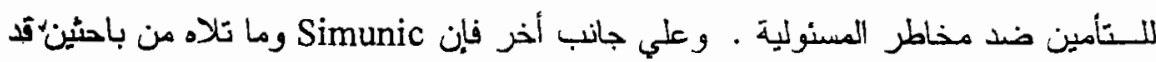

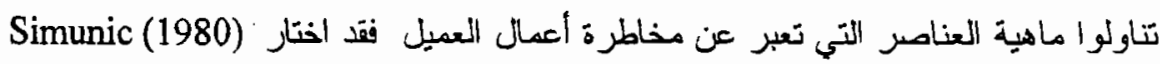

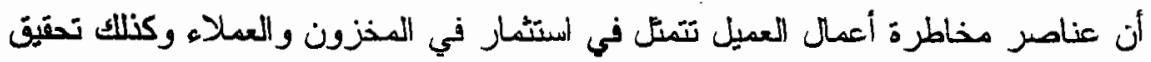

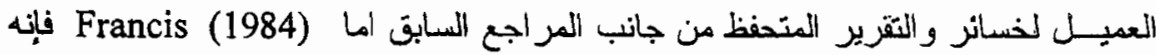

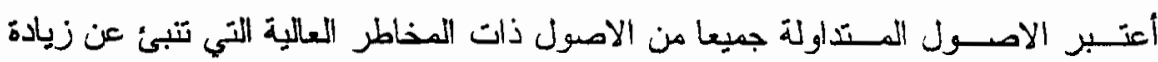

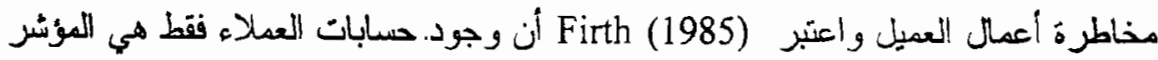
عـن وجـود مخاطر لدي العميل بيئما اعتبر Simon) حسابات المخزون و التقرير 
المتحفظ هما مؤشر أت مخاطز الحميل أما م Palmrose فقد الضافت عنصر الملكية

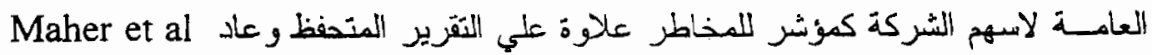

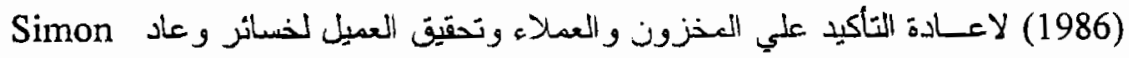
lind Francis (1988)

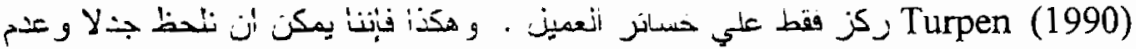

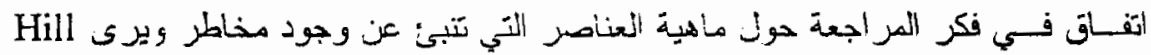

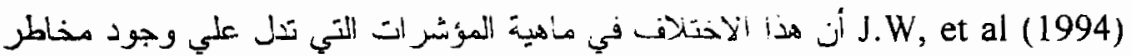

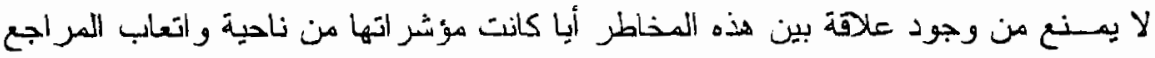

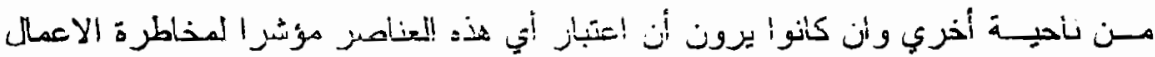

سون يختف من صناعة لاخري وفي نفس ما ردده وطالب به أيضا (1993) Beatty .

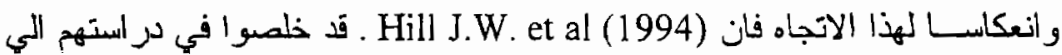

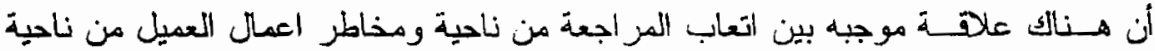

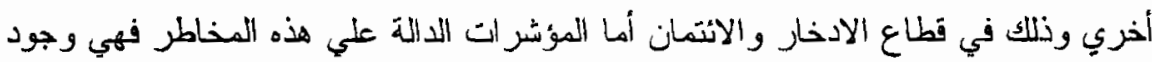

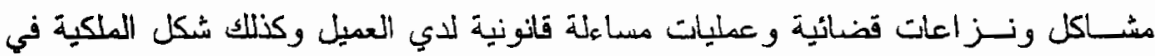

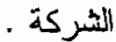

ويسرى الـباحث أن مخاطر أعمال العميل في البيئة المعاصرة تتألف من مجموعة

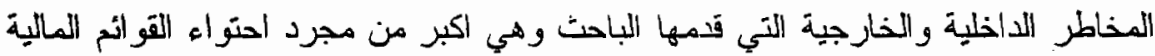
علي عنصر أو أكثر من عناصر الخطر ومع هذا المثمول في مفهوم مخاطرة أعمال العميل

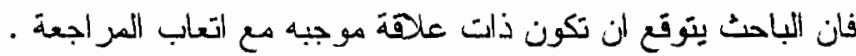

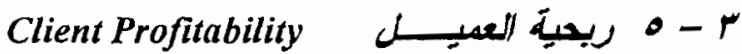

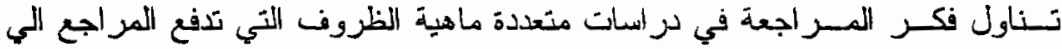

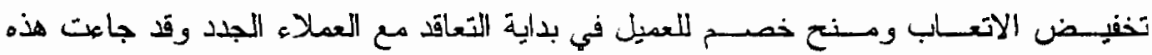

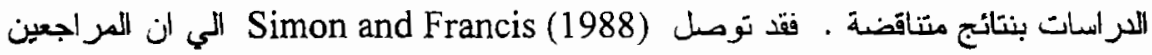

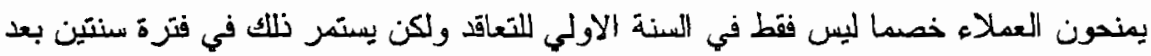

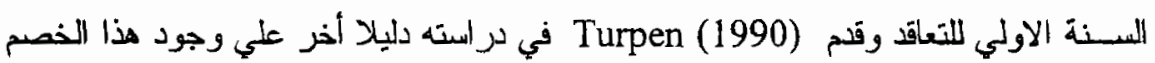

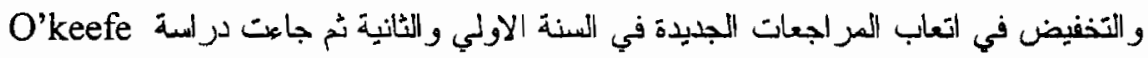

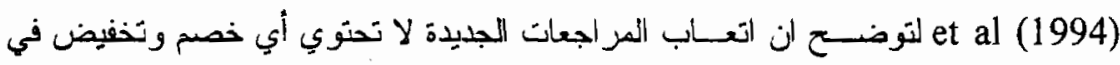

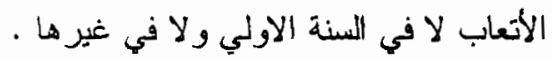




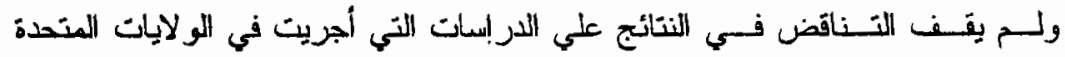
الأمسريكية فقد توفع (1995) Butter Worth and Houghton أن هناك اتجاها متز ايدا لهـذا الســلوك في استراليا ولكن در استهم لم تؤيد وجود مدل هذا السلوك بينما قدم كل من Collier 1996, Pong ad Whittington (1994) بـريطانيا ويستفق الـباحث مع (2000) Walker and Casterella في تفسير هم لماهية

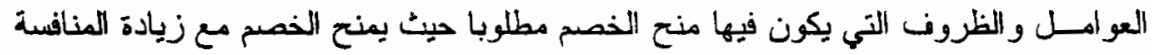

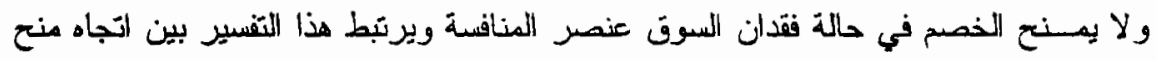

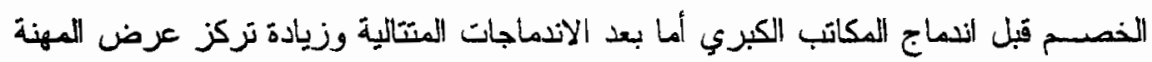

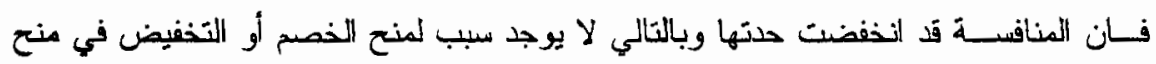
الاتعاب .

وانطلاقا من التفسير العبابق فقد اتجها فكر المراجعة نحو بحث أثر ربحية العميل علي

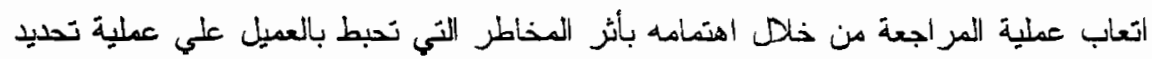

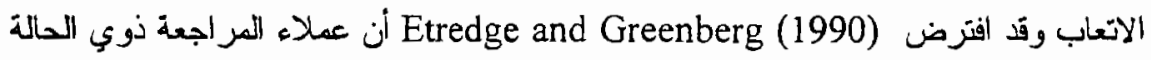

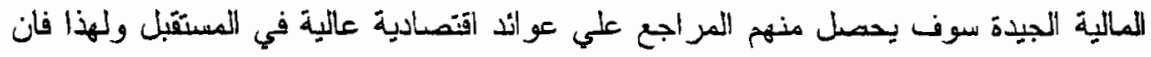

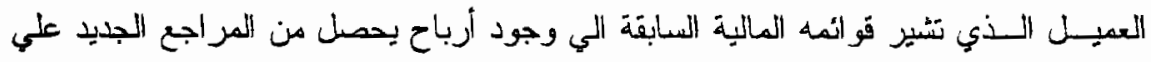

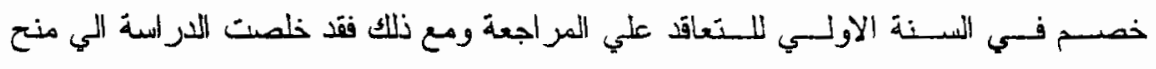

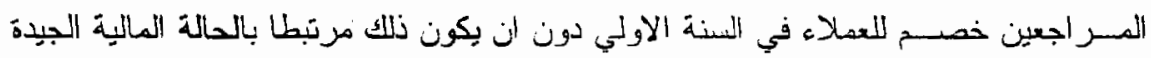

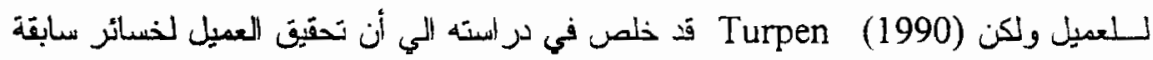

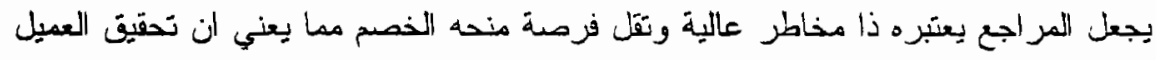

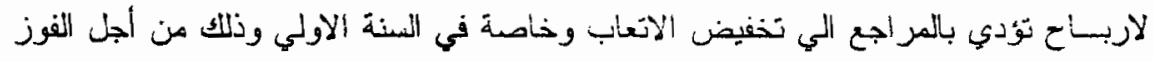

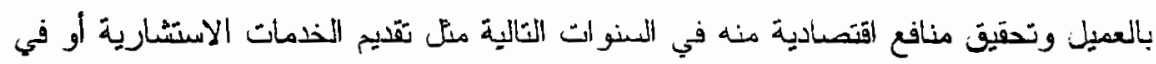

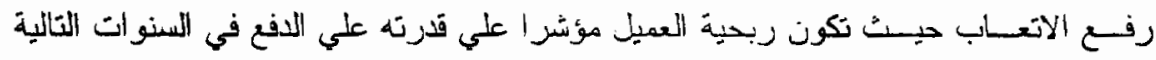

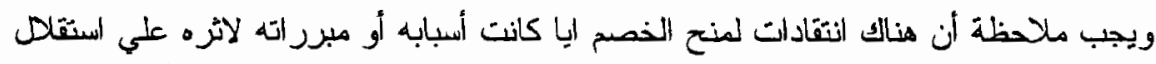

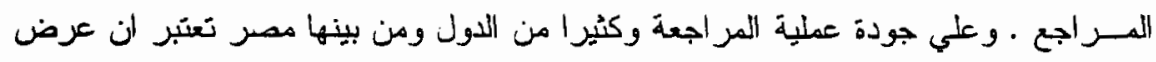

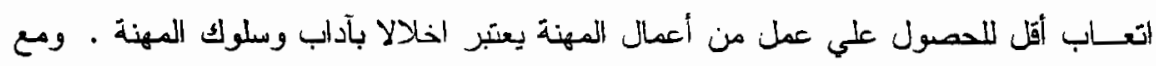

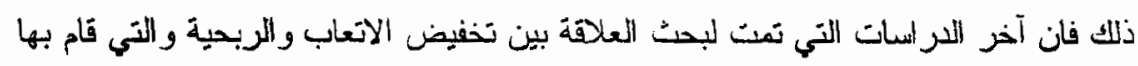
Walker and Casterella (2000)

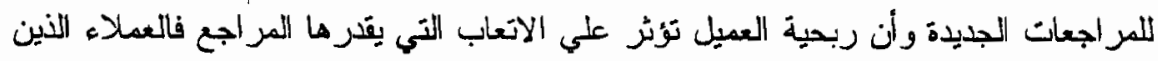

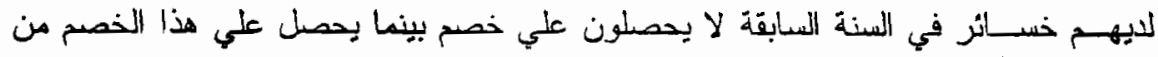

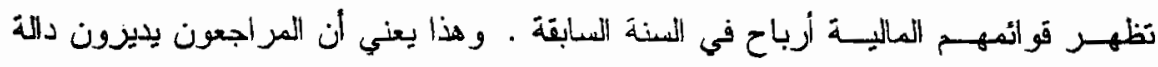




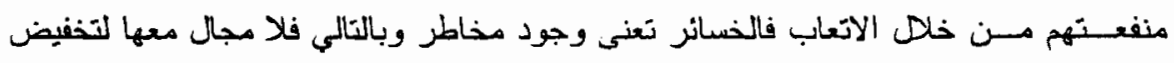

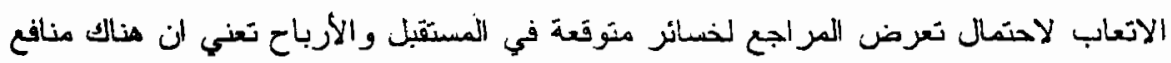

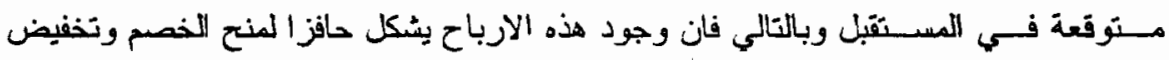

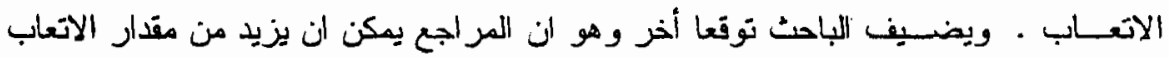

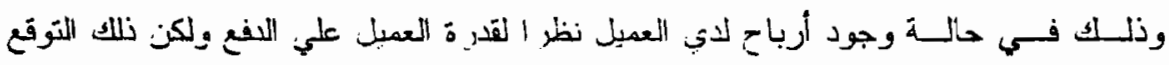

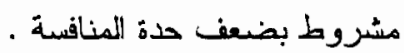

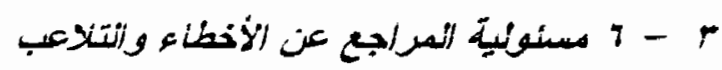

\section{Auditor's Responsibility For Errors and Fraud.}

مـن المعزون ان ظهور أي قواعد جديذة لاعداد التقارير المالية أو معايير للمرجعة

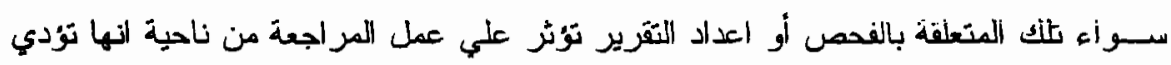

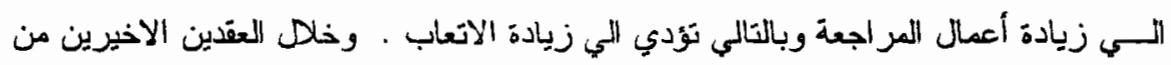

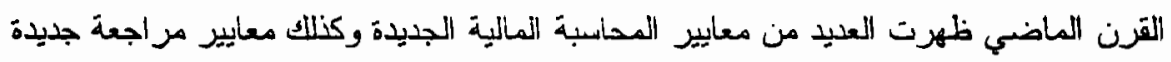

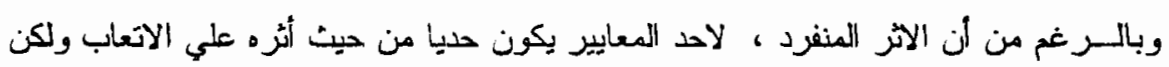

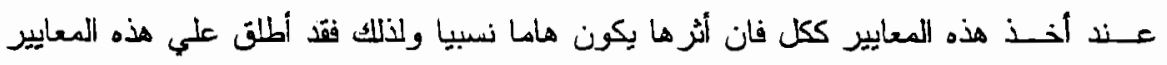

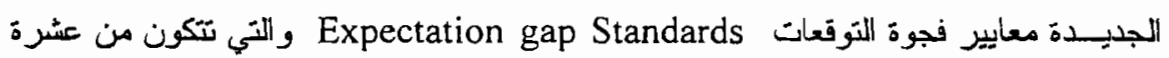
معايير مراجعة جديدة أصدر ها مجلس معايير المراجعة بمعهد المحاسبين الامريكي في أبريل

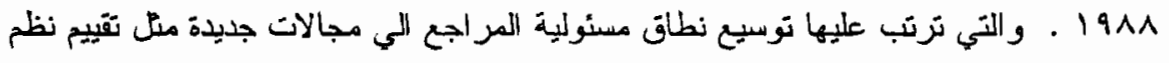

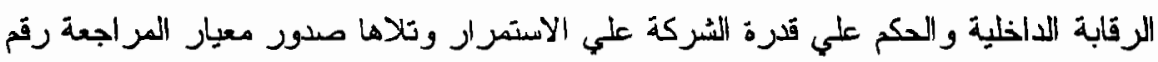

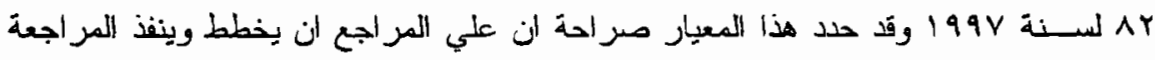

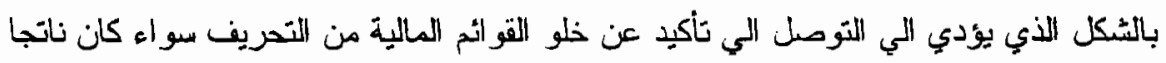

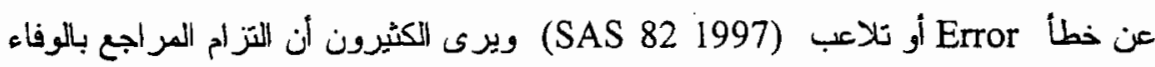

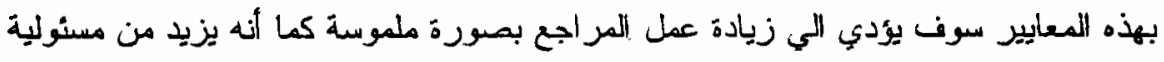

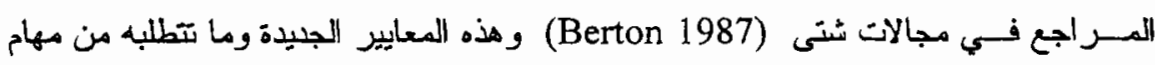

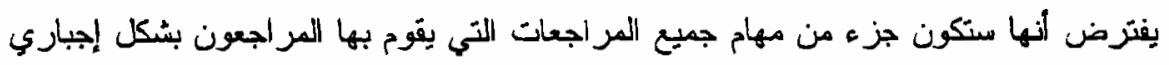

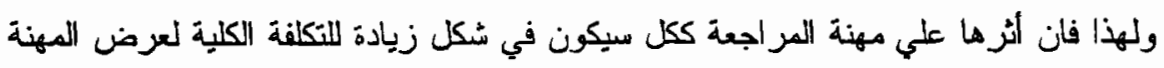

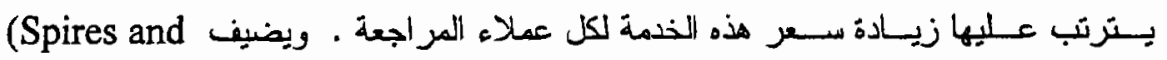

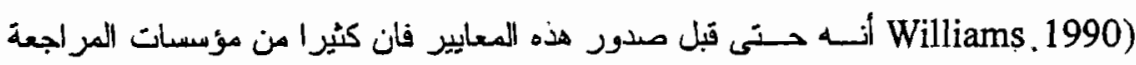

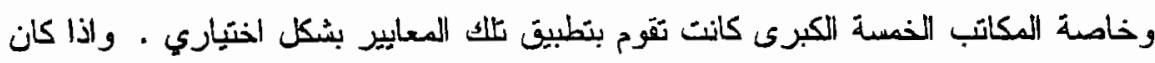

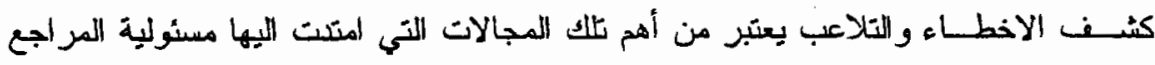

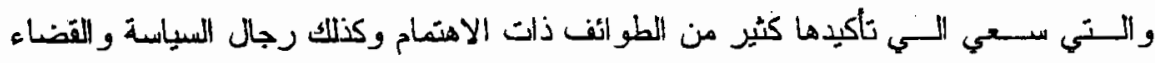




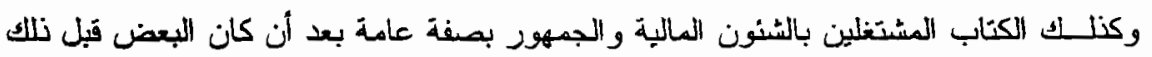

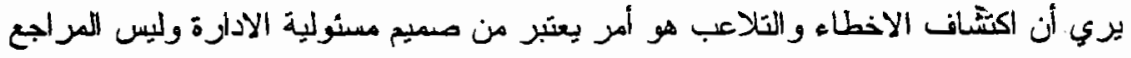

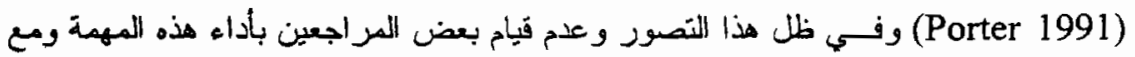

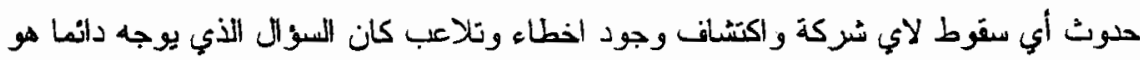

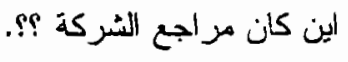

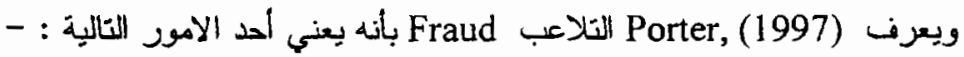

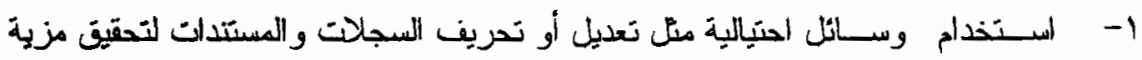
مالية غير مشزروعة . ب- الدذف أو القيد أو التعبير أو الإفصاح الخاطئ والمتعدد للسجلات المحاسبية أو القوائم المالية . r- التطــبيق الخاطئ و المتعدد لمعايير المحاسبة بخصوص تقييم أو تبويب عناصر القواثم المالية . ع- سرقة الأصول أو عدم نوفير الحماية المناسبة لها .

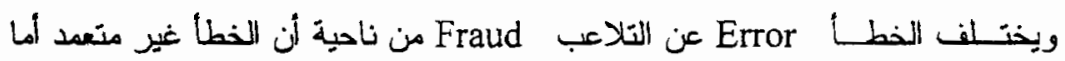

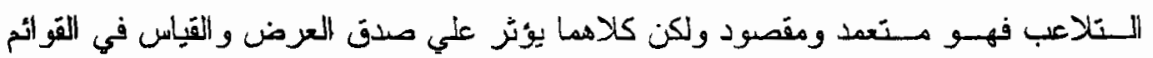
المالية .

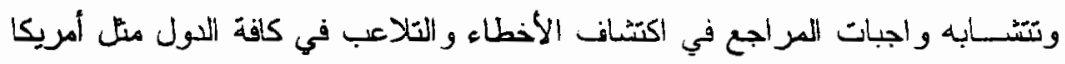

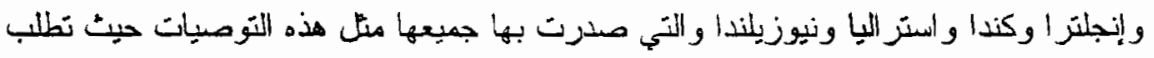

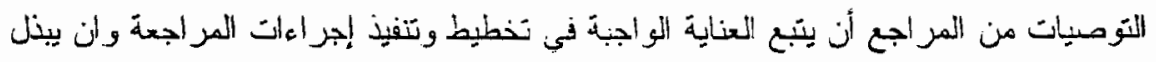

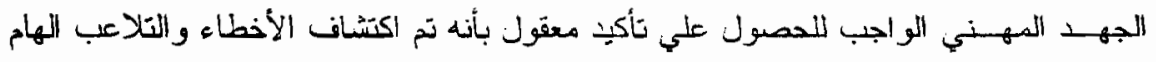

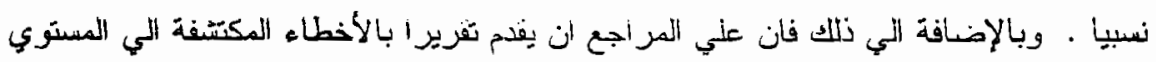

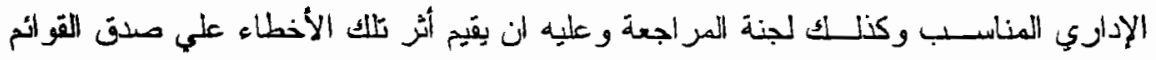

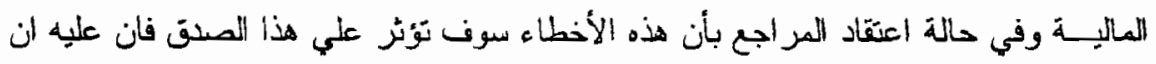

$$
\text { يضع التحفظ المناسب في تقريزه . }
$$

ويسرى الباحث ان تحميل المراجع بهذه المسئولية عن اكتشاف والتقرير عن الأخطاء

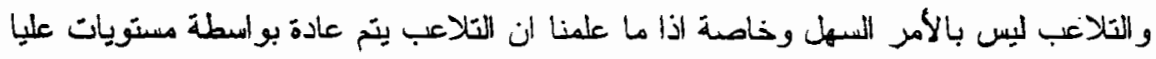

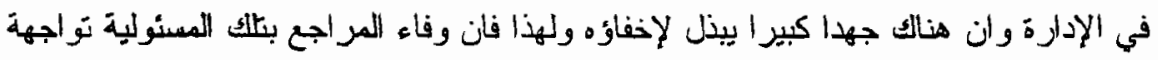
ثلاثة تحنيات:1- كيـف يمكـن تحسـين مقدرة المراجعين علي كافة المستويات علي اكتشاف الأخطلاء و التلاعب . 


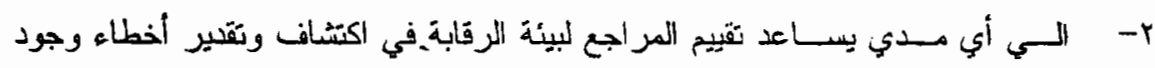

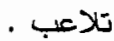

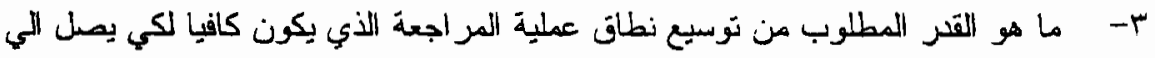

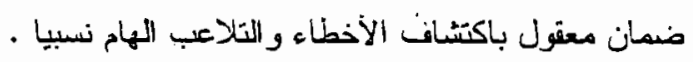

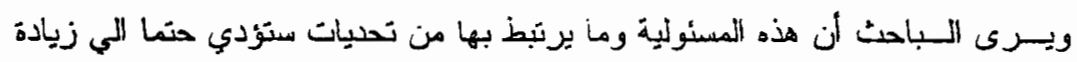

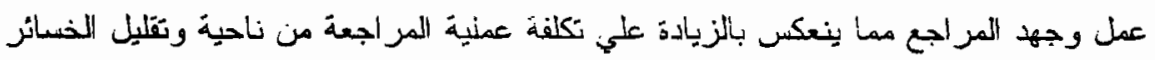

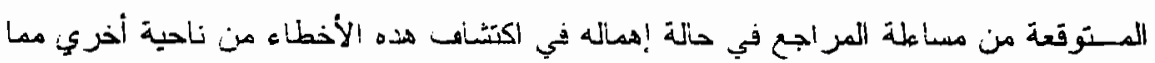

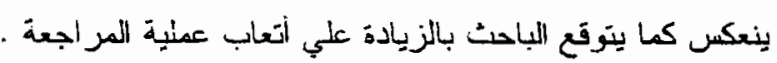
V-r

عرفت النوصية رقم VI V من نوصيات المراجعة مخاطرة أعمال المراجعين بأنها

The risk of loss to an auditor's practice from litgation, adverse publicity or other event arising in connection with financial statements or reported on (AICPA, ASB. SAS 47. 19)

وتــكون مخاطرة أعمال المراجع من مجموعة من التكاليف القانونية بعضها تكاليف

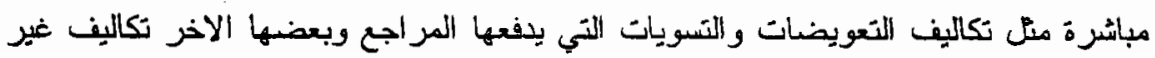

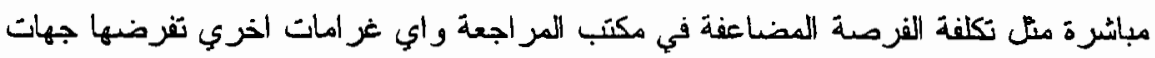

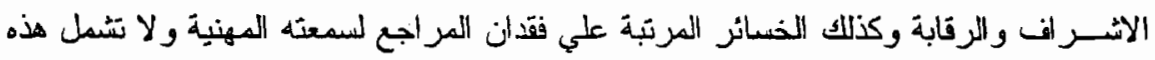

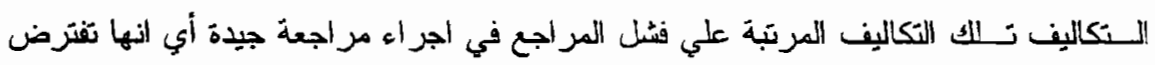

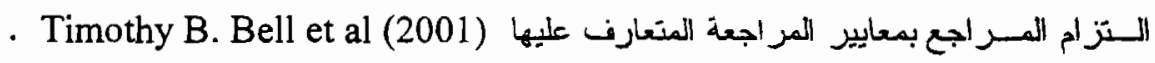

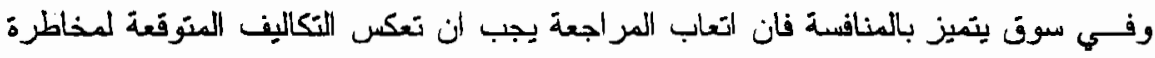

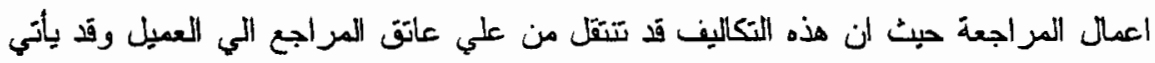

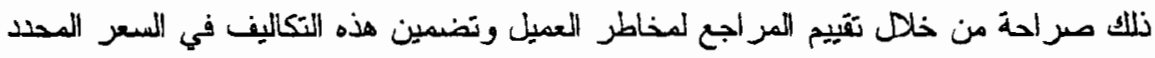

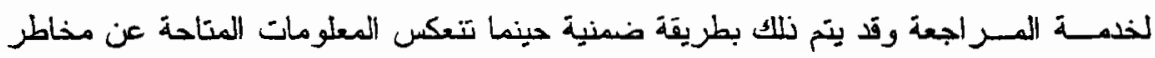

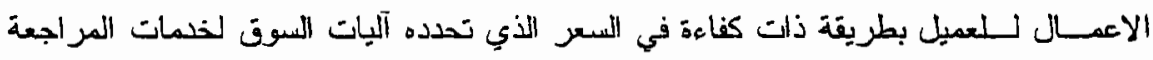

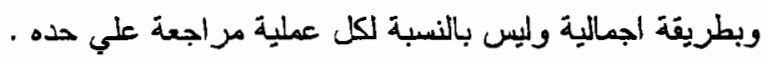

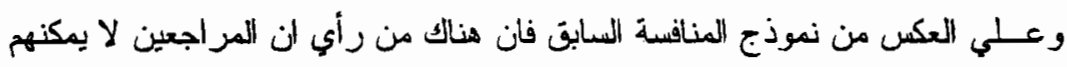

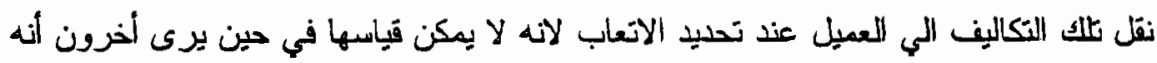

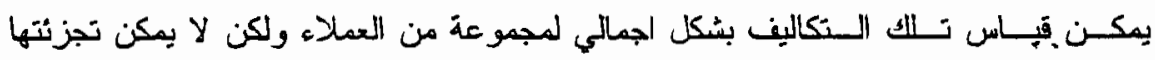

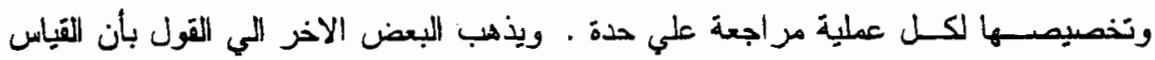
مكـن و التجزئة ممكنة و التخصيص ممكن ولكن ظروف السوق و المنافسة لن تسمح بتضخيم 


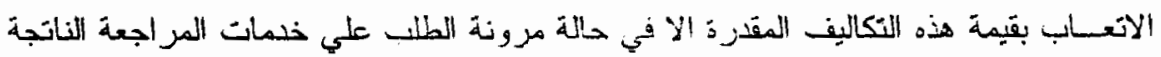

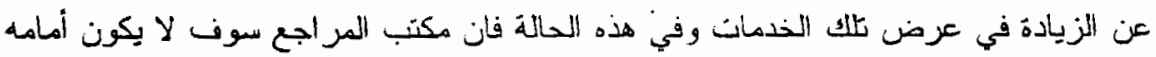

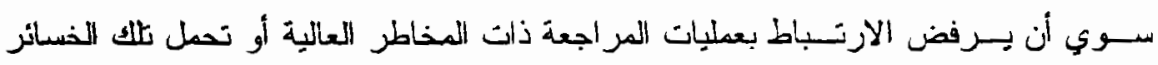

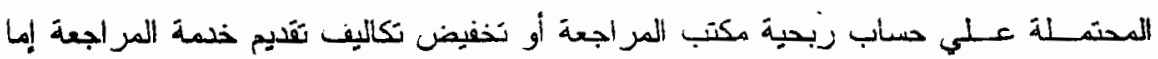

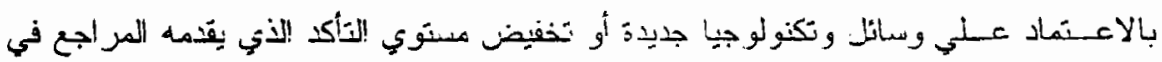

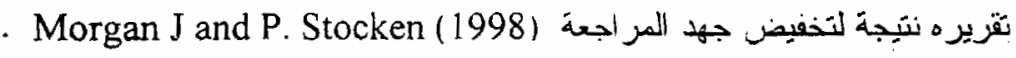

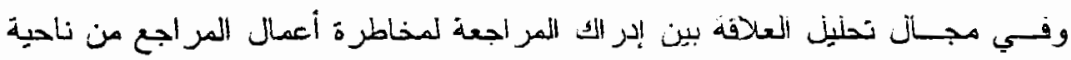

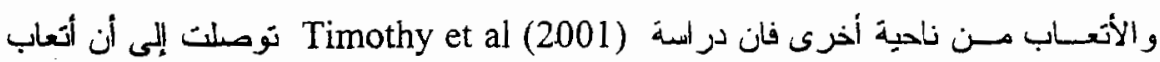

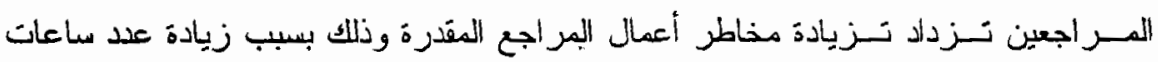

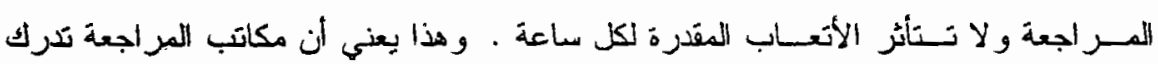

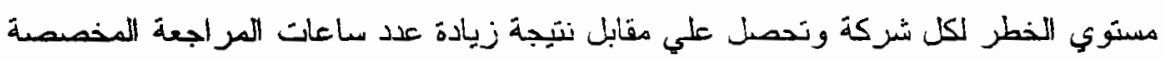

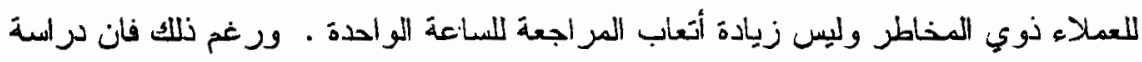
Gramling et al (1998)

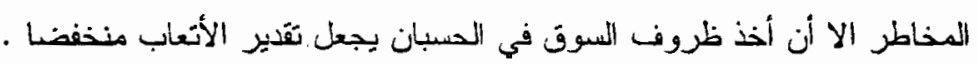

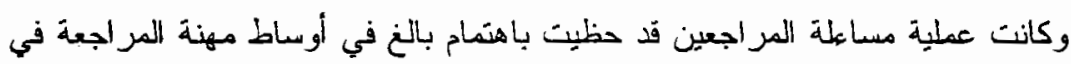

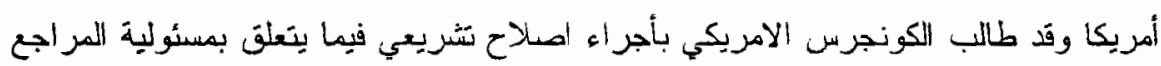

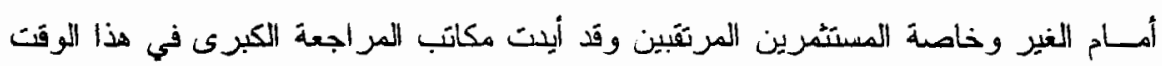

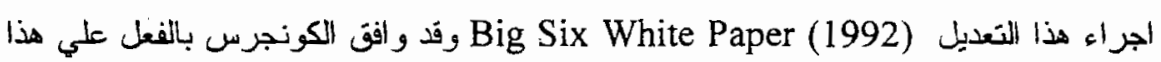

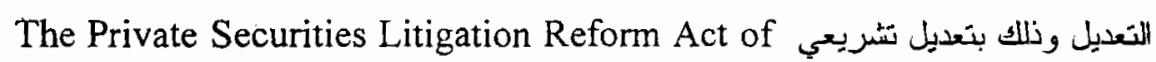
1995.

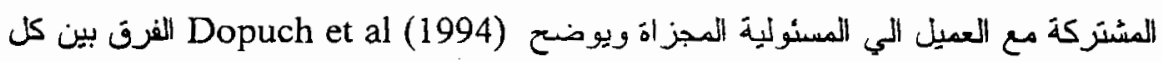
النوعين من المسئولية في موقفين محتملين هما : - -

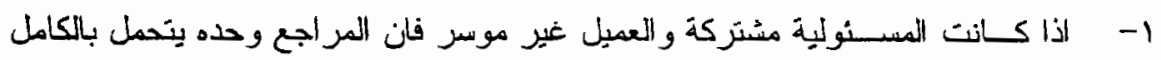

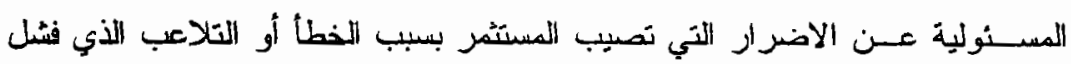

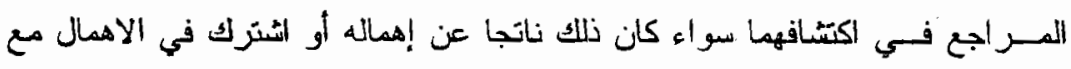

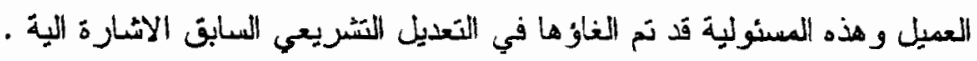

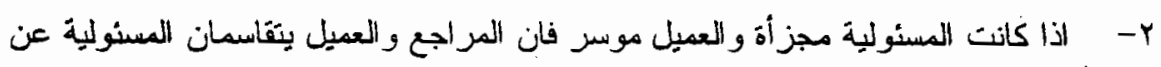

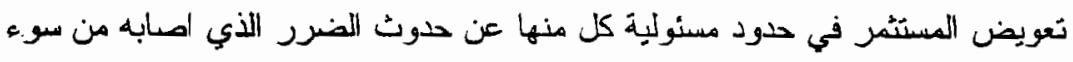

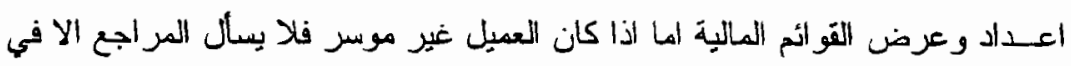

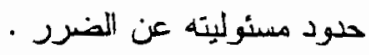


وقَند أدي هــذا التحول في مساعلة المراجع المي تغير في سلوك المر اجعين حيث كان

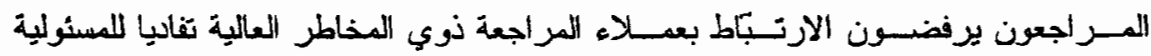

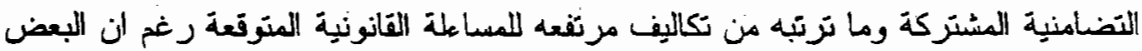

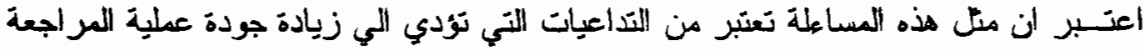

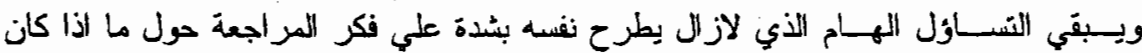

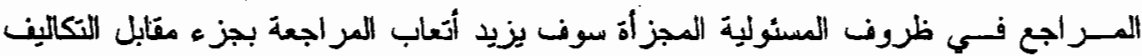
المتوقعة للمساعلة القانونية أم ان صعوبات القياس أو ظروف المناقسة سون تحول بينه وبين

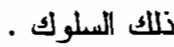

وفــي الواقــع المهـني أيضا فقد كثرت الكتابات والشكاوي عن زيادة معل مساعلة المر اجعين بسبب فتل الشركات بعد المراجعة . وقد حذرت إحدى شركات المحاسبة الكبرى

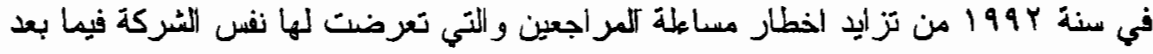

بقولها :

The Flows in the liability system are taking a severe tall on the accounting profession. If these flows are not corrected and the tort system continues on its present inequitable course, the consequences could prove fatal to accounting firms of all sizes. (Arthur Andersen \& Co. et al 1992)

ولكــن المــر اجعة كــانت ولاز الت وستظل مهنة اقتصادية تخضع لما تخضع له له

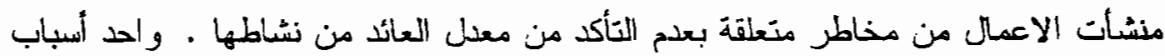

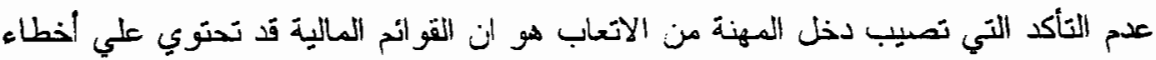
هامة نسبيا لم يتم اكتشافها وتكتشف بعد تقرير المراجعة وهذا الاكتثاف البعدي لعposit

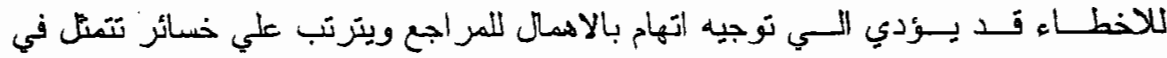

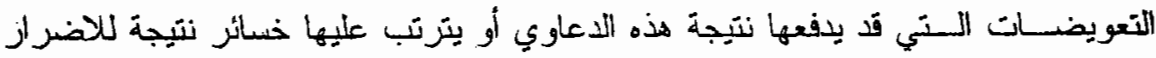

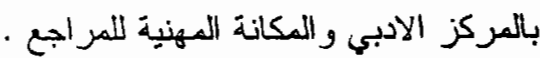

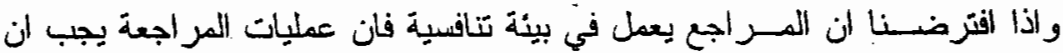

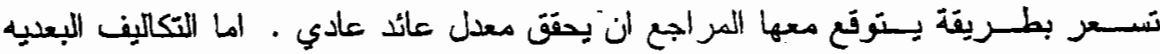

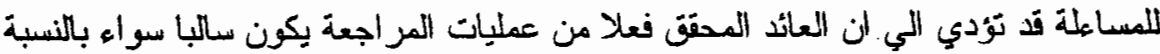
لعمـلية يعينها وربما بالنسبة لمحفظة عمليات مكتب المر اجعة ككل لان اتعاب المر اجعة لا

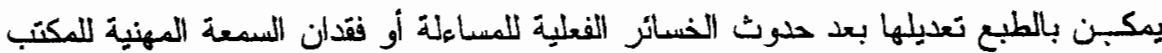

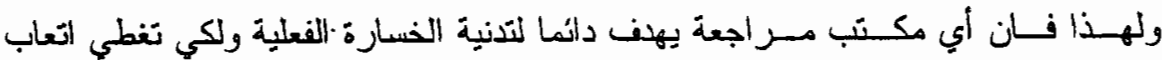
المـر اجعة كل خسائر التعرض المساعلة القانونية وعندما يفشل بكتب المراجعة في تحقيق 
هذا الهذف فانه قد يتعرض للإفلاس في حالة ما اذا كان عدد عملاء المكتب صغير ا بالنسبة

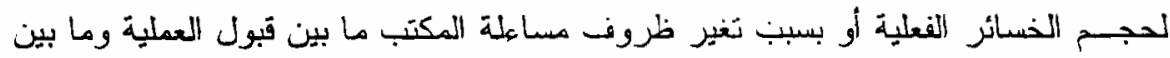

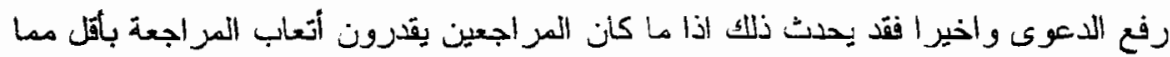

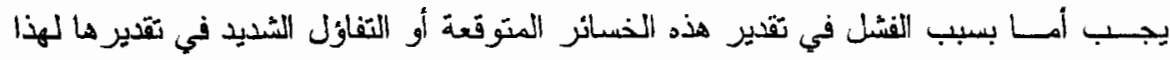

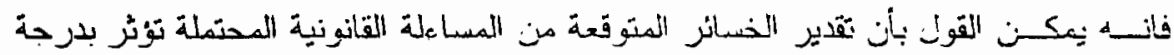

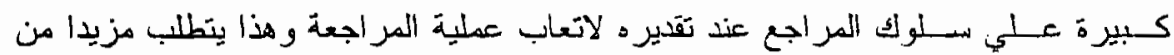
التحليل لاقتصاديات تسعير وتحديد تكلفة مخاطر لمساءله القانو نية للمر اجعة . وقد قام البحث في اقتصاديات تسعير تكاليف المساعلة القانونية علي اسساس ان سوق

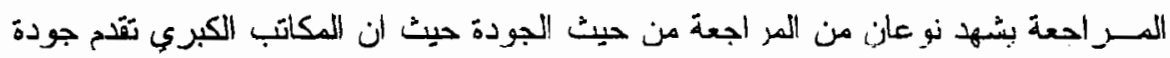
عاليــة بعكـس المكـاتب الاخري وتشير البحوث الميدانية ان خدمة المر اجعة التي تقدمها

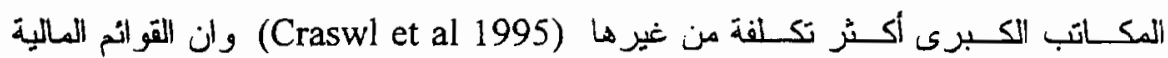

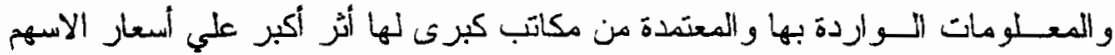
Seoch and Wong (1993) غير ها و هذا كله يؤكد ان المكاتب الكبرى تقدم لعملانها جودة أفضل مع مستوي عال للتاكد. ويترتب علي هذا الغرض ان كل هن الطلب علي المر اجعة ذات الجودة العالية التي تقدمها

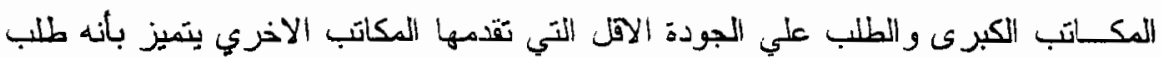

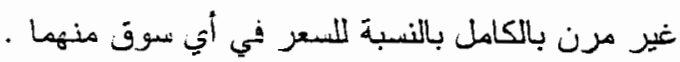

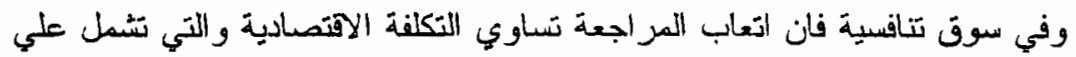

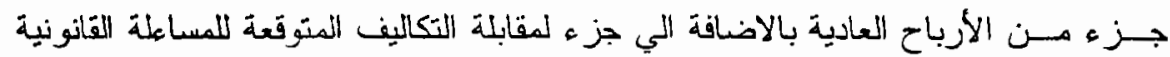
وبصورة اخري فان دالة تكلفة المراجعة نتكون بصورة رئيسية من عنصرين أولهما تكلفة

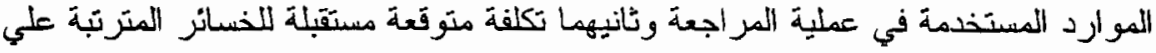

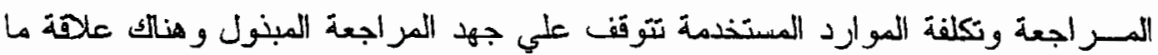
بيــن جهد المر اجع في عملية المر اجعة من ناحية وتكلفة الخسارة المتوقعة من ناحية أخري

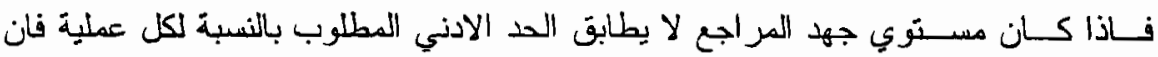

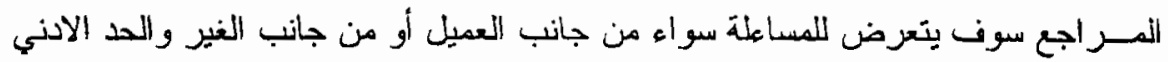
مـن الجهد المطلوب لكل عملية هو ما تحدده معايير المر اجعة المتعارن عليها ولهذا فانه

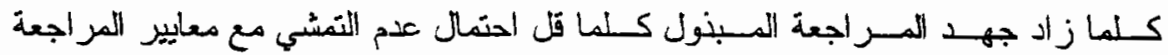
المنعارن عليها ويقل بالتالي احتمال التعرض للخسائر و هذه العلاهة تأخذ هذا الثنكل لسببين

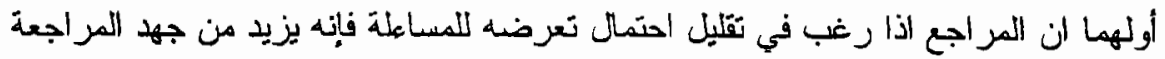


لاكتشـاف كل الاخطاء الهامة نسييا في القوائم المالية وبانيهما أنه يزيد من جهد المراجعة

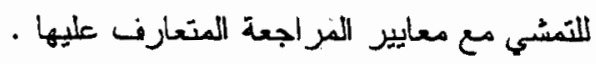

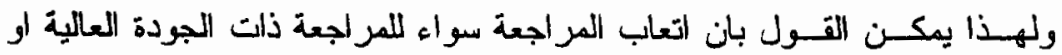

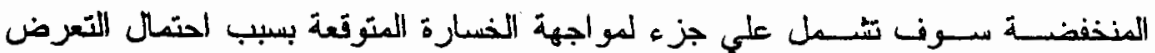

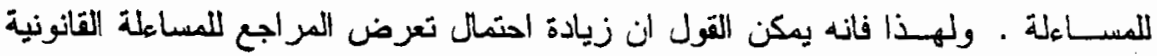

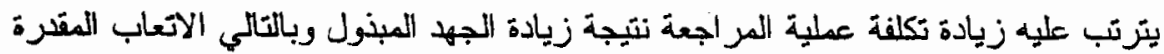

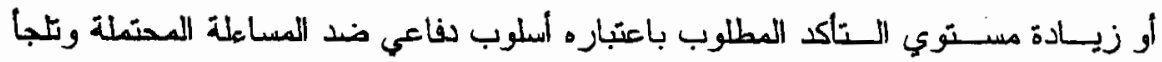

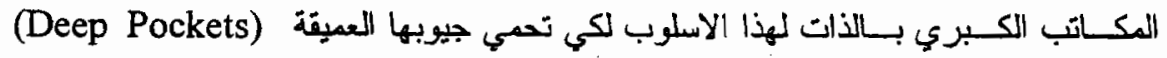

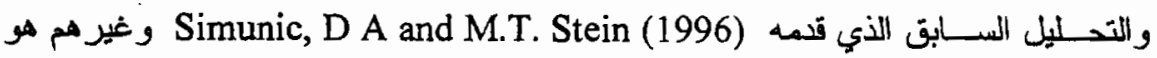
مجرد تحليل نظري معياري لهذه العلافات - - حيث كانت بلك العلاقات محل الهنام العديد

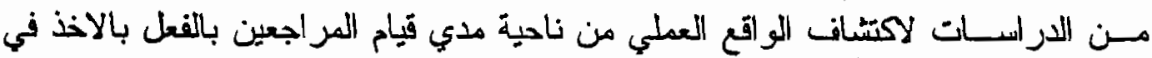

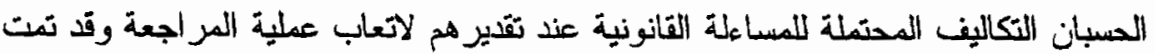

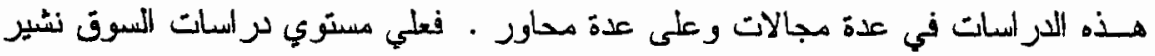

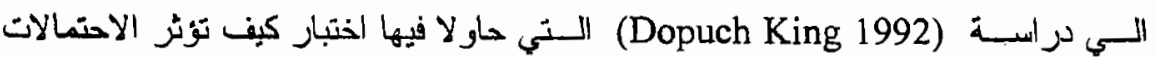

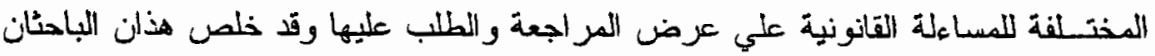

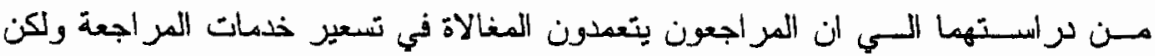

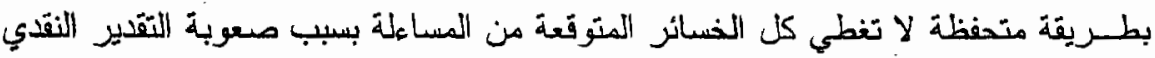

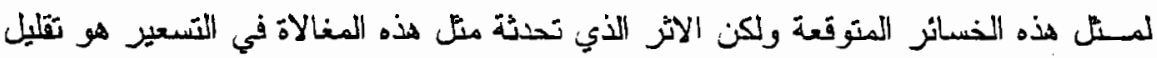

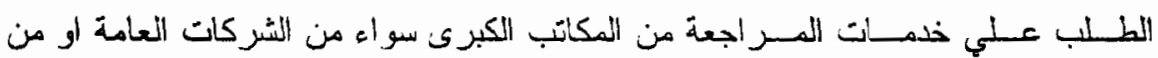

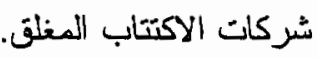

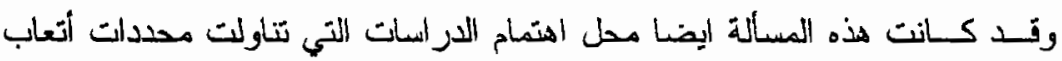
المـر اجعة فان Simunic وجد ان هناك زيادة في اتعاب المر اجعة نتيجة اخطار

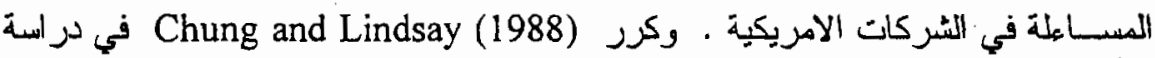

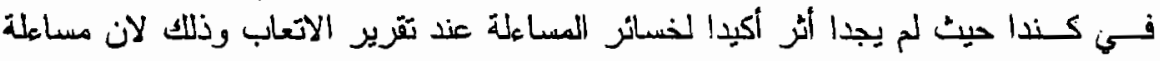

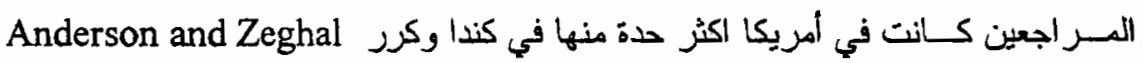

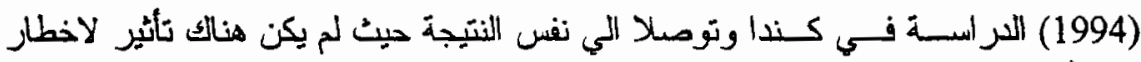

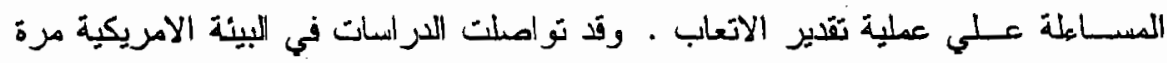

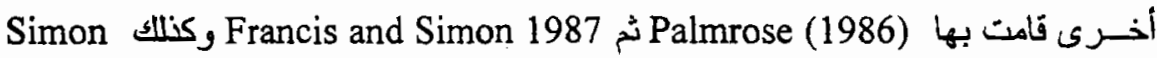
and Francis (1988) 
احستمالات نعرض المر اجع المساعلة ولكن أخر الدراسات التي قام بها (1993) Betty

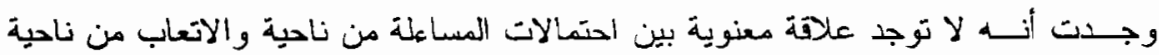

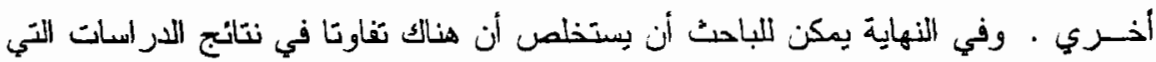

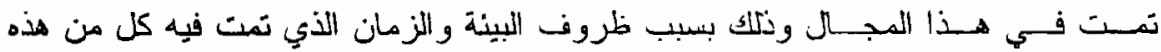

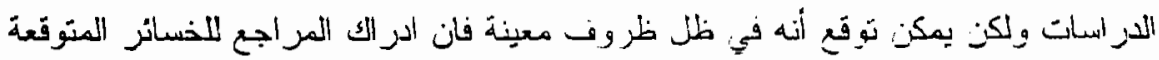

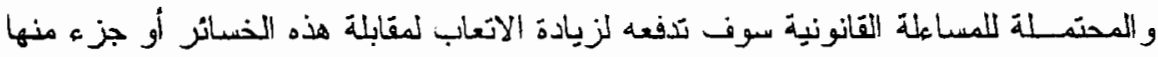

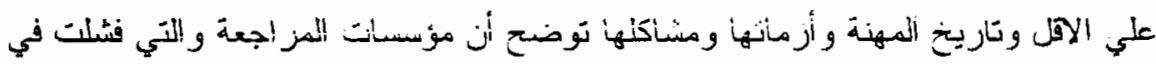

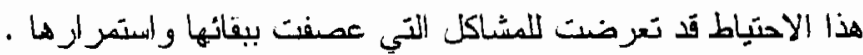

\section{Auditor Switch}

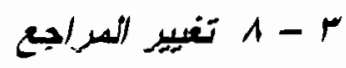

ويعتـبر تغييـر مراجع الحسابات من الموضوعات التي نالت اهتماما من حيث أثرها

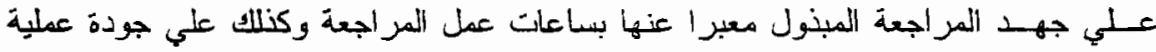

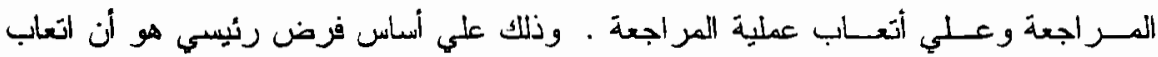

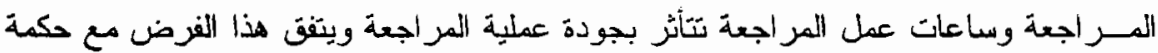

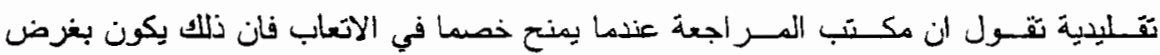

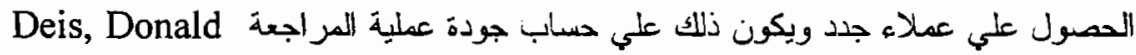
وقد سبق ان حذرت لجنة من معهد المحاسبين الامريكيين R. Jr and Giroux. C. (2000)

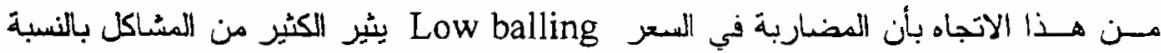

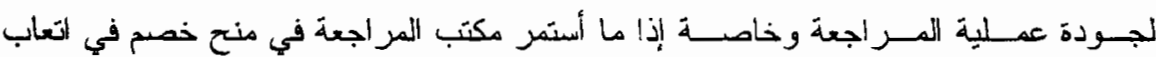
المراجعة في السنوات التالية للسنة الاولي (AICPA 1978. 1112 ) .

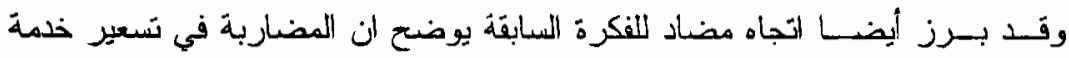

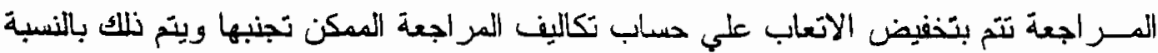

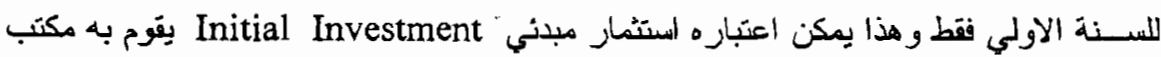

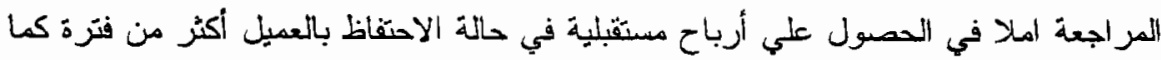
ان تكـاليف المــراجعة تتخفض في السنوات التالية للسنة الاولي نتيجة لسريان منحنى التعلم

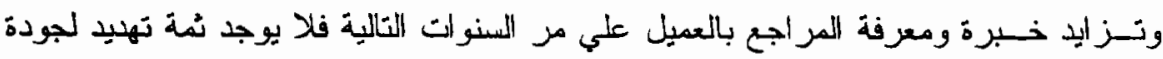

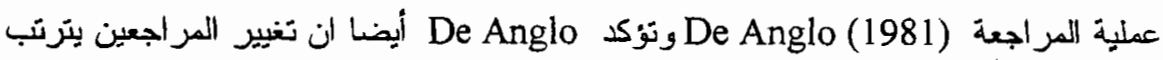

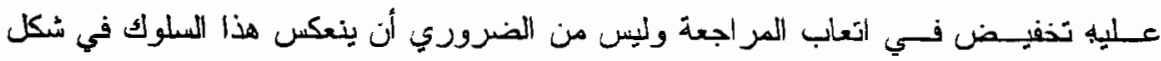

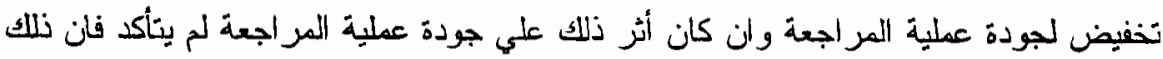

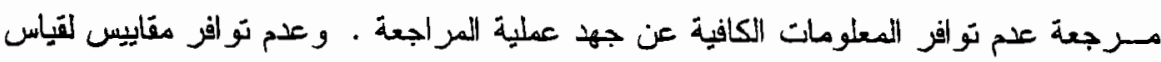


جودة عطلية المراجعة (2000) Deis D.R. Jr nd Giroux ولم يقف تتاقص النتاثج عند هذا

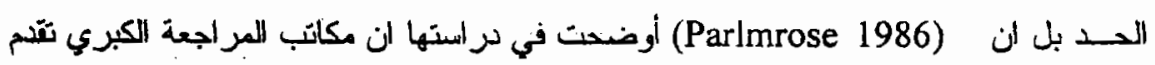

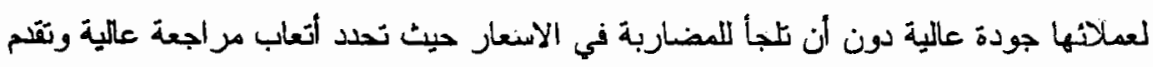

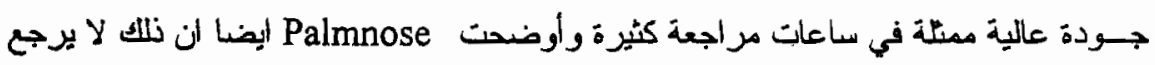

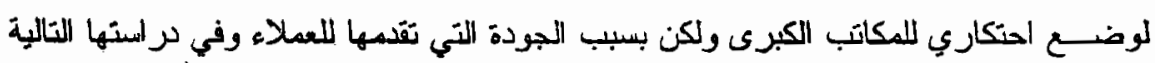

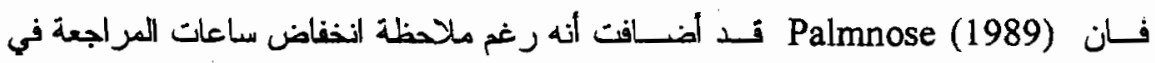

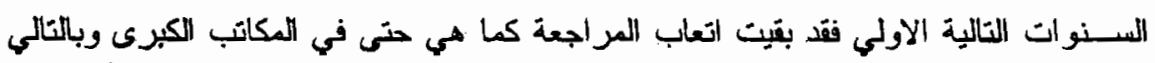

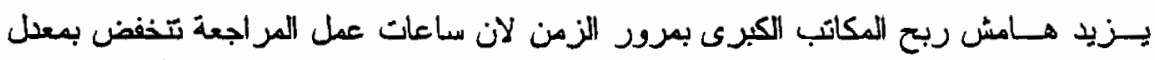

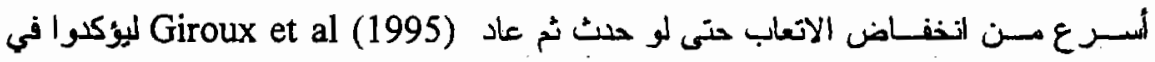

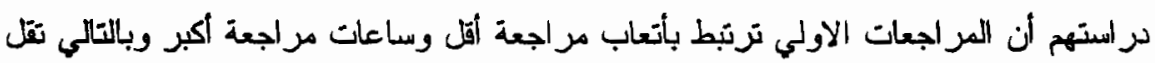

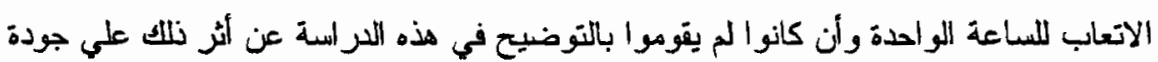

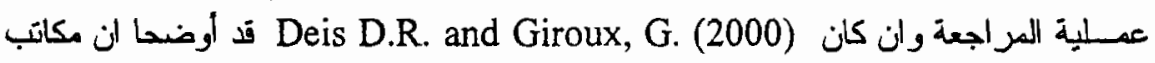

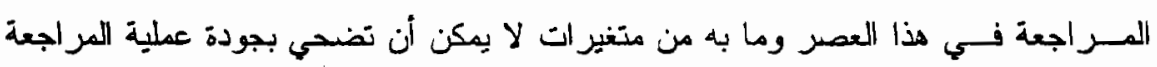

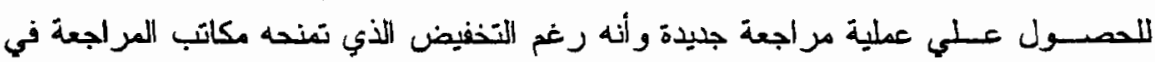

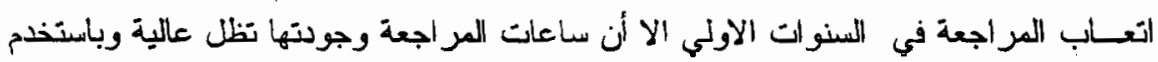

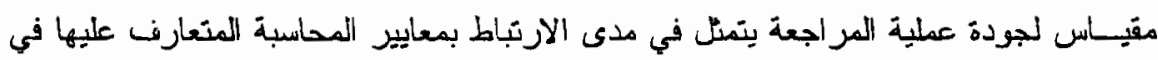

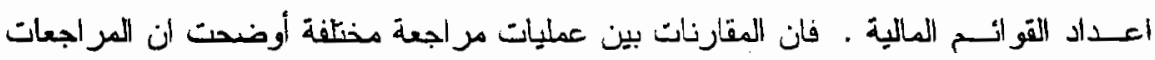

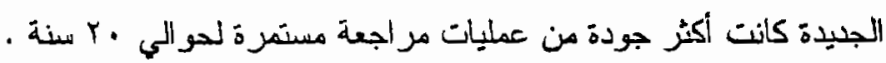

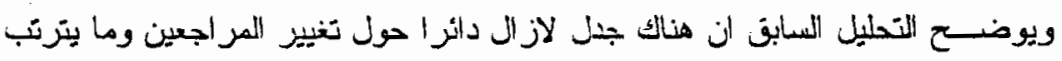

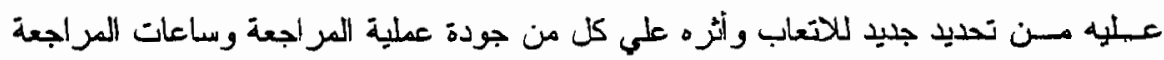

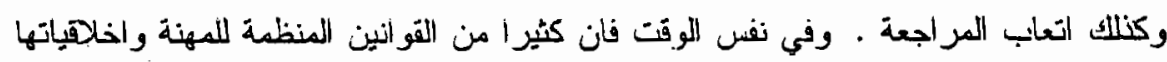

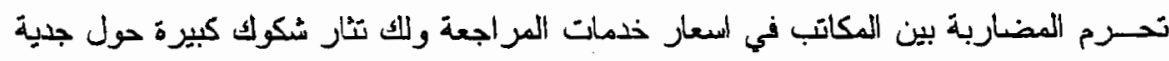

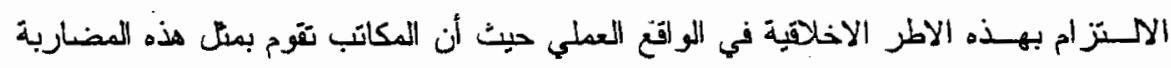

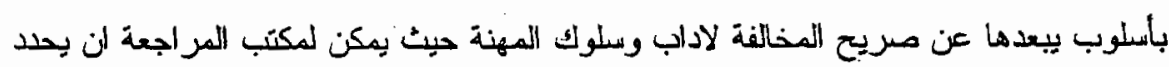
أسعارا للمراجعة الجليدة تقل عن الواجب املا فتط في الحصول علي العميل وعم نقدانه .

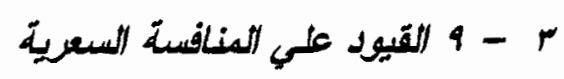

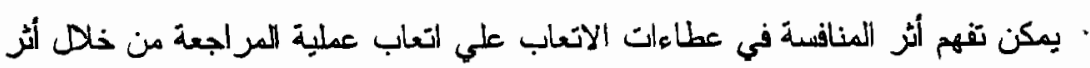

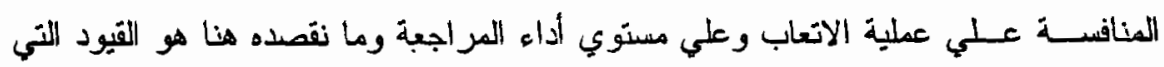

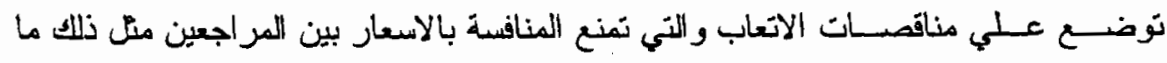




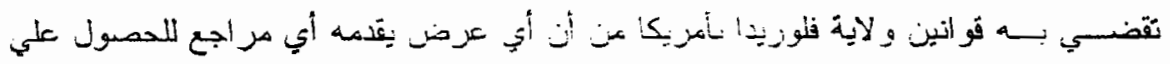

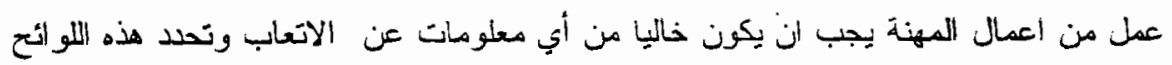

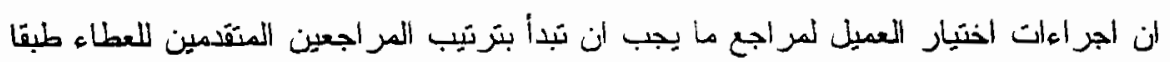

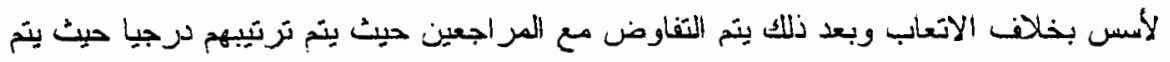

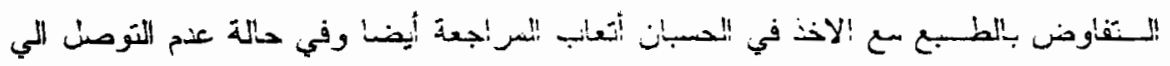

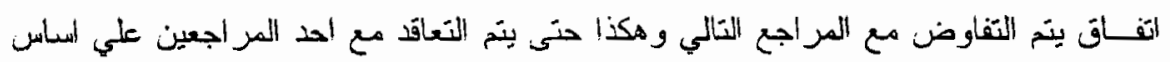

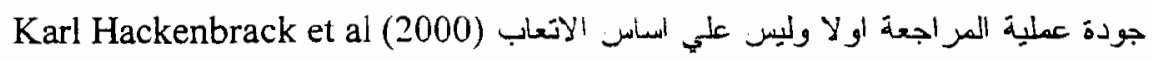

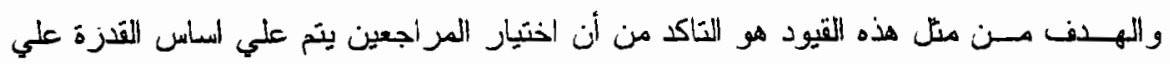

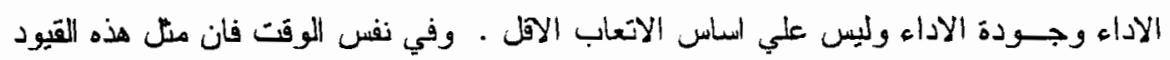

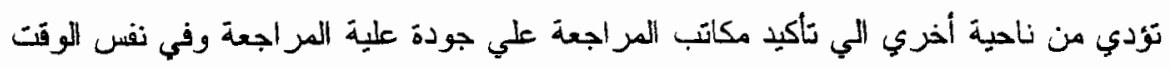

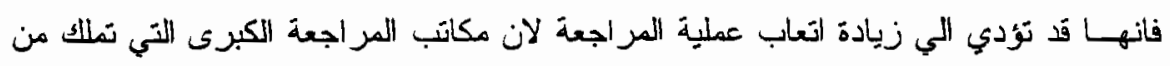
القدرة علي زيادة جودة عملية المر اجعة في ظل قيرد المنافسة العبرية فانها سترفع من أتعابها

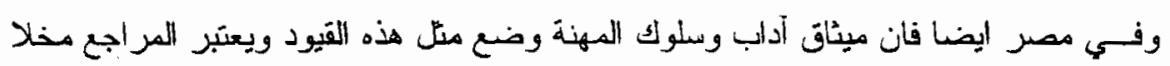

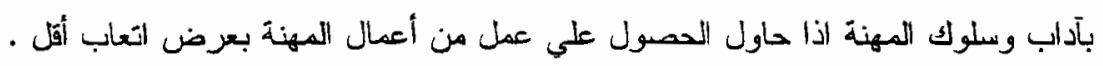

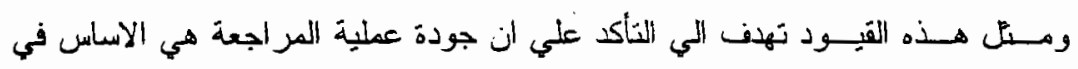

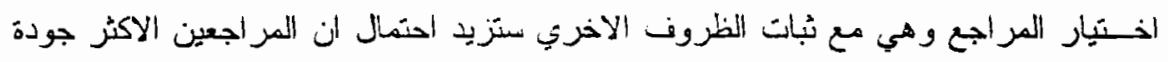

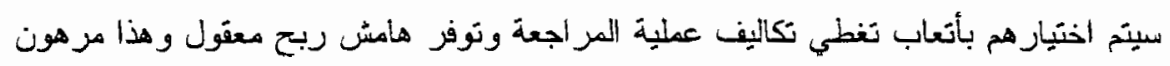

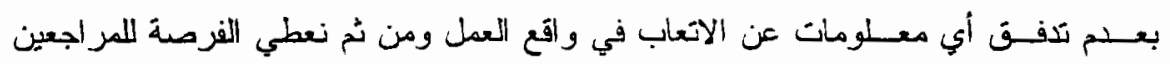

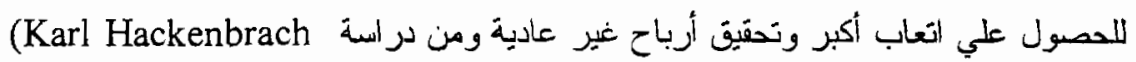
et al 2000)

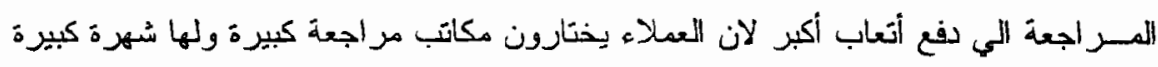

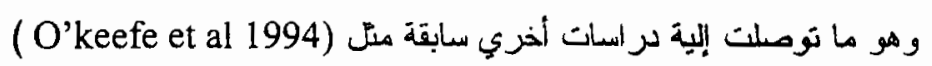

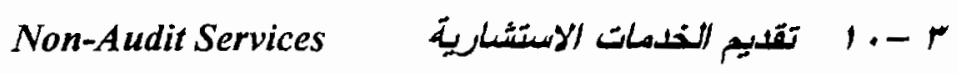

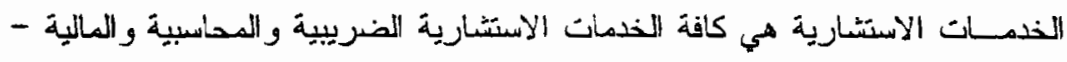

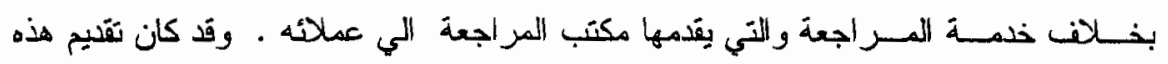

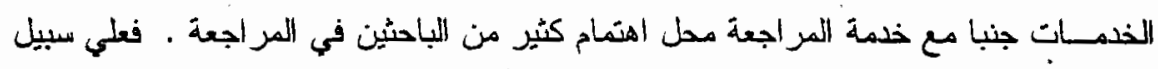

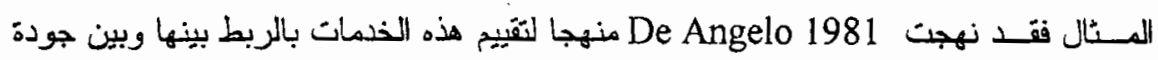

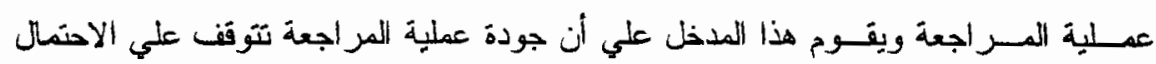

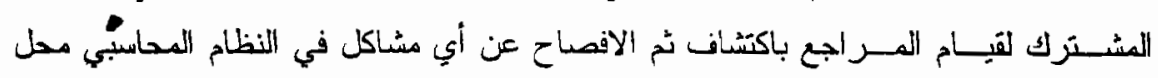


المـراجعة وتتوقف قرة المر اجع علي اكتُشاف هذه المشاكل علي حسن تخطيط وبتفيذ عملية

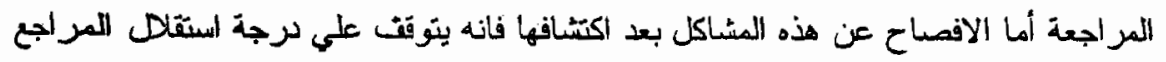

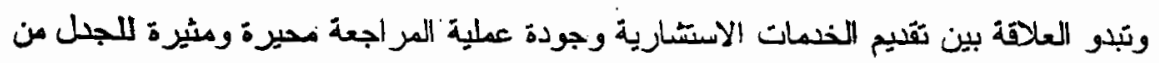

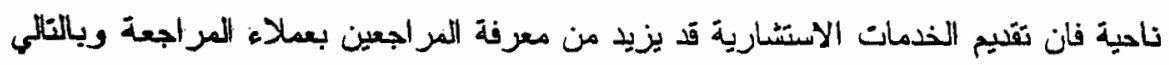

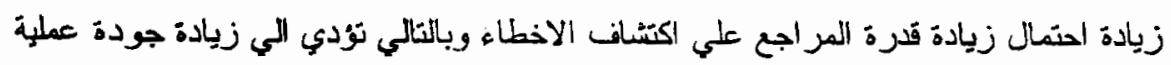

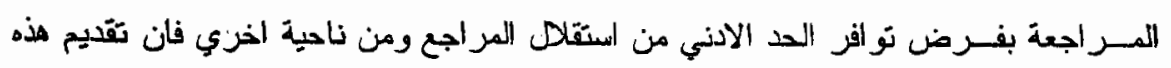

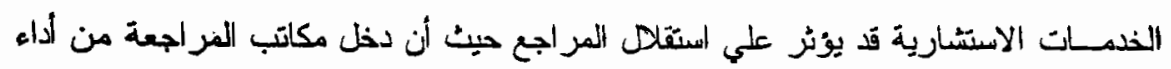

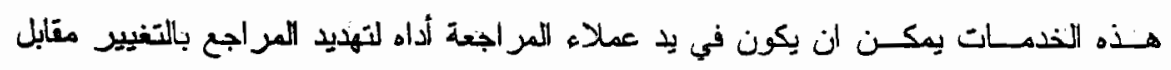

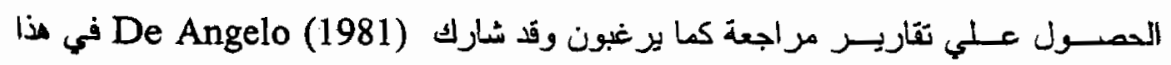

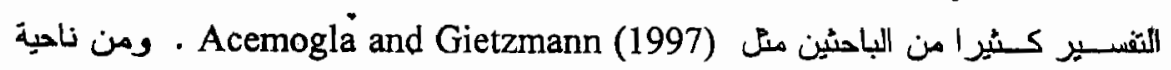

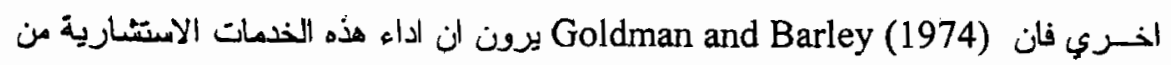

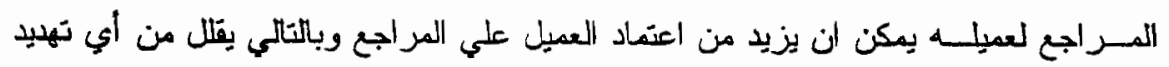

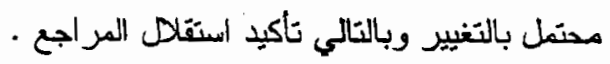

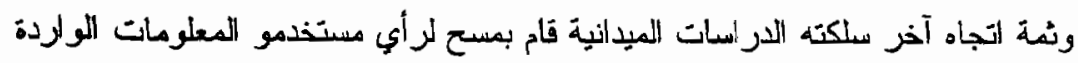

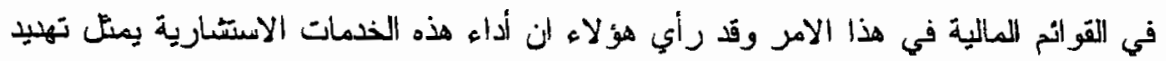

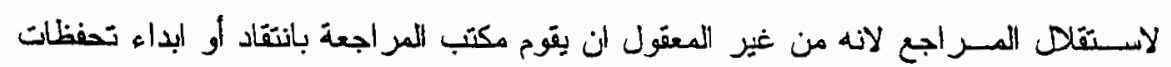

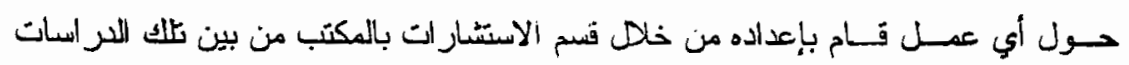

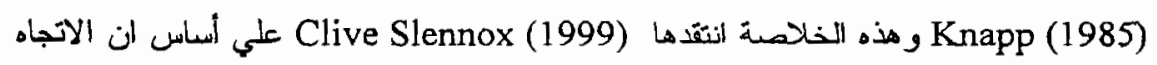

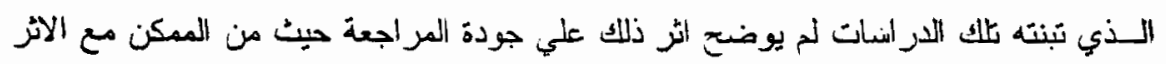

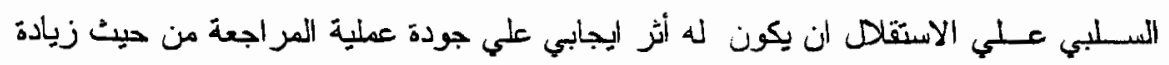

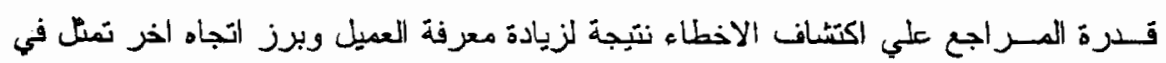

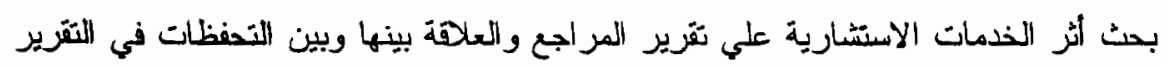

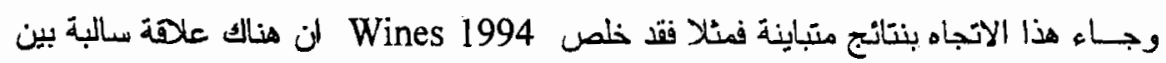

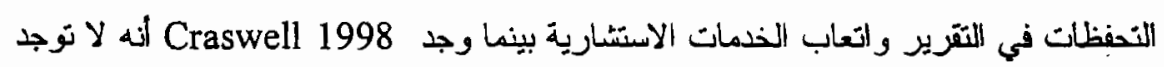

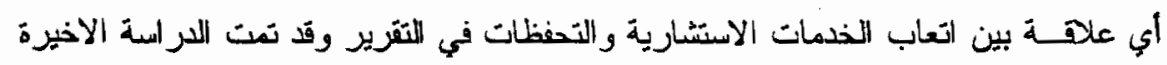

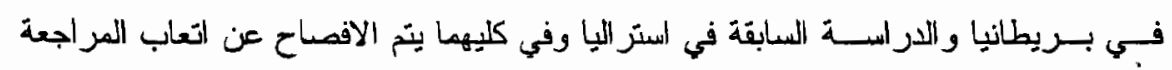

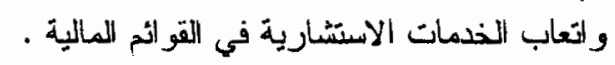

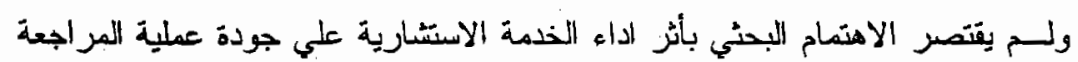

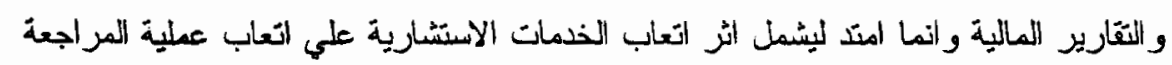

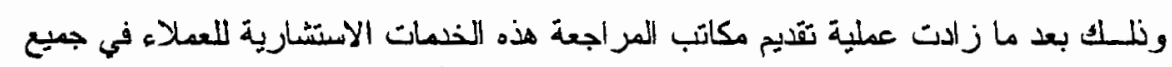


انحاء العالم و الذي اسفر عن انذناض نسبة دخل مكاتب المراجعة من عملية المراجعة مقارنة

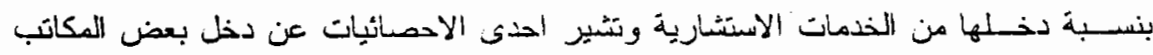

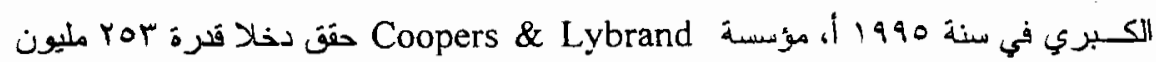

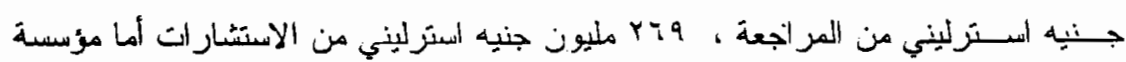
Arthur Andersen

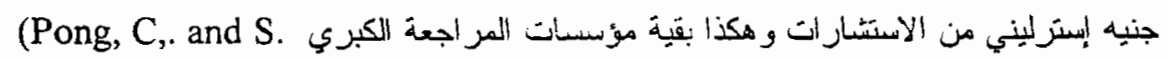
Turley 1997)

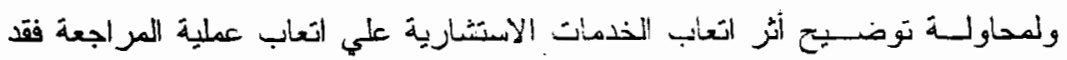

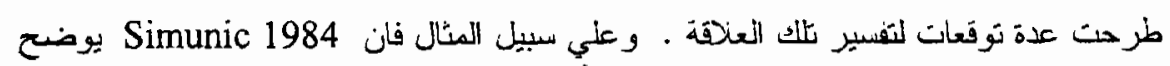

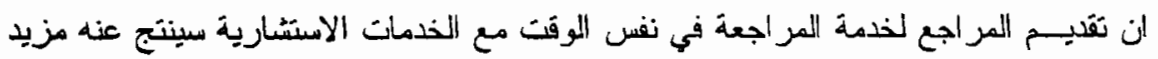

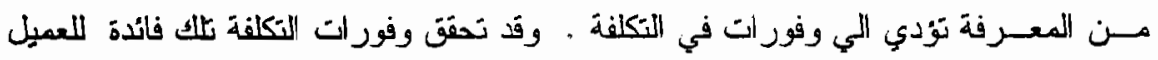

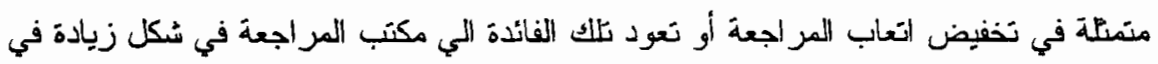

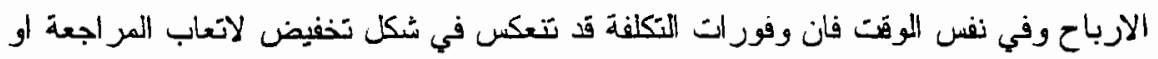

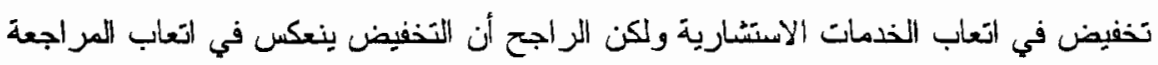

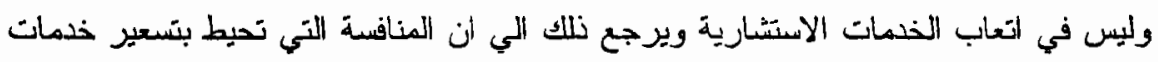

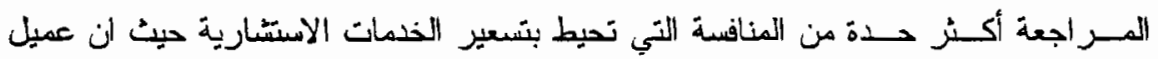
المراجعة يهفف دائما الي البحث عن خدمة المراجعة التي يحصل منها علي تقرير نظيف بأتل

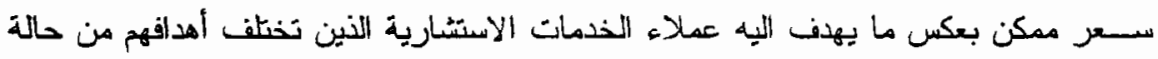

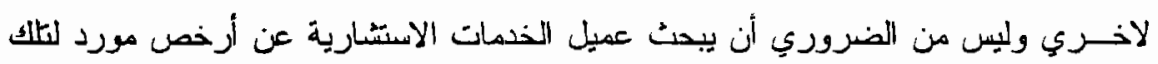
الخدمسات (Clive S. Lennox 1999) ويتوقف الاتجاه الذي ستخجه اليه وفورات التكلفة

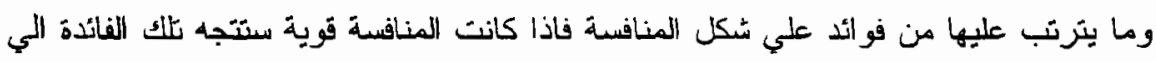

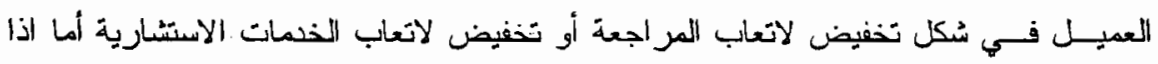

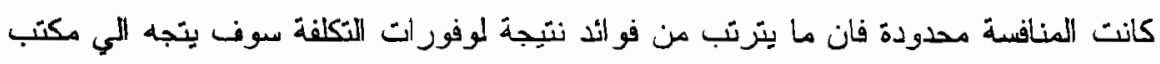

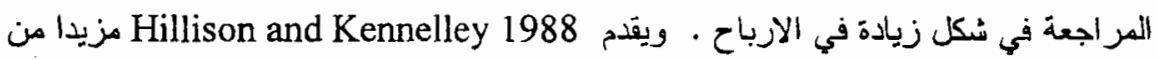

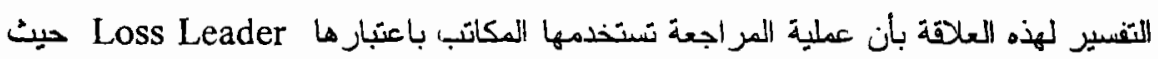

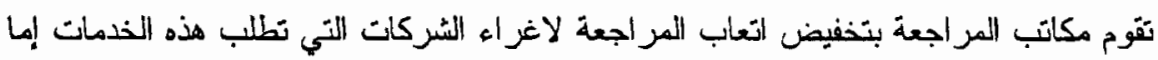

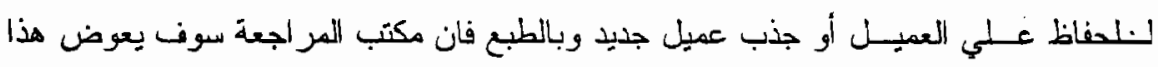

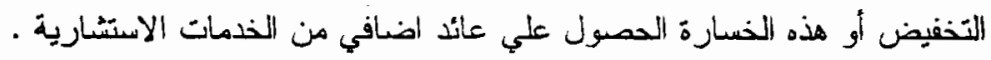

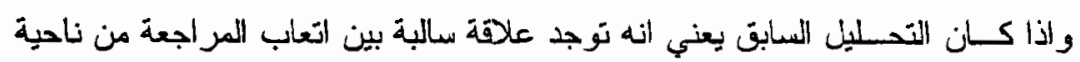

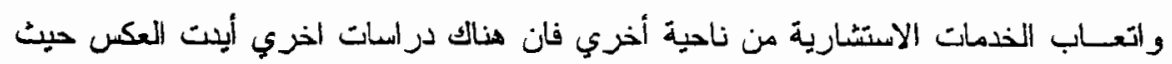


خلمت الي وجود علاقة موجبه بين اتعاب المر اجعة واتعاب الخدمات الاستّارية حيث تزيد

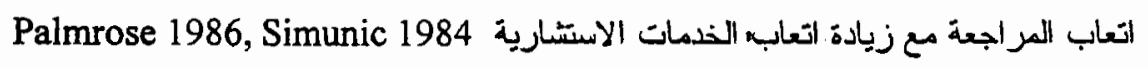

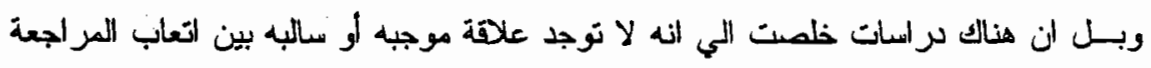

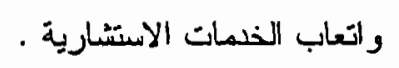

ولكـن الباحث يتفن مع التحليل الاول من حيث توقع ان تكون هنأك علاهة سالبة بين

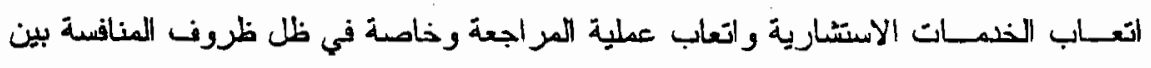

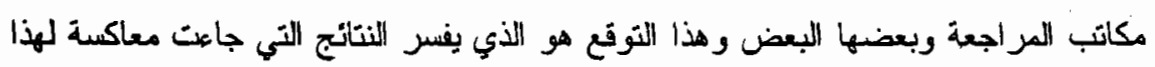

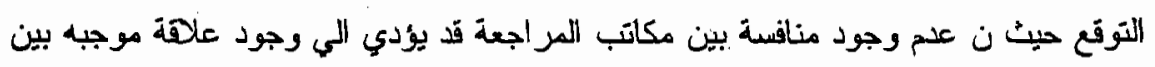

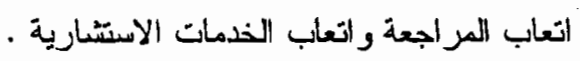




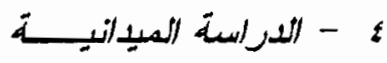

\section{- -}

قام الباحث بإجراء دراسة ميداني علي عينة من المراجعين أصحاب المكاتب الخامية و الثُركاء ومديرو المر إجعة في بعض المكاتب بالقاهرة وطنطا والإسكندربة وقد تمت الدراسة درنة

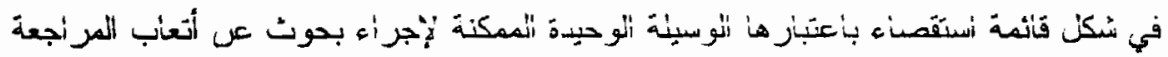

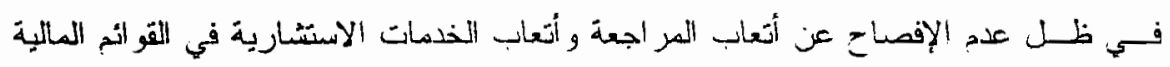

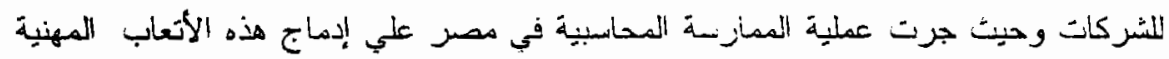

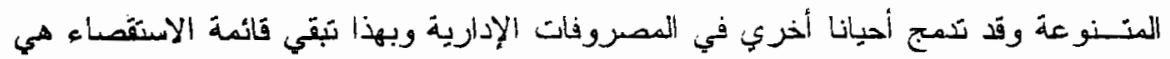

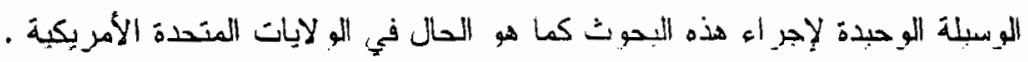
وقد احتوت قائمة الاستقصاء علي إحدى عشر سؤ الا يختار كل مشُشك درجة الموافقة

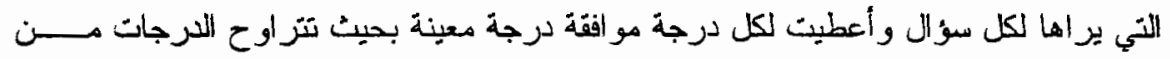
$.5-1$

يوضح الجبول التاني نسبة استجابة عينة البحــــث :

\begin{tabular}{|c|c|c|}
\hline نسبة الاستجابــة & عدد الردود & عدد الاستمارات الموز عــة \\
\hline 62.2 & 56 & 90 \\
\hline
\end{tabular}

\section{r}

احستوت قائمة الاستقصاء علي إحدى عشر سؤالا يتعلق كل منها بأحد الفروض التي

تقوم الدراسة باختبارها ونلك في ضوء مفهوم اختبار الفروض الإحصائية في مجال الدراسات

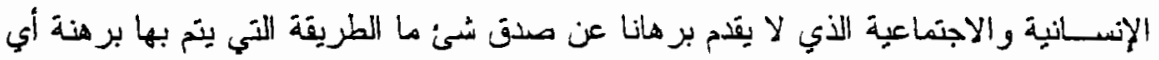

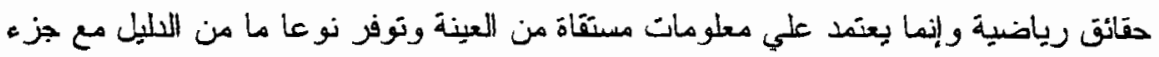

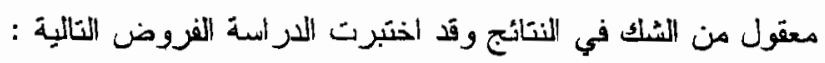

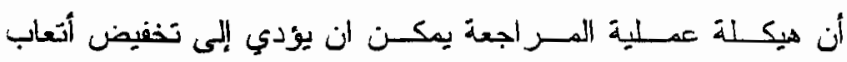

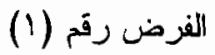
المر اجعة أنة

ان أتمتة عملية المر اجعة يمكن أن تؤدي المي تخفيض أتعاب المر اجعة

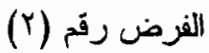

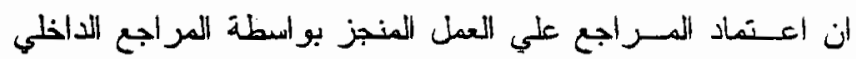

الفرض رقم (r) (r)

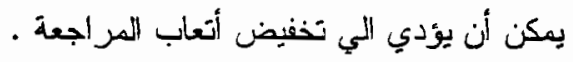

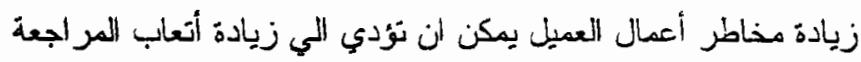
المـر اجع بمـنح خصما في الأتعاب في السنة الأولى للشركات التي تئي

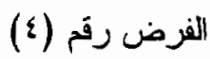

(القزرض رقم (ن) تحقق أرباحا . 
تحميل المراجع مسئولية اكتثاف الأخطاء والتلاعب يزيد من لُتعاب

(7) - (الفرض رقم

$$
\text { المر اجعة . تحميل }
$$

تـزيد أتعـاب المر اجعة مع زيادة القيمة المتوقعة لمخاطر المساعلة

(V) - (الفزض رقم

$$
\text { القانونية . تلزية }
$$

يقـسر المسراجع أتعاب أقل من المر إجع السابق لأي عملية مزاجعة

(1) - (الفزض رقم

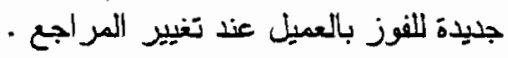

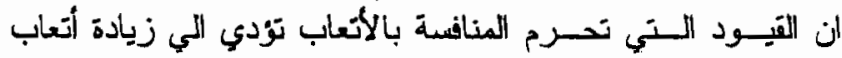

(9) الفرض رقم

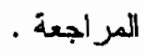

ان تقديم الخدمات الاستَّارية يؤدي المي تخفيض أتعاب المراجعة .

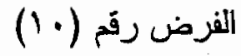

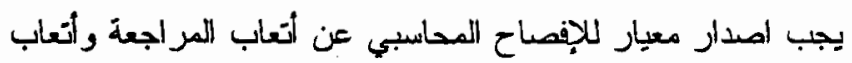

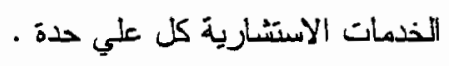

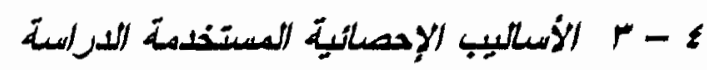

$$
\text { - التقدير الإحصائسي }
$$

وبعـد حساب المتوسط الحسابي لكل فرض (

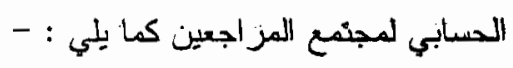

$$
\bar{X} \pm 2.58 \frac{\mathrm{s}}{\sqrt{n}}
$$

Confidence Interval of or Population Mean $=$

= S = S

$$
\text { حيث }
$$$$
\text { = }=n
$$

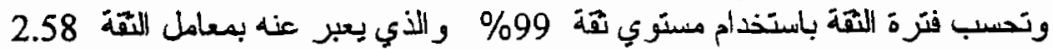

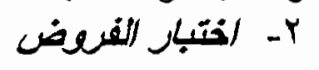

يتم اختبار الفروض باستخر اج قيمة Z وفروض الدراسة التي يجري اختيارها هي

$$
Z=\frac{\overline{\mathrm{x}}-\mu}{\frac{s}{\sqrt{n}}}
$$

فروض من أتجاه واحد .One tailed Test وحيث بعبر عن لم متوسط المجتمع 
دائما بقيمة 3.5 فأكثر و الثبي تمنّل أدني درجة للمو أفقة علي قبون الفرض والتي تمند

$$
\begin{aligned}
& \text { حتى } 5 \text { درجات أقصي درجات المو افقة } \\
& \text { r- - ترتيب الفروض بشكل دطلت }
\end{aligned}
$$

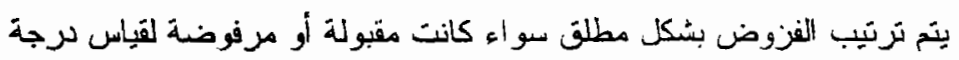

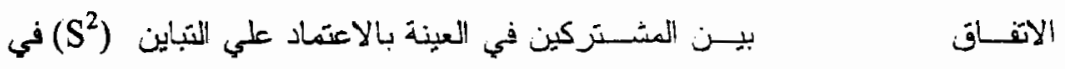

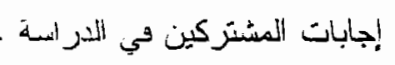

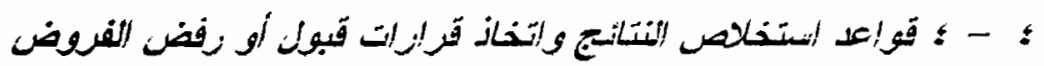

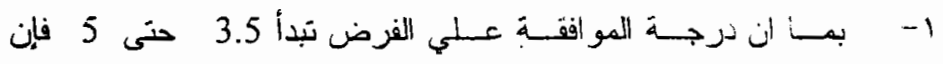

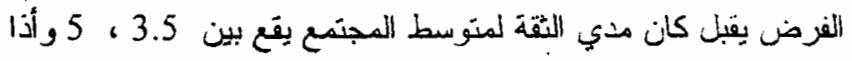

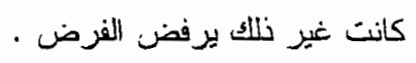

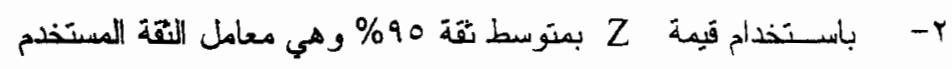

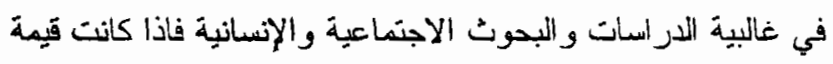

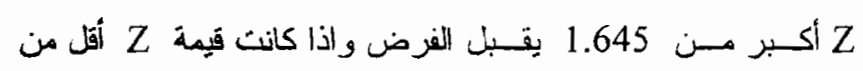

$$
1.645 \text { برفض الفرض . }
$$

\begin{tabular}{|c|c|c|c|c|c|c|c|}
\hline \multirow[t]{2}{*}{$\mathrm{H}$} & \multirow{2}{*}{$\bar{x}$} & \multirow[t]{2}{*}{$S$} & \multicolumn{2}{|c|}{$\begin{array}{l}99 \% \text { Cofidence Interval } \\
\text { for Population mean }\end{array}$} & \multirow[t]{2}{*}{$S^{2}$} & \multirow[t]{2}{*}{ Rank } & \multirow[t]{2}{*}{ Z } \\
\hline & & & Lower & Upper & & & \\
\hline $\mathrm{H}_{1}$ & 2.82 & 1.34 & 2.36 & 3.28 & 1.82 & 11 & -3.79 \\
\hline $\mathrm{H}_{2}$ & 3.00 & 1.19 & 2.59 & 3.41 & 1.42 & 8 & -3.14 \\
\hline $\mathbf{H}_{3}$ & 3.89 & -.91 & 3.58 & 4.20 & -.83 & 3 & 3.25 \\
\hline${ } \cdot \mathrm{H}_{4}$ & 3.92 & 1.14 & 3.53 & 4.31 & 1.31 & 7 & 2.80 \\
\hline $\mathrm{H}_{5}$ & 3.88 & 1.10 & 3.50 & 4.26 & 1.21 & 6 & 2.59 \\
\hline $\mathrm{H}_{6}$ & 2.71 & 1.20 & 2.30 & 3.12 & 1.44 & 9 & -4.92 \\
\hline $\mathrm{H}_{7}$ & 3.03 & 1.22 & 2.61 & 3.45 & 1.49 & 10 & -2.93 \\
\hline $\mathrm{H}_{8}$ & 3.87 & -.97 & 3.54 & 4.2 & -.95 & 4 & 2.85 \\
\hline $\mathrm{H}_{9}$ & 3.84 & 1.009 & 3.71 & 3.97 & 1.02 & 5 & 2.62 \\
\hline $\mathrm{H}_{10}$ & 3.91 & -.88 & 3.61 & 4.21 & -.78 & 2 & 3.49 \\
\hline $\mathrm{H}_{11}$ & 2.52 & -.87 & 2.40 & 2.64 & -.76 & 1 & -8.17 \\
\hline
\end{tabular}

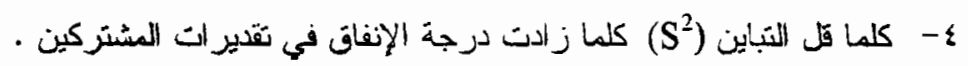

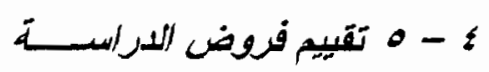

- الجدول التَالي يبين النتائج الإحصائية للدراسة : -

\section{Statistical Results}




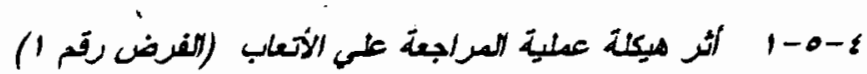

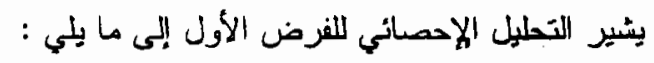

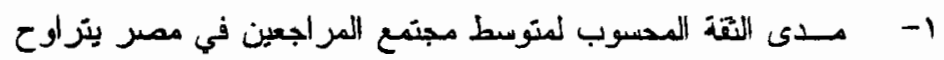

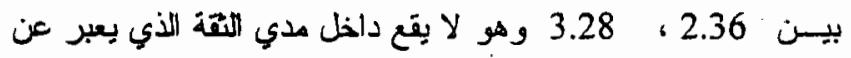

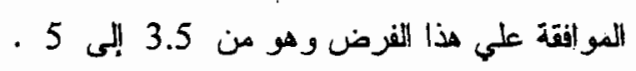

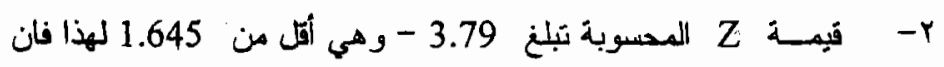

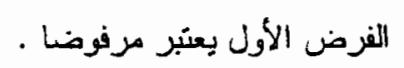

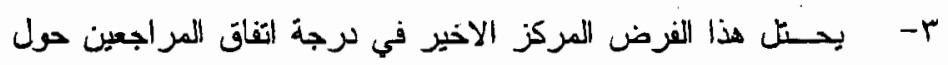

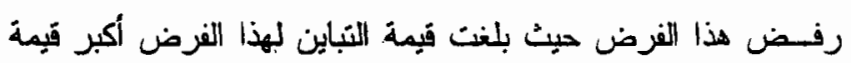

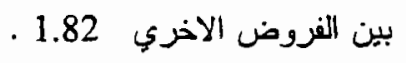

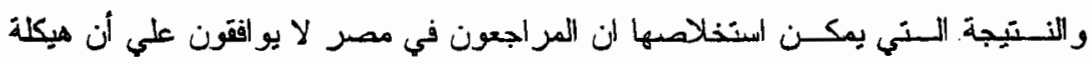

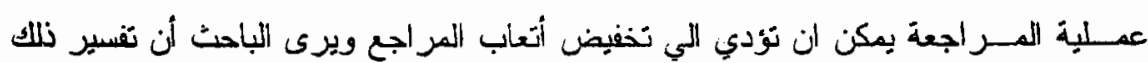

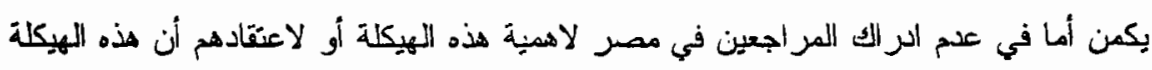

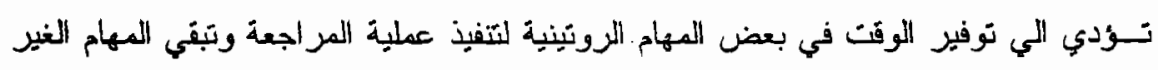

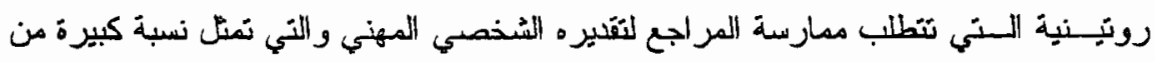

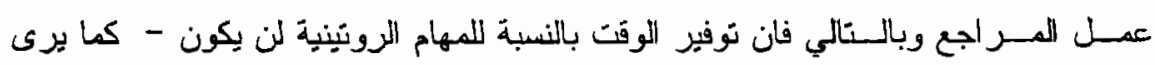

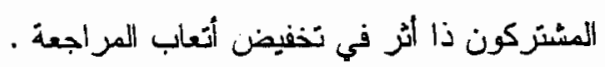

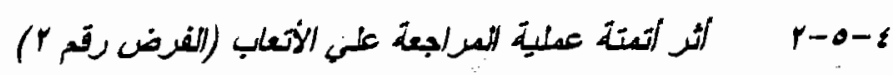

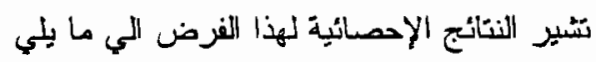

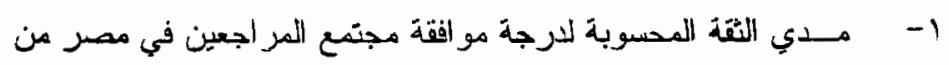

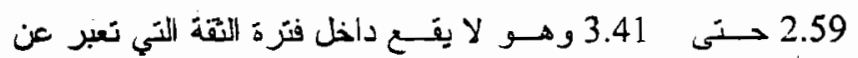

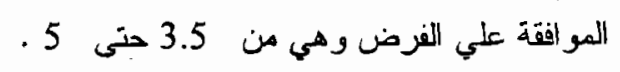

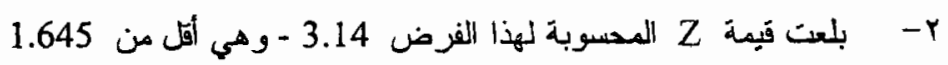

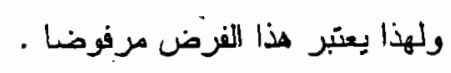

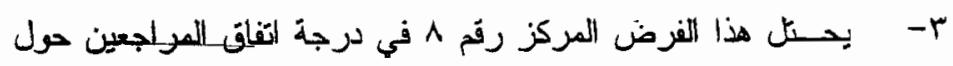

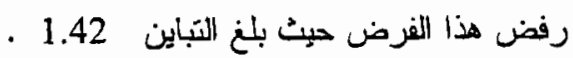

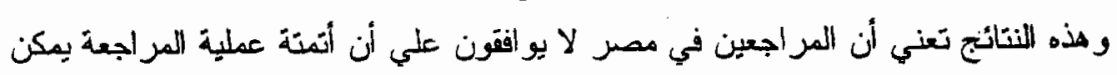

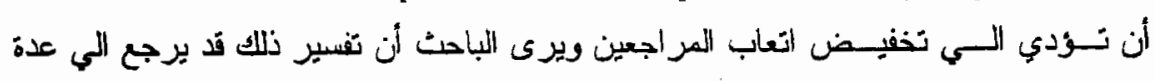


1- اعتقاد المراجعين في مصر ان التكاليف المبدئية لتصمبم وتتفيذ هذه النظم الالية وها

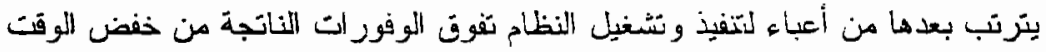

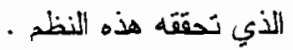

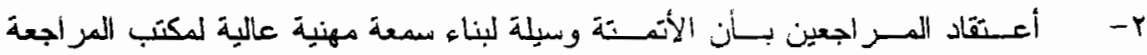
و الاعسلازن عـن خدمة مر اجعة عالية الجوندة بيتوقعون معها ارتفاعا وليس انخفاضلا

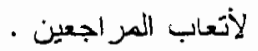

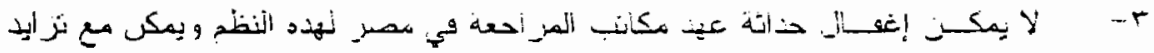

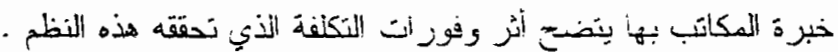

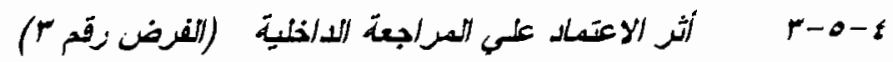
تشير النتائج الإحصائية لهذا الفرض الني ما بلي : 1- مدى الثقة المحسوبة لمتوسط المجنمع 3.58 حتى 4.2 وهي ثَقع داخل مدي

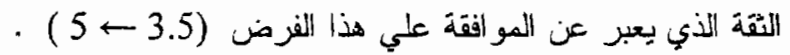
Y- بلغت قيمة

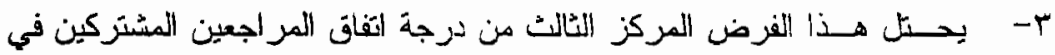
قيوله حيث التباين = 83.- وهذا يعني موافتَة مجتمع المر اجعين في، مصر

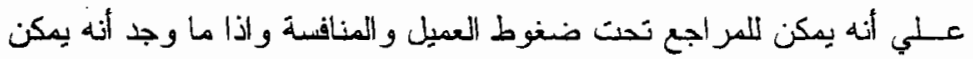
الاعـــاد عـلي عمل المراجعة الداخلية أن يخفض من أتعاب المراجعة نظرا للاعتماد علي عمل المر اجعة المداخلية في تخفيض جهد المراجع الخارجي -

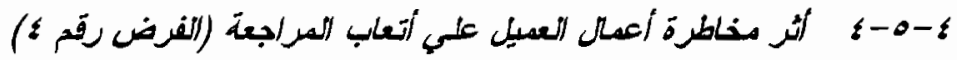
تشيّر النتانج الإحصائية لهذا المغرض الي ما يلي : 1- تبلغ مدي انثقة المحسوب لمتوسط مجنمع المر اجعين 3.53 ـ 4.31 وهو يقع داخل مدى الإقة الذي بعير عن المو افقة علي هذا الفرض .

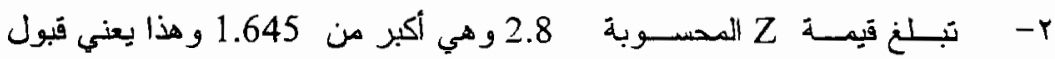
الفزض

r- بح يـل هذا الفرض المركز السابع في درجة اتفاق المراجعين المشتركين في

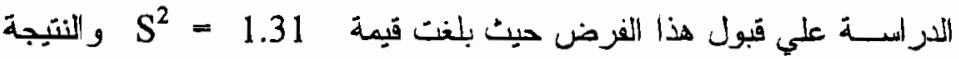
التي بمكن استخلاصها من قبول هذا النرض هو مو افقة المراجعين في مصر

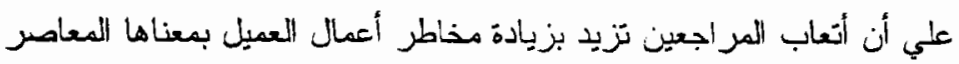
وليس مجرد وجود حساب أو أكثر من الحسابات ذات الخطر العالي . 


$$
\text { -0-0-0 أثر المريحية علمى الأتعاب ( الفرض رقم ه) }
$$

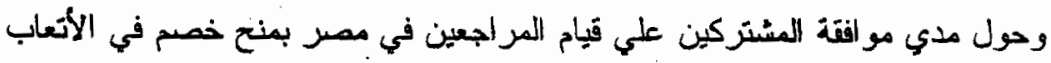

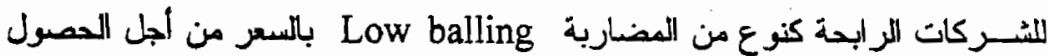

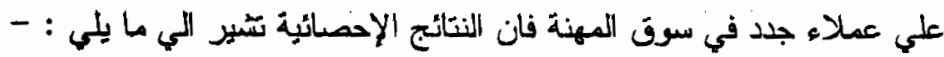

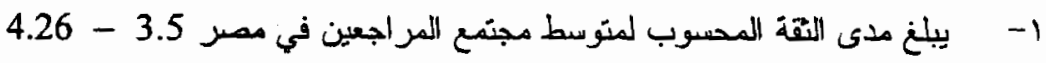

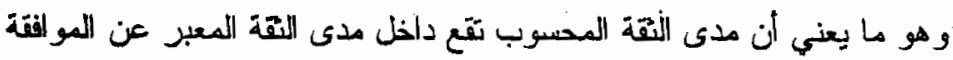

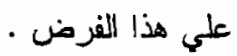

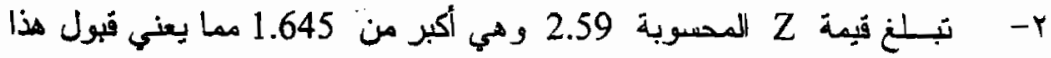

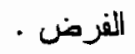

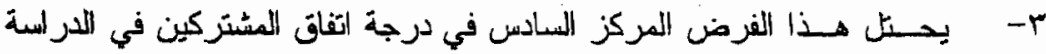

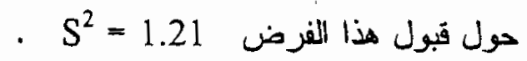

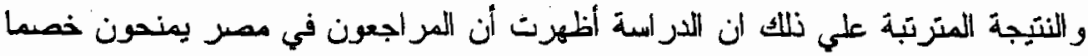

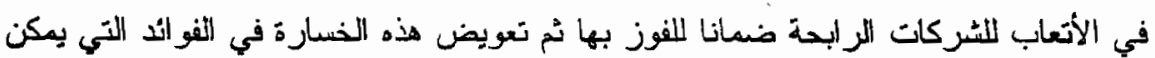

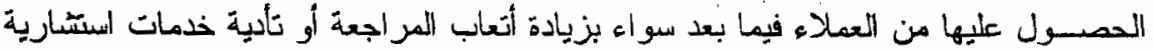

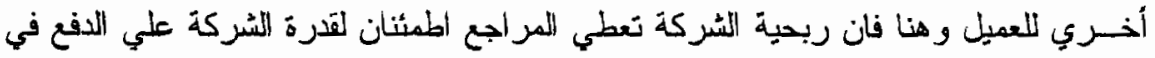

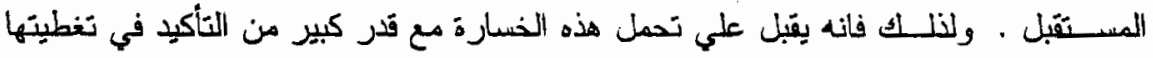

مسنقبلا

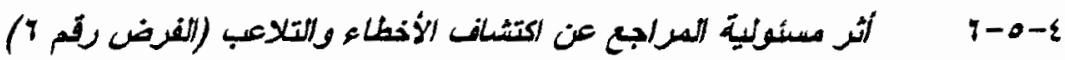

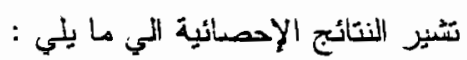

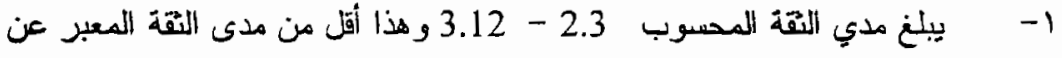

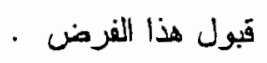

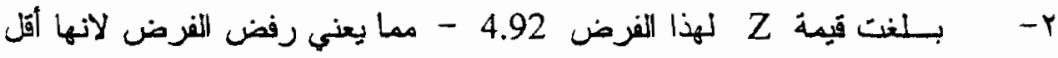

$$
\text { من } 1.645 \text { هن }
$$

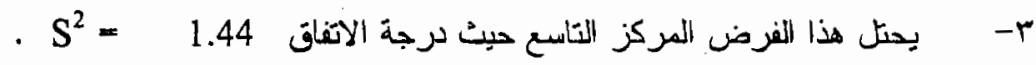

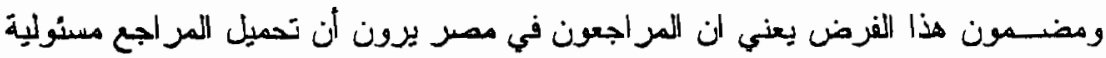

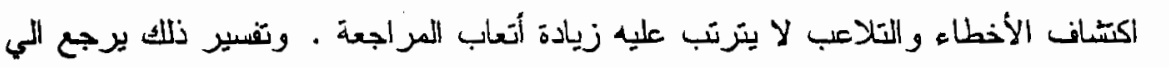

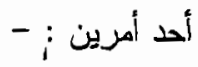

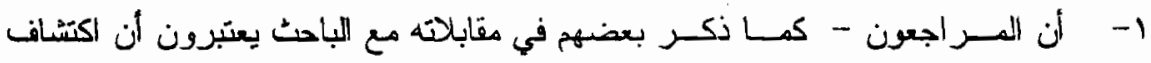

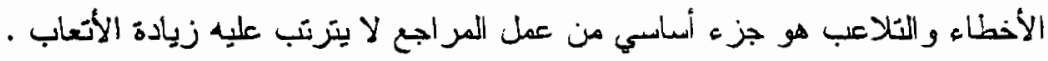




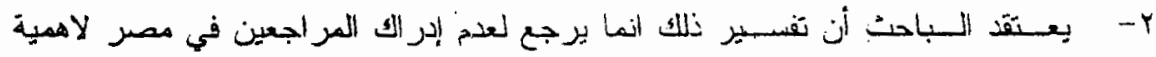
أكتشاف الاخطاء و التلاعب وكما سيتضح فيما بعد فنان ذلك مرتبط بعنم إبراكهم لاثر الخسارة المستوقعة من المساعلة القانونية علي الاتعاب .

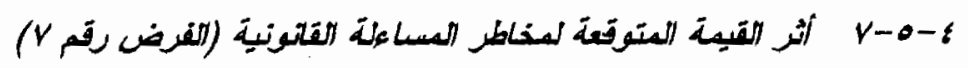

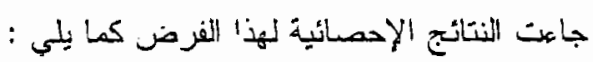
1- - مدى التقة لتقدير منوسط المجنمع 2.61 - 3.45 و هي أقل من مدى القبول

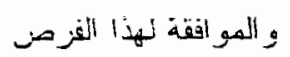

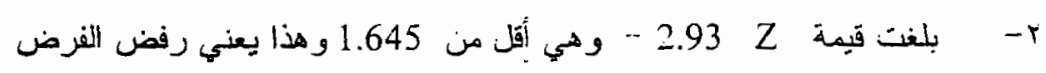

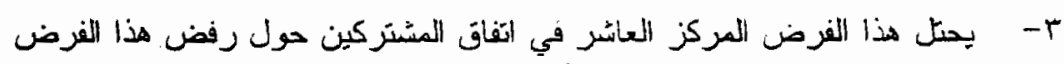

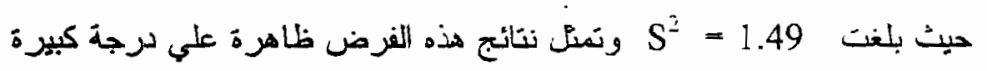

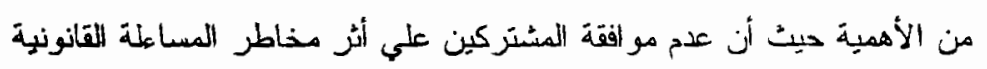
علي الأتعانب نعني كما يرى الباحث عدم إبر الك المر اجعين في مصر لاثز هذه

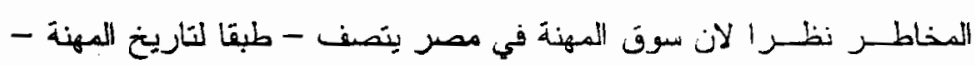

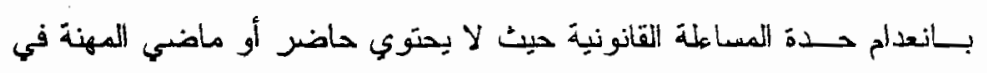
مصر على حالات مساعلة قانونية الا فيما ندر و الذي تم بناء علي تكخل جهات

$$
\text { حكومية . }
$$

$$
\begin{aligned}
& \text { ك-0-1 أثر تقيير المرلجع علمي الأتعلب (الفرض رقم م) }
\end{aligned}
$$

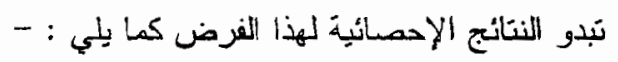

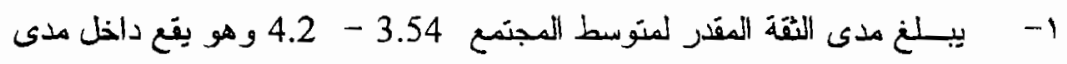

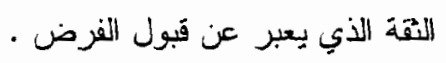

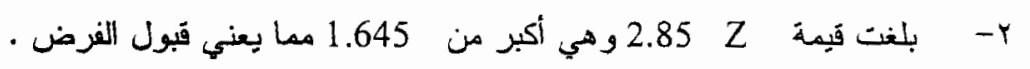

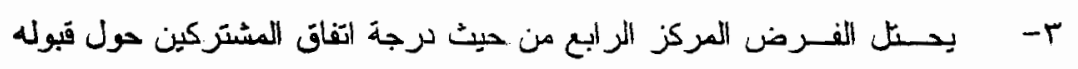

$$
\text { - } \mathrm{S}^{2}=-95 \text { حين }
$$

وتقدم نتائج هذا الفرض دليلا أخر علي ممارسة المر اجعين في هصر عملية المضاربة

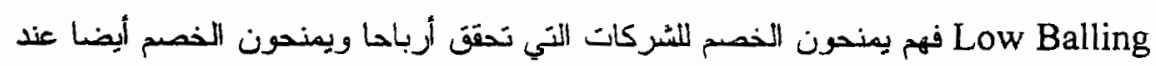
تغييسر المراجعين ويقدرون أتعاب أفل من المر اجع السابت لضمان الفوز بالعميل وتوفر نتائج الفزرين 5 ، 8 دليلا علي شعور المر اجعين في مصر بحدة المنافسة في سوق المهنة . 


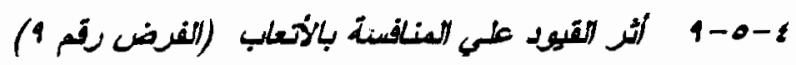

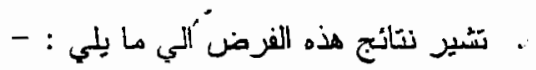

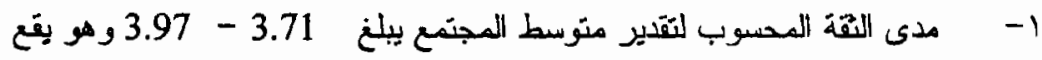

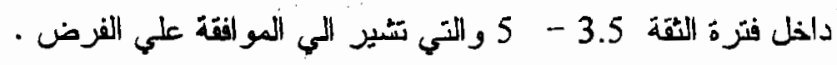

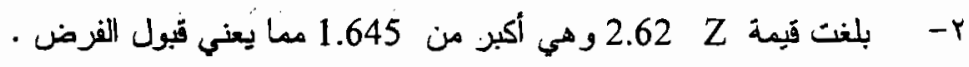

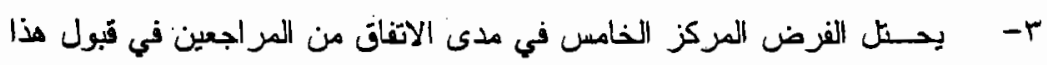

$$
\text { الفرض حيث } 1.02 \text { الفئ }
$$

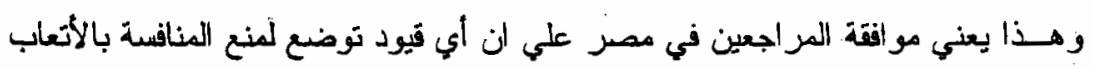

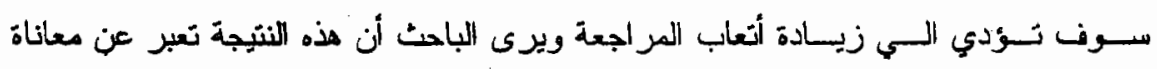

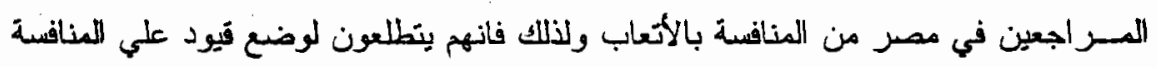

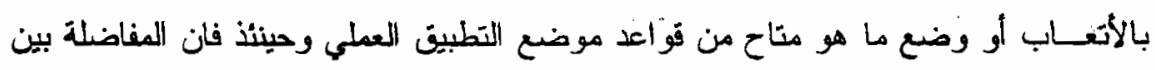

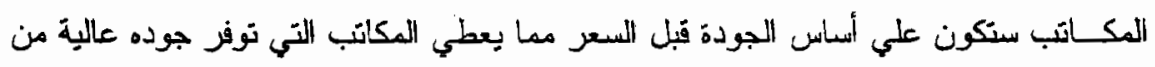

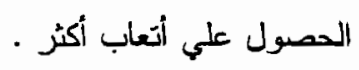

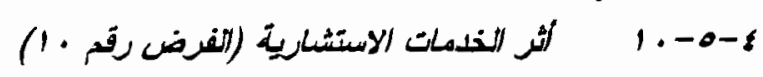

$$
\text { وقد جاعت نتانج هذا الفرض كما يلي : - }
$$

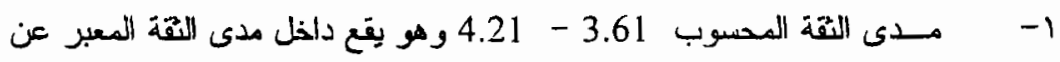

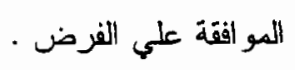

r- ت بيمة

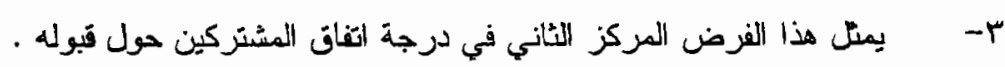

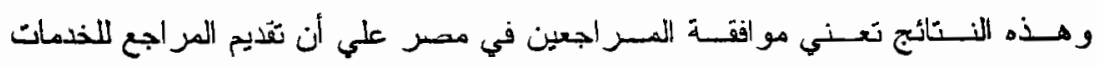

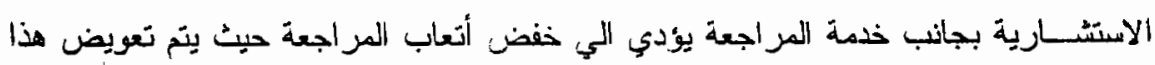
الخفض بالاخل من الخدمات الاستشارية .

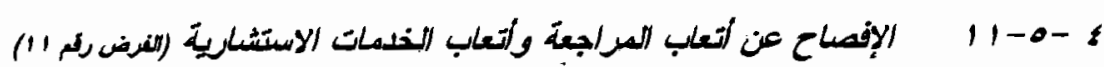

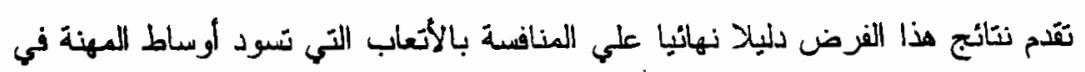

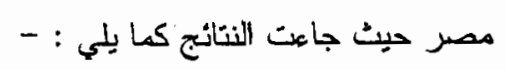

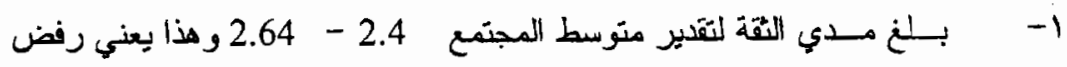

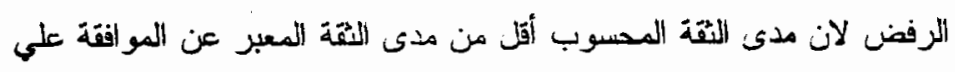

$$
\begin{aligned}
& \text { الفرض . المرنا لان } \\
& \text { r- بلغت قبعة } 8.17 \text { - مما بعني رفض الفرص . }
\end{aligned}
$$




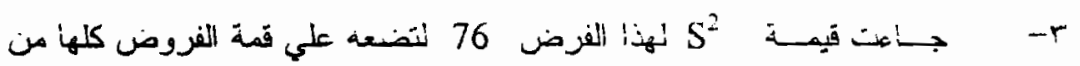

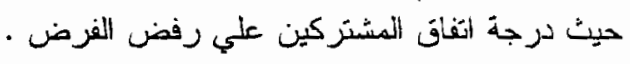

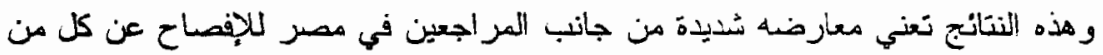
أتعباب المر أجعة وأتعانب الخدمات الاستشارية في القوائم المالية ويرجع ذلك - كما أفاد كثير

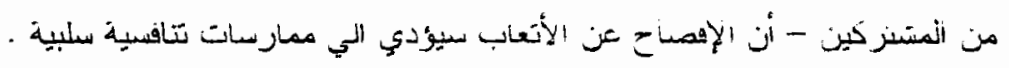

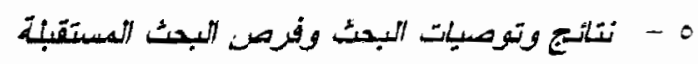

$$
\text { م } 1 \text { - نتاتسج البحث }
$$

أمكن للباحث من خله البحث من التوصل الفي التتائج التالية : -

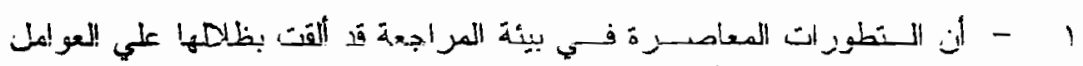

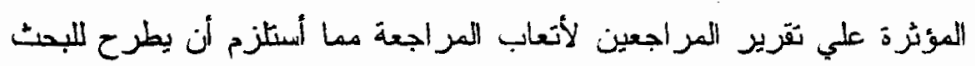

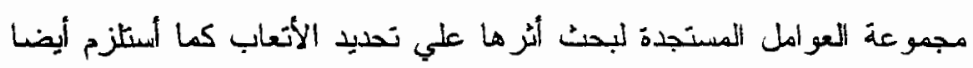

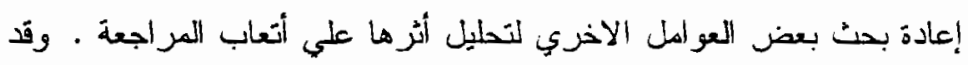
اتضتح من خلم التحليل ان كل من هذه العو امل يمكن حال تو اقر أسبانب معينة

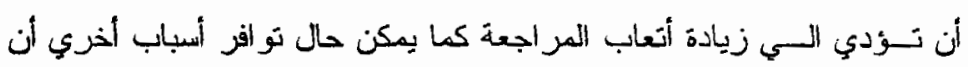
يؤدي إلى تخفيض أنعاب المراجعة . ويزى الباحث أن نيكل المنافسة في سون

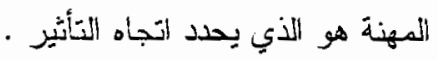

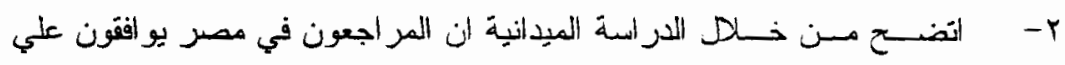

$$
\text { الفزوضر المتالية }
$$

أ- - أن المراجع يمكن تحث ضغوط المنافسة والعميل ان يخفض من اتنعابب

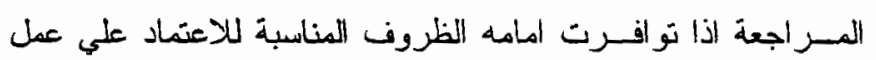

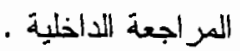

ب- ان المراجع يزيد من أتعاب المر اجعة بزيادة مخاطر اعمال العميل .

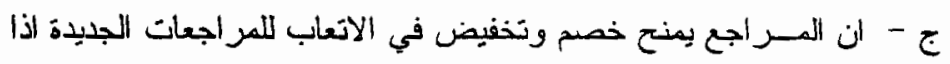

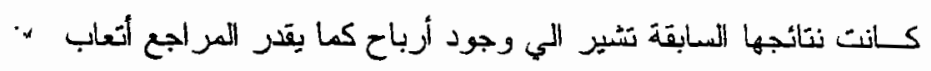

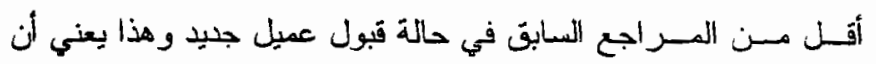

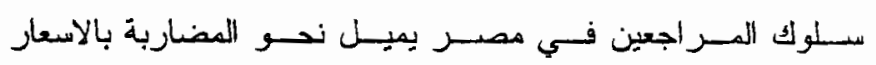

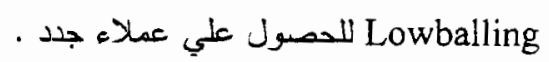

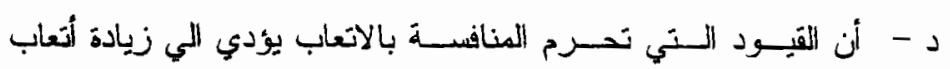

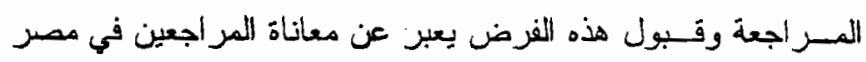

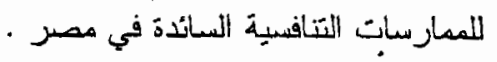


هـ - ان تقديـر الخدمبات الاستشارية الضريبية والمالية والادأرية للعملاء

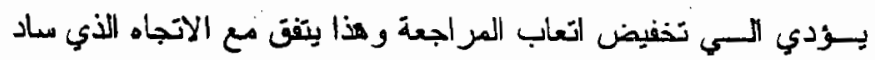

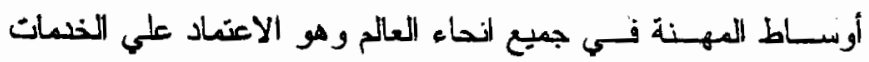

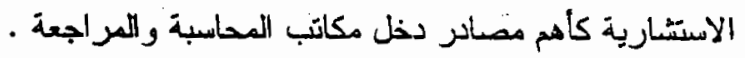

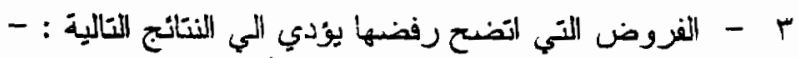

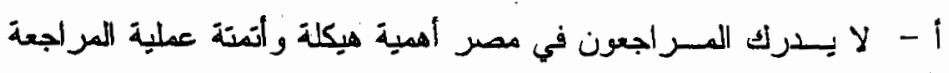

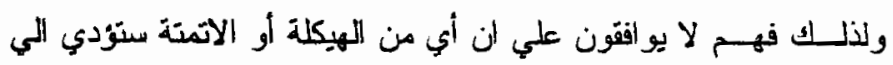

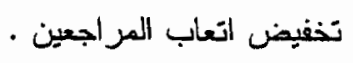

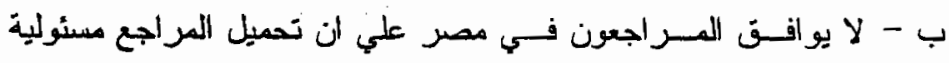

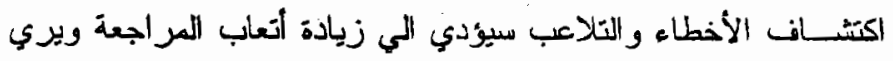

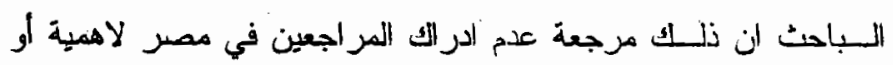

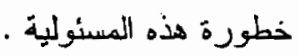
ج - لا يدرك المراجعون في مصر الآثار المحتملة للمساعلة القانونبة علي

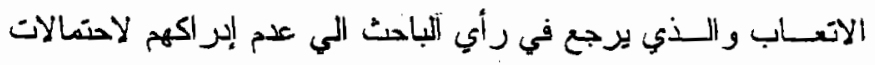

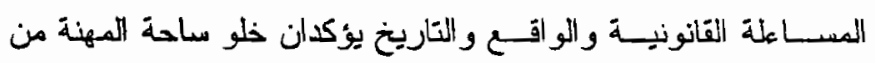
حالات المساعلة . د - لم يوافق المراجعون في مصر بلرجة عالية من الاتفقق علي الافصاح

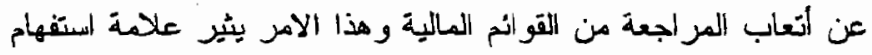

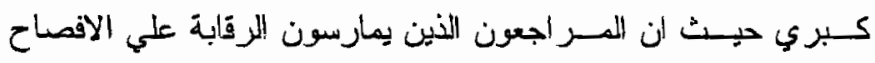

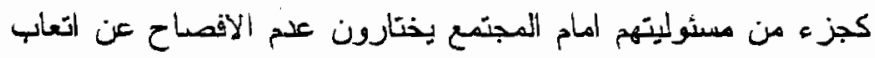

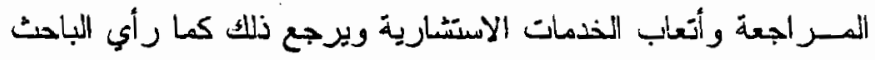

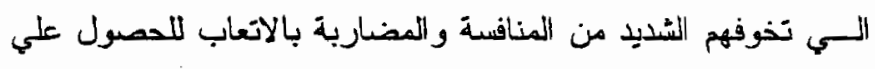
مملاء جلد

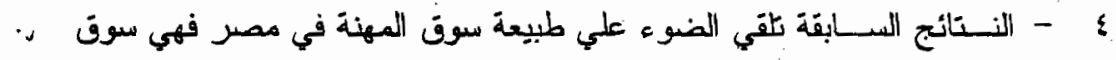

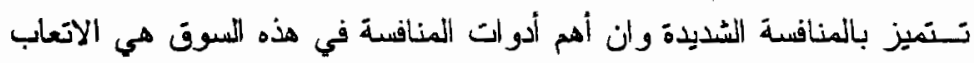

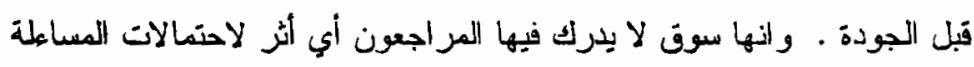

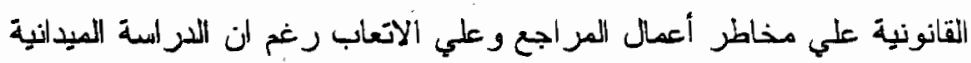

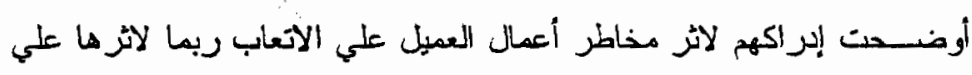

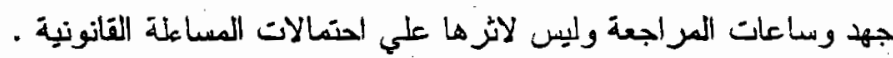


1- زيــادة الاهـــمام بالمــر اجعة الاخلية ووضع معايير خافسة للمر اجعة الدأخلية

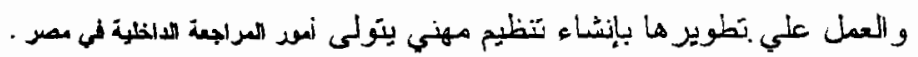
r - العمـل علي تخفيصر مهنة المراجعة في مصر من السلوكيات التتافسية السلبية

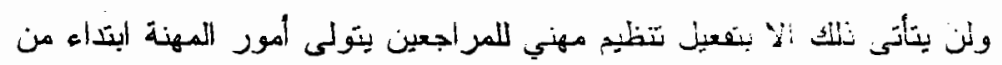

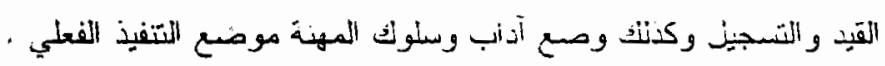

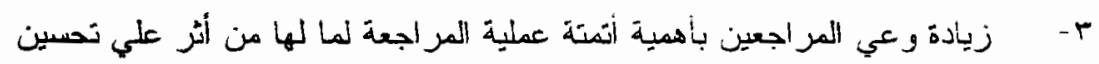

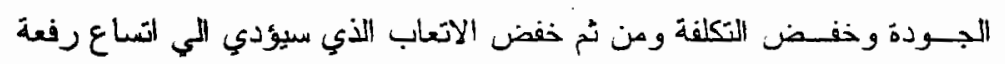

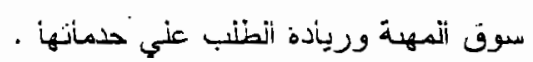

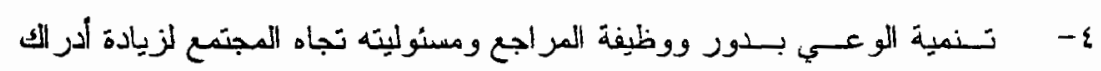

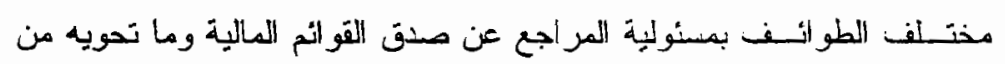
معلومات و التي تشاهم في التخصيص الفعل لموارد المجنمع .

\section{م-برف المبحث المستقبلة}

بعسد أن أيقن الباحث أنه لا توجد دلالك حول قرب التوحل الي عمومبات حول عو امل

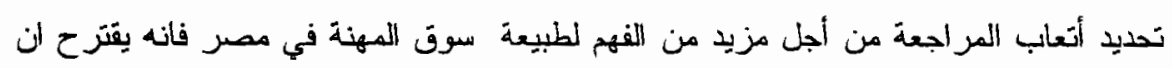
هناك حاجة لان تثواصل جهود البحث علي الابعاد التالية : 1- عو امسل تحديس الاتعسب في صناعات متخصصة مثل المؤسسات المالية و الشركات المصناعية و غير ها من قطاعنت السوق . Y- بحسث كهل عامل من عوامل تحديد الاتعانب منفردا بحيث بغطي هجموعة من قطاعات السوق و ان يشمل جانبي العرض و الطلب علي المهنة في هصر - لمئ

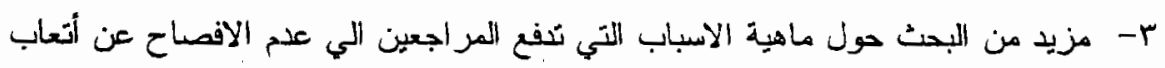

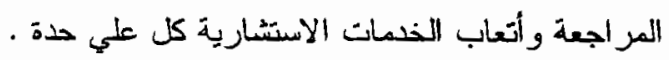




\section{References}

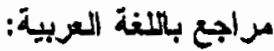

راضى - محد سلمى - دكتول - 991 - تحليل العو المل المؤثرة في تحديد أثعاب المراجعة المجلة العربية للمحاسبة - المجلد الثناني - العدد الاول - نوفمبر TY-VY.

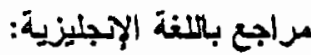

Abdel-khalik, A.R. (1990): The Joint ness of Audit Fees and Demand for MAS: A Self-Selection Analysis; the Accounting Review, Vol 6 No2, 295-322.

Acemoglu, D and Gietzmonn. M.B. (1997): Auditor Independence, Incomplete Contracts And the Role of Legal Liability" European Accounting Review, 6 (3): 355-375.

American Instruite of Certified Public Accountants (AICPA), The Commission on Auditors' Responsibilities Report, Conclusions, Recommendations New York. NY: AICPA.

Arthur Anderson \& Co., Coopers \& Lybrand, Deloitte \& Touche, Ernst \& Young, KPMG Peat Marwick, Price Water House (1992). The Liability Crisis in the United States: Impact on the Accounting Profession Big Six White Paper- A statement of Position.

Barkess L. and R. Simnett (1992): "An Empirical Investigation of the Relationship Between Audit Fees and the Provision of other Services by the Incumbent Auditor-Australiaan Evidence; Working Paper" (University of New South Wales). 
Beaty, R. P. (1986): The Initial Public Offering Market for Auditing Services, Proceedings of the 1986 University of Illinois Auditing Research Symposium Urbana, University of Illinois at Urbana - Chmpaign.

Berton, L. (1987). Panel to recommend stiffer penalties, more audit safeguards to fight fraud. Wall Street Journal (April 27).

Bierstaker, J.L. and A Wright 1999: "The effects of fee pressure on Audit Planning Decisiolns. Working Paper, University of Massachusetts Boston.

Butterworth, S., and K. A. Houghton (1995): Auditor Switching: The Pricing of Audit Services. Journal of Business Finance of Accounting 22:323-344.

Calegari, Michael., J. W. Schatzberg and A., Sevcik. (1998): "Experimental Evidence of Differential Auditor Pricing and Reporting Strategies". The Accounting Review. Vol. 73. No. 2 April 255-275.

Clatworthy M. H. Mellett and M. Peel. (2000). "External Audit Fee Levels in NHS Trusts. Public Money \& Management Journal. January - March 63-68.

Clive S. Lennox 1999: "Non Audir Fees, Disclosure and Audit Quality" The European Accounting Review, 8:2. 239-252.

Craswell, A., J. Francis, and S., Taylor (1995): Auditor Brand Name Reputations and Industry Specializations, Working Paper. University of Missouri, Colambia Mo.

Cushing, B. and J. Loebbecke. 1986. Comparison of Audit methodologies of large accounting Firms, Sarasota: AAA. 
De Angelo, L.E. 1981: "Auditor Independence, "Low Balling" and Disclosure Regulation, Journal of Accounting and Economics. $3(2): 113-128$.

Deis, Donald R, and G., Giroux. 2000: "The Effect of Auditor Changes on Audit Fees, Audit Hours and Audit Quality Journal of Accounting and Public Policy (2) 55-76.

Dopuch N., R. King, and J. W. Schwartzberg 1994. "An Experimental Investigation of Alternative Damage Sharing Liability Regimes with an Auditing Perspective" Journal of Accounting Research (supplement) 103-130.

Ebbage, $K$ (1993): Audit Automation Benefits or Just Costs Auditing IT, No. 15. 3-6.

Ettredge M. and R. Greenberg 1990: Determinants of Fee Cutting on Initial Audit Engagements. Journal of Accounting Research 28: 198-210.

Francis J. E. and D. Simon (1987). A Test of Audit Pricing in the SmallClient Segment of the US Audit Market. The Accounting Review 62: 195-157.

Firth, M. Spring 1985. An Analysis of Audit Fees and their Determinants in New Zealand. Auditing: A Journal of Practice \& Theory $4(2): 23-37$.

General Accounting Office (GAO) 1989. CPA Audit Quality Failures of CPA Audits to Identify and Report Savings and Loan Problems Washington D.C.: General Accounting Office. 
Gibbins, M. and J D. Newton 1994: "An Empirical Exploration of Complex Accountability in Public Accounting Journal of Accounting Research 32 (Autumn): 165-1186.

Goldman, $A$ and Barlev B (1974) "The Auditor-Firm Conflict of Interests: its Implication for independence" the Accounting Review, 49: $707-718$

Goodacre, V.BA, K. Pratt and J. Stevenson (2001). "The Determinants of Audit Fees - Evidence from the Voluntary Sector". Accounting and Business Research Vol 31. No.4, 243-274.

Gramling, Audrey, W.S. Jeffrey, D.B. Andrew and M. Zhang, 1998: "The Impact of Lega! Liability Regimes and Differential Client Risk on Client Acceptance, Audit Pricing and Audit Effort Deciscions" Journal of Accounting, Auditing and Finance.6. $437-460$.

Gramling, Audrey A. 1999: "External Auditors Reliance an Work Performed by Internal Auditors: The Influence of Fee Pressure on this Reliance Decision". Auditing A Journal of Practice \& Theory Vol 18. Supplement. $117-135$.

Graswell, A. (1998) Threats to Auditor Independence: The Case of NonAudit Services' Mimco.

Hilison, W. and. Kenelley (1988): The Economics of Non. Audit Services" Journal of Accountancy September. 32-40.

Hill, J. and Metzger, M. 1992: Auditor Liability and the S \& L Crisis: Shaping the Future of the Profession? Annual Review of Banking Law [1-263-333. 
R.J Ramsay and Daniel Simon 1994: "Audit liees and Client Business Risk During the $S$ \& Crisis Empirical Evidence and Directions for Future Research" Journal of Accounting and Public Policy . 158-203.

Houston R. 1999: The Effects of Fee Pressure and Client Risk an Audit Senions' Time Budget Decisions. Auditing: A Journal of Practice \& Theory (Fall). 70-86.

Instuite of Chartered Accountants in England and Wales (ICAEW) (1993): Audit Automotion, IT Briefing No. 4 London Charrtech Books.

Johnstone K. M. and J. C. Bedard (2001). "Engagement Planning, Bid Pricing, and Client Response in the Market for Initial Attest Engagements". The Accounting Review. Vol. 76 No. 2 April 199-220.

Karim, A. K. M. Waresul and P. Moizer (1996). "Determinants of Audit Fees in Bangladesh". The International Journal of Accounting. Vol. 31 No. 4 497-509.

Karl Hackenbrack, Kevan L Jensen and Jeff L. Payne (2000) "The Effect of a Bidding Restriction on the Audit Services Market" Journal of Accounting Research Vol. 38 No. 3 Autumn. 355 - 374.

Knapp. $M$ (1985): "Audit Conflict: an Empirical Study of the Perceived Ability of Auditors to Resist Management Pressure. The Accounting Review, 60:202-211.

Knechel, W. Robert 2001. "Auditing Assurance \& Risk $2^{\text {nd }}$ ed. South Western Collage Publishing USA. 
Knights. D, Murray F., 1992. "Politics and Pain in Managing Information Technology- a Case Study from Insurance" Organization Studies: $13.2,217-28$.

Lyer V. M. and G. S. Lyer (1996): Effect of Big 8 Mergers on Audit Fees. Evidence from the United Kingdom. Auditing. A Journal of practice \& Theory Voi. 15 No. 2. Fall 23-32.

Magee, R. and M. Tseng (1990): Audit Pricing and independence. The Accounting Review. April 315-336.

Maher. M., P. Tiessen, R. Colsson, and A. Broman. 1992. compettion and audit fees. The Accounting Review 67 (January) 199-211.

Menon, Krishnogopal and David D. Williams (2001): "Long-Term Trends in Audit Fees" Auditing: A Journal of practice \& Theory vol 20 No 1 March 115-136.

Mogan, C. E., and C. Jeter (1999): "Industry Specialization by Auditors". Auditing: A Journal of Practice \& Theory (Spring). 1-17.

O'Keefe T. B., R. D. King and K. M. Gaver (1994): "Audit Fees, industry Specialization, and Compliance with GAAS Reporting Standards". Auditing A Journal of Practice Theory. Vol. 13, No. 2. 41-55.

O'keefe, T.B., D.A. Simunic and M.T. Stein 1994: The Production of Audit Services: Evidence from a major public accounting firm. Journal of Accounting Research 32:241-261.

Palmrose, Z-V. (1986): "The Effect of Nonaudit Services on the Pricing of Audit Services. Further Evidence" Journal of Accounting Research Vol. 24. (Autumn) 405-411. 
1986: "Audit Fees and Auditor size: Further Evidence Journal of Accounting research 24 (1) 97-110.

1989: "The Relation of Audit Type to Audit Fees and Hours.

The Accounting Review 64 (3) 488-499.

(1998): "An Analysis of Auditor Litigation and Audit

Service Quality". The Accounting Review. 63: 55-73.

Paul L. Walker and Jeffrey R. Casterella (2000): The Role of Audite Profitability in Pricing New Audit Engagements. Auditing A Journal of Practice \& Theory. Vol. 19 No.4 Spring: 157-164.

Pong, Chris and Stuart Turley. (1997). "Audit Firms and the Audit Market" in Sherer M., and S. Turley 1997. Current Issues in Auditing". Paul Chapman Publishing Ltd London. 85.

Porter, B. A. (1991). Narrowing the Audit Expectation-Performance Gap: A Contemporary Approach, Pacific Accounting Review, Vol. 3. No. 1: 1-36.

(1997). Auditors' Responsibilities with Respect to Corporate Fraud-A Controversial Issue in Sherer M. and S. Turley Current Issues in Auditing" 3ed. Paul Chapman Pub. Ltd. London.

Pratt, Jamie and J. D., Stice. (1994). The Effects of Client characteristics on Auditor Litigation Risk Judgments, Required Audit Evidence and Recommended Audit Fees." The Accounting Review, Vol. 69. No. 4 Oct. 639-656.

Schatzberg, J. and G. Sevick (1994). A Multi Period Model and Experimental Evidence of Independence and low balling". Contemporary Accounting Research. Summer: 137-174. 
Simon, D.T and J. R. Francis. 1988: The Effects of Auditor Change an Audit Fees: Test of Price Cutting and Price Recovery. The Accounting Review 63: 255-269.

Simunic, D.A. 1984 "Auditing, Consulting and Auditor Independence". Journal of Accounting Research (Autumn) 679-702.

Spires, E. and D. D. Williams. (1990). Auditors' Adoption of SAS 58 Audit Reports: Accounting Horizons (September) 76-82.

Stuart Manson, Seun Mc Cartney and Michael Sheren (1997): Audit Automation: Improving Quality or Keeping up Appearances in M. Sheren and S. Turley (1997) Current Issues in Auditing, $3^{\text {rd }}$ ed. Paul Chapman P. Ltd. 245-272.

2001."Audit Automation as Control within Audit Firms. Accounting. Auditing \& Accountability Journal, Vol. 14.1.

Sullivan, J. 1984. The Ease for the Unstructured Audit Approach: Auditing Symposium VIl. Lawrence University of Kansas.

Taylor, M. H. and Simon D. T. (1999). "Determinants of Audit Fees: The Importance of Litigation, Disclosure and Regulatory Burdens in Audit Engagements in 20 Countries. The International Journal of Accounting vol. 34 No. $3: 375-388$.

Teoh, S. M. and T. J. Wong (1993). Perceived Auditor Quality and the Earnings Response Coefficient. The Accounting Review. 68: 346-367.

Timothy, B. Bell, W.R. Landsman and D.A. Shackeford 2001. Auditors' Perceived Business Risk and Audit Fees: Analysis and 
Evidence Journal of Accounting Research Vol. 39 No.1 June $35-43$.

Turpen. R.A. 1990: Differential Pricing on Auditors Initial Engagements: Further Evidence. Auditing: A Journal of Practice \& Theory 13: 128-142.

Weiss, M. I. 1994. "Auditors Public Both Need Though Liability Rules" Accounting Today o(January 24)9.

Wiliam, D., and m. Dirsmith 1988. The Effect of Audit Technology on Auditor Efficiency: Auditing and the Timeliness of Client Earnings Announcements. Accounting. Organizations and Society B Septemper.

Williamson, A.l. (1994) "Audit Automation Digest No 318, ICAEW,

Wines, G. (1994): "Auditor Independence, Audit Qualifications and the Provision of Non-Audit Services a Note" of Accounting and Finance, $34(1): 75-86$. 


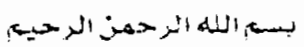

$$
\begin{aligned}
& \text { ملحمق البسته }
\end{aligned}
$$

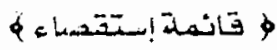

| السيد الجانستاذ

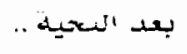

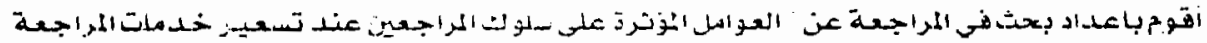

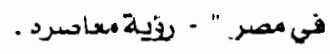

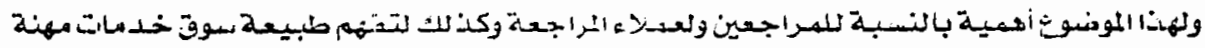

$$
\text { الكراجعة في معمر . }
$$

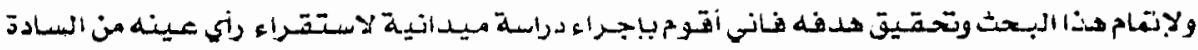

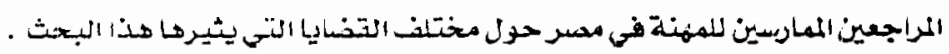

برجاء التفضل بالاجابة على أسنلة الإستهارد المرفتة .

$$
\text { البامث }
$$

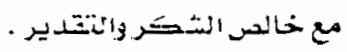

دكتور / عارف عبد اللله عبد الكيريه

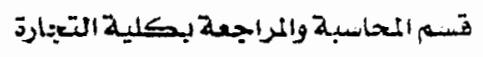

جامعلة طتصل

$$
\text { هكتب المسراجعة المثترك }
$$


هرجاء وقع علامد / لمقل الاختيار الدني ترنه مناسبا لكل حالح .

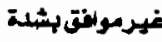

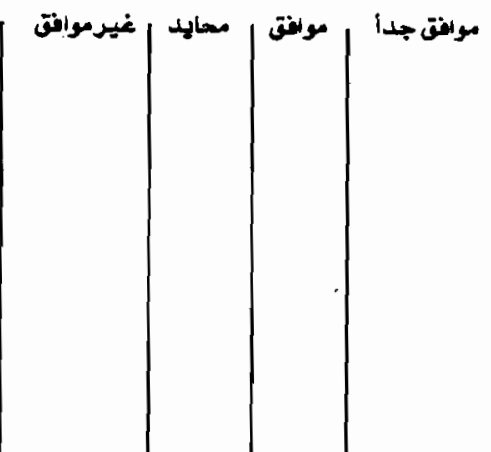

1 - إن تننيذ معليم/المراجعلمن خـلال يرنامج معد مقدما يتضضن اجمراهات وخطط منظهلم لتنفيذ

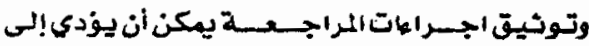
تغتيض أتعاب المراجعة .

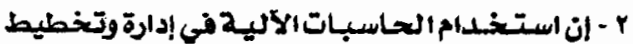

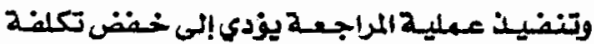
عمليح المراجعد واتعاب المراجعة.

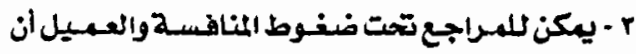

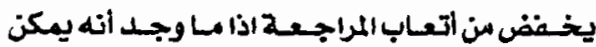

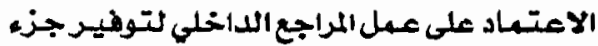
من جهد المراجعة الخارجية .

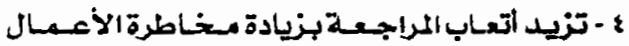
المتعلقد بالشركة مونسوع المراجعة لهري

0 - المراجيع يمنحخــصسما في الأتعـاب للشـركـات التي تعقق ارياحا في السنح الاولى للتعاقد .

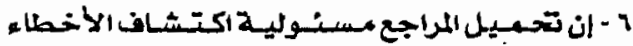
والتحلاعبه يزيد من اتعاب المراجعة . Y - تزيد اتعاب المراجع مع زيادة التيهم المتوقعة لهخاطر المساءولة المقانونية للهراجع لفي المستقبل . 


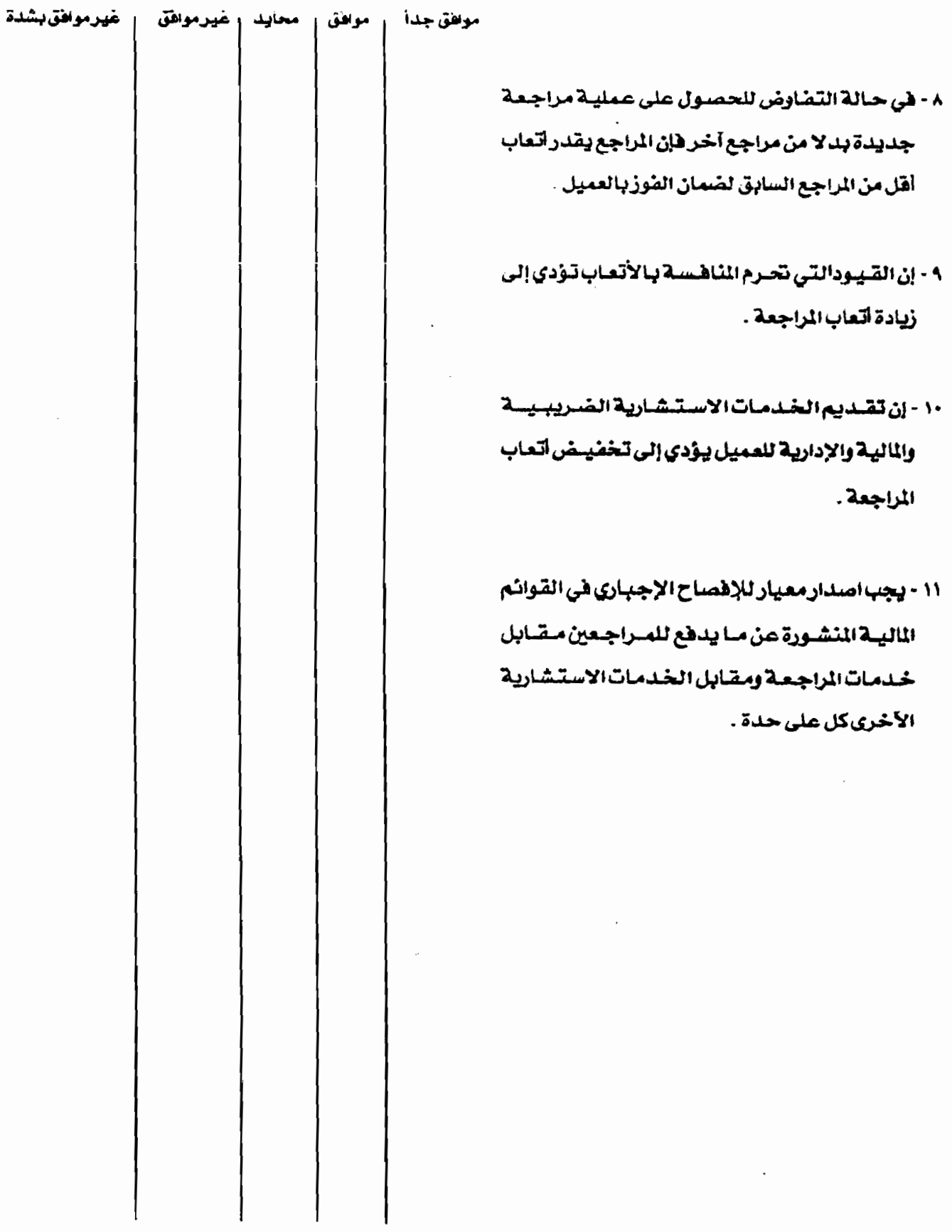

